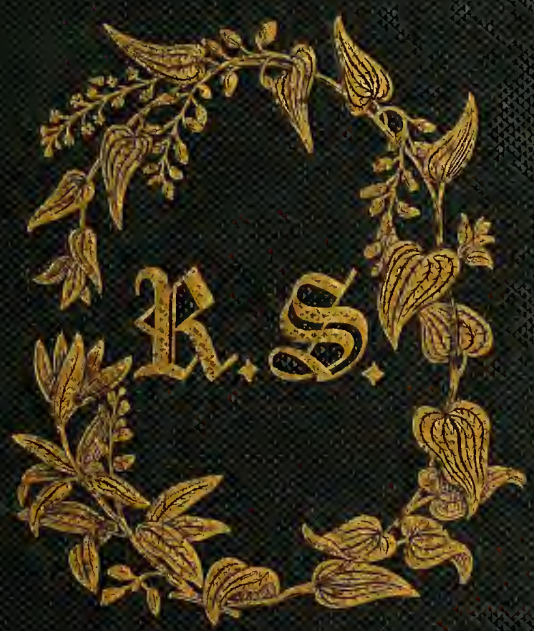


ifteb a Colloctions

$$
Z_{13.4551 .5} \text { KF } 27622
$$

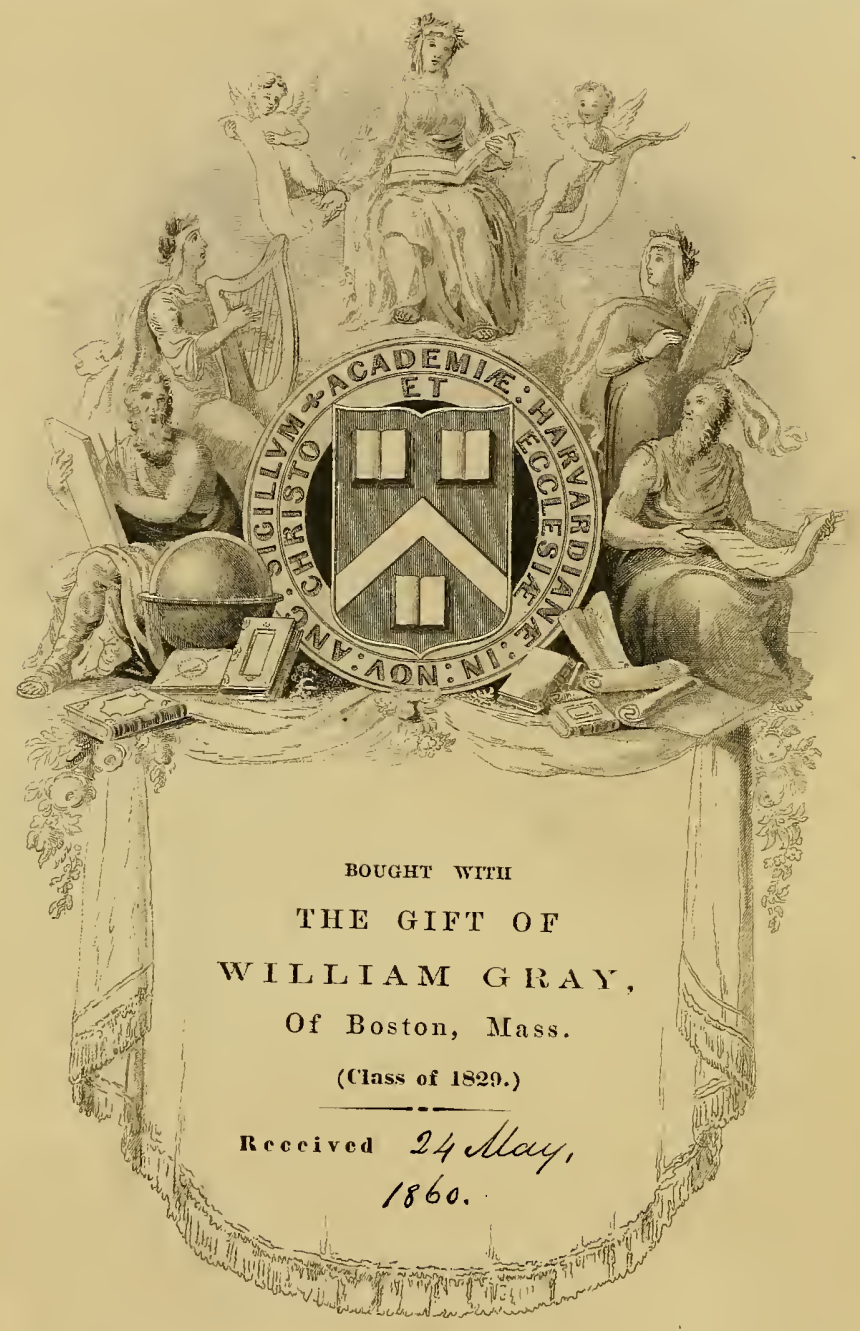




THE

\section{$\begin{array}{llllllllll}\text { R A } & Y & \text { S } & 0 & \text { C I } & \text { E } & \text { T } & \text { Y. }\end{array}$}

INSTITUTED MDCCCXLIV.

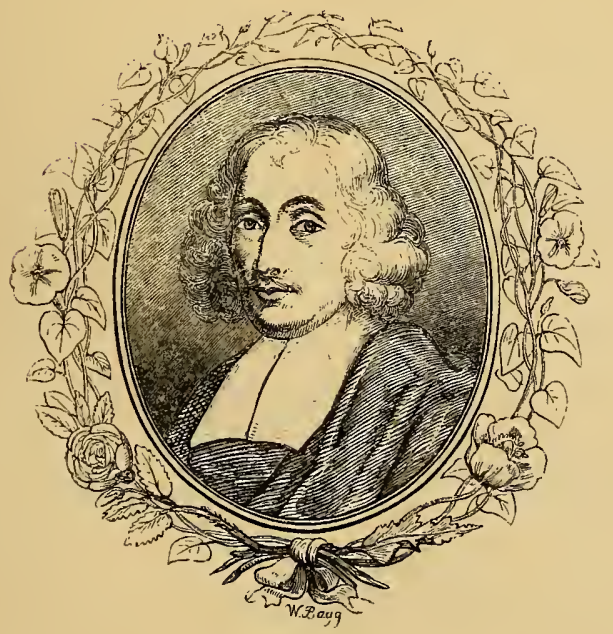

L O N D O N.

MDCcCXLV. 

ON THE

\section{ALTERNATION OF GENERATIONS;}

$$
\text { OR, }
$$

THE PROPAGATION AND DEVELOPMENT OF ANIMALS

THROUGH ALTERNATE GENERATIONS :

A PECULIAR Fori of Fostering THE young IN THE LOWER CLASSES OF ANiMALS.

BY

JOH. JAPETUS SM. STEENSTRUP, LECTURER IN THE ACADEMY OF SÖRO.

TRANSLATED FROM

THE GERMAN VERSION OF C. H. LORENZEN,

BY

GEORGE BUSK.

- LONDON :

PRINTED FOR THE RAY SOCIE'TY.

MDCCCXLV, 


$$
Z_{13,45} S+.5 \quad k F 27622
$$

$$
\begin{aligned}
& 1860 \text { and } 24= \\
& \text { chem }
\end{aligned}
$$

9 was J ow of is, 800

$$
20+\frac{1}{6}=\$ 56.25
$$

C AND J. ADLAKD, PLANTERS, BARTHOLOMEW CLOSE, 


\section{NOTICE BY TRANSLATOR. :}

THe object of this little work, and the mode in which the subject is treated, are so fully exhibited in the Author's Preface, that it is scarcely necessary farther to advert to them, excepting for the purpose of impressing upon the reader, that he is not to expect in the account here given of the phenomena intended to be comprised under the term of 'Alternation of Generations,' or 'Alternating Generations,' anything more than a mere outline of the subject; nor is it proposed by the author to be more than the rough sketch of a picture, to the filling up of which naturalists may, perhaps, be the sooner incited to direct their attention, by learning from the ingenious speculations here set forth the probable existence of such a mode of development in some form or other, in most, if not all, of the lower classes of animals. 'Chamisso's Observations,' published so far back as 1819, on the apparent alternations of generation in the Salpe, may perhaps be considered as affording the earliest glimpse of the subject. 'The subsequent observations of Sars on the development of the Medusa in 1828, and which were continued in 1835,1837 , and 1841, corroborated as they were in great measure by those of Siebold in 1837; and the researches of Lovén in 1837, on the development of Campanularia, \&c., considerably enlarged the number of facts relating to this mode of development. No one, however, 
appears to have entered upon the general question of the existence of an analogous course of development throughout the lower classes of animals, until the author of the present work, who was already favorably known among naturalists by other publications. He has taken up the subject with the view principally of tracing its general connexion between the various classes. Whilst doing this, however, he has made some very important and highly interesting special observations on the development of the trematode entozoa. In this he has undoubtedly opened up a most extensive field for future inquiry ; and there is every reason, from what he states, for believing that numerous and important additions will be made to facts, serving for the foundation of a sufficient theory of alternating generations, from investigations relating to the multiform class of animals comprised under the entozoa.

In the present work, owing to the paucity of the materials afforded by previous observations, the speculations of the author may, at first sight, appear bold, and his conclusions in some places hastily drawn; but, in many respects, there must be conceded to them the character of great ingenuity and considerable originality. Most of the observations themselves are not brought forward as new; but the attempt at giving these phenomena a natural explanation, and at showing their mutual analogies, is, to a great extent, as novel as the full elucidation of the subject will be beneficial to the progress of invertebrate zoology.

With respect to the use of several now terms in this translation, the author's apology will apply as well to their use in this version as to their original adoption. 
The subject itself must be better understood before the provisional terms now employed can be replaced by more elegant or more correct expressions.

Allowance also for certain ambiguities of expression will perhaps be made, when it is remembered that this is a translation of a translation, and that the author's meaning: may probably have suffered a little in each change of language.

The introduction of the "Anastatic" process for the copying of plates, having appeared to be a highly desirable object, if found applicable in some of the publications of the Ray Society, it has been tried on a small scale in the present volume. The two latter plates have been copied from the original lithographs by this means, and it is hoped that the figures will be found sufficiently good for all their purposes; though it cannot perhaps be said that the process by which they have been copied has as yet arrived at the perfection which it is much to be hoped it will ultimately attain.

G. B. 


\section{CONTENTS.}

Preface to the German Version

PAGE

\section{CHAPTER I.}

The development of the Medusæ (Scyphistoma-strobila, Medusa), tab. I. figs. 1 to 40

CHAPTER II.

The development of the Claviform Polypes (Coryne, Syncoryne, Corymorpha, Campanularia, ) tab. I. figs. 41-57

CHAPTER III.

The alternate generation of the Salpæ (Proles gregata, Proles solitaria) 38

\section{CHAPTER IV.}

The development of the Trematoda . . . . . 52

(a) Cercaria echinata? (Siebold) tab. II. . . . . . 53

(b) Cercaria armata (Siebold) tab. III. fig. 1-6 . . . . 74

(c) Cercaria ephemera (Nitzsch), and Distoma duplicatum (Baer) . 87

(d) The development of other Trematode animals . . . . 94

\section{CHAPTER V.}

Concluding remarks on the alternating generations and their real nature 105

EXPLANATION OF THE FIGURES.

Plate I, The development of the Medusa aurita . . 117

II, The development of the Fluke, Distoma pacifica. . . 124

III, The development of the Distoma tarda . . . . 128 


\section{P REFACE}

TO THE GERMAN VERSION.

Greater publicity* is herewith given to an Essay, the contents of which will, I hope, prove interesting, not only to the professed naturalist, but to all of the generally well informed, who may be led to the consideration of the Harmonies of development in Nature. On whose account also I have endeavoured (with what success the kind reader may determine) so to arrange the exposition, that the least possible impediment should stand in the way of any one desirous of becoming acquainted with the mode of natural development in question.

The special subject of this Essay is the fundamental idea expressed by the words "Alternation of Generations," or the remarkable, and till now inexplicable natural phenomenon of an animal producing an offspring, which at no time resembles its parent, but which, on the other hand, itself brings forth a progeny, which returns in its form and nature to the parent animal, so that the maternal animal does not meet with its resemblance in its own brood, but in its descendants of the second, third, or fourth degree or generation; and this always takes place in the different animals which exhibit the phenomenon, in a determinate generation, or with the intervention of a determinate number of generations. This remarkable

* By the translation from Danish into German. 
precedence of one or more generations, whose function it is, as it were, to prepare the way for the later, succeeding generation of animals destined to attain a higher degree of perfection, and which are developed into the form of the mother and propagate the species by means of ova, can, I believe, be demonstrated in not a few instances in the animal kingdom.

The first division of the lower animals, in which I have observed its existence, are the Medusce (Chap. I) as they have been exhibited to us in the observations of Sars and Siebold, and especially of the former.

The polypiform animal Scyphlistoma-Strobila, into which the offspring from the ova of all the Medusæ is metamorphosed, and which, though it does not itself become a perfect Medusa, produces the larve which do, is in my opinion a precedent generation of the kind in question; and according to my own researches it resembles a polype only externally, and is in its structure really a Mechusa, though one which is attached by means of a stem to fixed objects. So also in the claviform Polypes, Corynce (Chap. II), the so-termed polypehead is a precedent individual which produces the more perfect and differently formed medusa-like campanulate animals which are developed in succession at the base of the clavate head, and the development of which, varies very much in the different species, before their separation from the preparative individual, and their becoming competent to propagate the species by ova, from which again proceed the Corynæ or preparative individuals. In the Campanularia, which is nearly allied to the Coryne, and in similar polypes, this relation is also very manifest, and in fact resides in an alternation of at least three successive generations, which act reciprocally in connexion with each other in the advancing of the species towards perfection. The phenomenon appears in a striking light, especially in the observations illustrated with figures, for which science has been lately indebted to the Swedish naturalist S. Lovén. The three generations are disposed in a definite 
manner on a common polypidom and form a whole, or colony which, as regards the welfare of the species, stands in the same relation to it, that the hive of bees with its colony of three differently-formed broods of young, does to the bee species. It naturally follows that mention should here be made of the mode of propagation of the Salpe (Chap. III), (although indeed the observation of the worthy Chamisso has been otherwise interpreted, but in a way of which science has not availed herself, however plausible the interpretation may have appeared to the superficial reader ;) and thus we have an alternation of generations, exhibited to us in the molluscous class, and it is certainly not confined to the Salpe only, but extends to all the compound Ascidians (Ascidice composite). In the class Entozoa my researches have sufficed to prove not only the existence of such an "alternation of Generations," but to show besides, that traces of a similar mode of development are visible in almost all the divisions of that class. According to recent observations it is, however, exhibited most clearly in the Trematoda (Chap. IV), in which I prove that the Cercarice are the larve of Distomata, and that they become true pupe; that the animals in which the Cercaria originate and grow up are peculiar trematode individuals, descended in the second or third generations from Distomata, and consequently not produced directly from their ova, but which, however anomalous they may at first sight appear, constitute a precedent generation having for its object the perfecting of the subsequent one.

To similar observations belong also the description given long ago by Ehrenberg of the cyclical development of the Vorticelle, and the already long-known though misunderstood mode of propagation which obtains in the Aphides.

The existence of an alternation of generations having in this way been established, not generally only, but even as it seems in all the lower classes, beyond doubt, it is 
proper to consider the relation which this kind of alternation bears to that with which we have hitherto been acquainted, as taking place in the propagation of the lower forms of animals; and this I have done in the last Chapter $(\mathrm{V})$ of the Essay. It appears to me very evident, that these preparative generations, all of which have this in common that they are invariably produced from ova, without being themselves oviparous, that they are all of the same sex, and all eliminate an offspring from the germs contained within them, which offspring in course of time becomes the animal from which the preparative generation had derived its existence, and that all, as it were, eliminate this progeny by their vital powers and by means of their bodies ; * it is evident, I say, that these generations represent in a lower degree what we have so long admired in the gregarious insects, or those which live in colonies, such as the Termites, Ants and Bees, \&c., because the precedent, preparative generations, are, in these instances, in consequence of the complete abortion of the sexual organs, converted into preparative broods, and the " nursing" (ammen), which in the lower animals is performed within or by the bodies of the "nursing" individuals, is for the same reason, in the above-named class of insects performed differently, being in them represented by a "fostering" of the young (Brutpflege) to the performance of which duty the "feeders" are impelled by an artificial instinct $\dagger$ or conscious exertion of the will, and of which they are rendered capable by the peculiar formation of certain organs, at the expense of

* On which account I have termed these generations " ursing generations" (ammende), and the individuals of which they are constituted "nurses" (ammen). [Though the word "nurse" in English does not exactly correspond with what the author intends to convey by the word "amme" (a wet-nurse), yet the translator has thonght that the use of this short word, till a better expression be devised, might be excused, not on the score certainly of its elegance, but because it more nearly corresponds with the meaning of the original than any other English word which suggests itself to him, and that by making use of it a constant periphrasis is avoided.]

+ Kunsttrieb, the iustinct to produce certain compound effects rescmbling those of human art. 
the sexual apparatus; so that the alternation of generations in this point of view becomes in its nature a necessary or unavoidable step of the development, and we may in the words of the great master, affirm, that " Nature pursues its course, and what we take for an exception is in accordance with law."

In what precedes, the object of the Essay, and the modes in which the results at which I believe myself to have arrived, have been obtained, will be sufficiently apparent. The "alternation of generations" is, as has been said, the fundamental idea followed throughout the book; I have wished to represent it in the reality which I am convinced it possesses, from the researches of others as well as from my own, however much it may have been combated, in the one particular in which an ingenious naturalist surmised its existence, even twenty years ago ; I have also been desirous of reviewing this phenomenon and its real significance, so far as I have as yet observed them in nature. With regard, however, to other points which have come out during the course of these observations and researches, viz., that the Cercuria are larva of entozoa, of the genus Distoma, and in fact of those species which inhabit the interior of fresh water snails (in the liver, \&c.); that the entozoa pass part of their existence in a state of freedom in the water external to the snail, which they afterwards inhabit, and that they re-enter them from without; * that whole established divisions of families of animals must be abolished, since they include only undeveloped forms, or forms which bear the same relation to the true and perfect form of the species, that the "workers" among ants and bees bear to the fertile females of those insects; $\dagger$ and, finally, that several forms which have been considered as of different

* Facts wlich I can now multiply from several other species besides those which I have adduced.

+ This may doubtless be assumed of most, if not of all the genera of the Coryne family, and of Siebold's division of the "Asexual Trematoda," \&c. 
species and genera are seen to be stages in the development of one and the same animal, \&c. All these must be considered as secondary results,--as facts which are only adduced, so far as they serve to illustrate the fact of the "alternation of generations."

In order to prevent my being further misunderstood, as I have repeatedly been in my oral exposition of this subject, and in the lately published Danish version of the work, I must remark that the phenomena, upon which my view of the alternation of generations rests, are, as every naturalist knows, new only in part, but that they have in this work received another, and, in my opinion, a natural explanation. They have generally been looked upon as instances of metamorphoses or transformation, the essential objection being overlooked, that a metamorphosis can only imply changes which occur in the same individual; but when from it other individuals originate, something more than a metamorphosis is concerned. Thus, it is quite erroneous to term a Scyphistoma the larval condition of Medusa aurita, since a Scyphistoma never becomes a medusa, but is the quasi mother of some scores of them. Sars and Lovén have taken a more correct view of the relation in which these creatures stand with regard to each other, seeing in the development of the Medusa and Campanularia a series of generations undergoing metamorphosis.

It is of the more essential importance that the distinction between an alternation of generation and a metamorphosis should be understood, because a metamorphosis may readily occur in one or other of the alternating generations themselves, as we see, for example, in the Distomata and Aplicies. There is no transition from a metamorphosis to an alternation of generations, and a metamorphosis once commenced, cannot be continued beyond the generation, nor from the living or dead individual to another individual. I am not aware that any one has published concerning the alternation of genera- 
tious of the Sulpa, except those who have been disposed to see something paradoxical in it. Professor Eschricht has recently expressed himself upon it, and is of opinion, that although in appearance it affords an instance of alternating generations, yet that the whole may be more readily explained by supposing a double mode of propagation in the solitary individuals; that is to say, that the Salpe in their younger state produce solitary young, and at a later period those of the associated or catenated form,-an opinion to which I have mole particularly adverted in the proper place.

In the class of Entozoa, the Cercariae with their pupe still remained a great enigma, although the opinion which was at first entertained of their being equivocal animals was I know wholly rejected; for their relation to the animals " nursing" them was very far from being understood. Sometimes they were considered to be necessary parasites of the " nurses" who were unable to exist without them, as they always contained them and died upon losing them ; again, they were considered as embryos living: in a peculiar detached organ, which the "nurses" were supposed to be, and in consequence received the new name of "germ-sac" (Keimschlauch), being no longer regarded as independent creatures. With respect to the remaining divisions of this class, I will now only refer to the late views proponnded by Professor Eschricht on the cestoid worms, as to their being compound animals (animatia composita) though not animals organically connected into one whole, or belonging to two generations. The alternation of generations in the Aplicles as a superfecundation is sufficiently well known.

So much for the prevailing scientific notions with regard to the relations which I have endeavoured to collect under one fundamental idea.

I beg it may be observed that I have tried as much as I could to collect scattered fragments into a whole, but that I have always considered this only as the first loose intro- 
duction to more extended labours in the same direction;labours which I had hoped to have seen entered upon by others, whom this essay of mine might probably stimulate to the undertaking. I believe that I have given only the first rough outlines of a province of a great terra incognita which lies unexplored before us, and the exploration of which promises a return such as we can at present scarcely appreciate. Several points of this continent have been touched at by naturalists, who have there erected their beacons usually without guessing that they were all in the same region; the recognition of these visited points, the discovery of a few new ones, and the tracing out of their connexion with the adjoining coast line, so that the connected figure of the continent might be more authoritatively laid down, is all that my researches claim. From the beacons erected by my predecessors, I have endeavoured to make a survey of the surrounding country, as far as it was possible for one to do so; I have been able to raise some of them to a greater height, in order to take a more extended view from their summits; and I have wished to render the general impression of the peculiar aspect of the continent derived from these isolated views as correctly as my conception of it would allow, being persuaded that by so doing I threw a clearer light, by means of this general picture, on the separate views of the landscape, and perhaps was thus afforded the only correct mode of viewing them.

I am well aware that many naturalists would not have ventured upon such general views, such generalizations as they are termed, as I have indulged in, partly in the Danish version of this essay, and partly in an earlier small work in an entirely opposite direction, and for which I have been exposed, on several sides, to objections and blame, on account of the dangerous consequences of such speculations, and the tendency they have to mislead others. I am, however, of opinion, that it would be a gain to science, and is imperative upon every one to take a survey of the field from the eminence on which he has 
instituted his inquiries, in order to observe how they may harmonize with those instituted at an earlier period in the same or in other fields, and that, together with the observations themselves, he should give a general view of those departments of Nature which he has been able to inspect, and indeed in the colours in which he believes he himself has seen them. By this method alone does a collection of many facts become of value; but this mode of generalizing is only of use when it assists in the assimilation of observed facts. The one subjective view follows the other, and is distinct from it: the one affords to the half or wholly ascertained facts, which may be compared to crude nutriment, a saliva ; the other, bile or pancreatic juice; and in this way Science, which by means of our periodicals had been oppressed and become dyspeptic with too much raw food, is relieved from her load.

With respect to the mode or way in which I should wish my Essay to be read, I may be allowed to remark, that the "Explanation of the Plates" is so arranged that it may be read through, while at the same time the plates are looked over, so that before perusing the work itself the reader may acquire a notion of its contents, and, if he be not a professed naturalist, he will thus be much assisted in his study of the subject.

In conclusion, I request indulgence for the terms which I have been obliged to invent for the expression of new ideas, which could not otherwise be expressed in the German or Danish language; they are, in fact, but few, although their number will be increased should the views I have sought to establish be confirmed.

I cannot flatter myself that the exposition might not in several places have been much better given than it is, but I have spared no pains in making it as clear as I could; with respect to this, I have to thank my friend, the naturalist J. Reinhardt, jun. not a little, who in the kindest manner undertook the not inconsiderable labour of re- 
vising the manuscript before it went to press, and by whose revision it has been benefited in many places.

I now commend to the kind reader this Essay, which indeed though presented to the greater German public as a translation, I am desirous should be regarded as an original work.

THE AUTHOR. 


\title{
ALTERNATION OF GENERATIONS,
}

\&c. \&c.

\author{
CHAPTER I. \\ THE DEVELOPMENT OF THE MEDUSA.
}

(Scyphistoma-Strobila, Medusa.)

Tab. I. figs. 1 to 40 .

I presuppose that my readers are acquainted with the animals vulgarly termed "jelly-fishes" or "sea-nettles," and in scientific language "Medusce." They are creatures of a gelatinous consistence, very soft, and transparent as glass, and are met with of various forms, discoid, hemispherical, or bell-shaped, and they may be seen swimning about immediately below the surface of the water, at sea or in creeks, from spring till late in the autumn, but only when the surface is tranquil and no rain has been falling. They occur in vast numbers, especially where streams fall into the sea or into a creek or bay, and they swim more deeply in the water when the surface is rough, or after a fall of rain, the slightest shower causing them to descend rapidly. On the approach of winter they withdraw themselves to a greater depth, or probably nearly all die at that period.

The circular border of the disc or bell of the Medusa is sometimes entire, and continuous without any division, and sometimes presents teeth, lobes, or fringes. This condition, however, varies very much in different genera, and, as we shall soon see, does so remarkably even in individuals of the same species, according to their dif- 
ferent degrees of development. The border of the discoid or campanulate body of the Medusa is also frequently furnished with extensible filaments or arms, of greater or less length, which either depend loosely beneath the animal, or twine themselves about from side to side in an undulatory manner, and serve most probably for the prehension of food (these are the so-called marginal tentacula or filaments). In many species, however, these organs are wanting. Similar filamentary appendages and fringes, in several species, surround the mouth, and stomach, which are placed in the middle of the bell-shaped, or depend from the centre of the discoid body, and they occur also in several situations on the under surface of the animal.

Although the Mechuse are usually observed to float with the currents of water, still they are possessed of voluntary motion, and perform a sort of rowing movement, peculiar to certain forms among the lower animals; this is effected by a powerful contraction of the body, by which the water contained in its hollow is expelled; and by such alternate contraction and dilatation of the body they are enabled to propel themselves with tolerable rapidity.

With regard to the propagation of the Mectusa, it had been observed, that the larger and more common species appear on our coasts and out at sea, in vast numbers at certain seasons of the year, and also that in the spring and beginning of summer the number of smaller or younger individuals preponderated. From the latter phenomenon, it might be concluded that the propagation of these animals took place probably towards or in the winter; still (when we consider the fact of their complete disappearance at that season) it could not occur in the same localities in which they swarm in such great numbers during the warmer months. Moreover, it was not known whether their propagation proceeded at the bottom of the sea or towards the surface, or whether the young, after birth, underwent a metamorphosis or not. 
The Swedish naturalist, M. Sars, was the first who, by his observations and researches, gradually removed the obscurity which veiled the propagation and development of the Meduse. No doubt had been entertained of this being quite simple, that is to say, that it was not only subjected to the general laws of development, but that it was closely comnected with the usual phenomena by which those laws are attended. The development of two species of Medusca-as it has been made known to us by this observer, and as it has been confirmed in certain of its stages by the observations of others, and especially with regard to its first stage by the important observations of Siebold-presents highly remarkable phenomena, which may truly be called peculiar, although they are not fundamentally isolated. It is my direct object in the following pages to endeavour to render this clear, and I shall proceed, with all brevity, to make the reader acquainted with this course of development, and select as an example that of the Meclusa aurita.

The full-grown Medusce which are met with in summer and autumn are not hermaphrodite, as was formerly believed, but of distinct sexes; some, consequently, are male and others female. The external form indeed of the generative organs is the same in all, but their internal structure and their object are entirely different, and it is simply from the similarity in the outer form of these organs that the erroneous notion has arisen, that hermaphroditism exists not only in this, but in many other families also. In the globular ova, while still in the ovaries, young are developed, of an oval or cylindrico-oval form, which, at a later period and after they have quitted the egg, are collected into special receptacles, formed at the same time in the four oval tentacles. In these receptacles they remain for some time, for the purpose of being, as it were, hatched in them, when they forsake the parent and swim about in the water, as a swarm of distinct creatures.

At this time they appear slightly compressed laterally, 
and one extremity is always thicker than the other. Internally they present a cavity, corresponding in form with the external shape. Their movement in the water as well as in the receptacles is effected only by means of cilia, with which their whole external surface is covered (figs. $1-5$,) and they thus outwardly resemble, rather the ciliated infusoria, such as Leucoplerys or Bursaria, than a Medusa. But there is also, in structure and in their manner of moving, a most essential difference between the young fry and the full-grown animal. But since Medusce do proceed from this fry, resembling the free swimming ones, it is evident, that some change must take place either gradually or by a sudden transition (metamorphosis, transformation.)

Let us now trace these young Mecluse further. When swimming, the larger extremity is always in advance, which exhibits a depression (fig. 5, ) and might readily be supposed to be the anterior extremity, and the depression in it to be an oral opening. But it will be immediately observed, that the animal after a short time attaches itself by this end to some fixed object (figs. 7, 8,) and the above-described depression then appears as a sort of suctorial disc or organ of attachment which at the same time secretes a viscous, tenacious fluid. The opposite extremity then projects from the object to which the animal has attached itself, and a real opening is formed in it, whilst at the same time it becomes larger and more club-shaped (figs. 8, 9.) The opening is at first very small, but soon increases and its surrounding border becomes flexible and moveable and assumes very various forms ; in the contracted state it is quadrangular, and at the four angles may be observed small protuberances, (figs. 10, 11, 12,) which soon increase in length and become slender, and finally, on the fifth or sixth day, shoot out into four long tentacula or arms (figs. 13-15.) At a later period, four other tentacula are formed between these, which on the seventh day also appear as small protuberances. Ten days after the little animals have 
left the parent receptacles, they have all eight tentacula (fig. 16,) and from three to five new ones begin to appear, and the older ones when extended, have already attained a length of from three to five times that of the body (fig. 17.) In this way the number of these organs continues to increase during the growth of the animal, and new ones are constantly springing up in the interspaces of the older ones, so that at length the number of tentacula amounts to $24-28-30$. From the size of a small grain of sand the body becomes about a line in length, and the original brownish colour passes gradually through a reddish gray to a transparent grayish white.

In this fixed condition the animal in its external form very much resembles a polype, but it now, although unable to move about in the water, approaches the Medusa form much nearer than when in the infusory form it sivam about by means of cilia.

This polypiform animal, which we shall afterwards consider as a pedunculated Medusa, is affixed at the bottom of the sea on various substances, as stones, or the shells of conchifera, but especially, as it would seem, on the stalks of the large Laminarie. When the animal has obtained its full number of arms or tentacula, or, as it may be expressed, has reached its full growth, but a short time elapses before a new life commences in it. Transverse wrinkles are formed around the body, which increases at the same time considerably in size, especially in length, and thence assumes a cylindrical form. These transverse wrinkles appear at first towards the superior extremity and thence gradually descend, retaining, however, always the same distance from each other ; they are at first faintly marked, and more like transverse lines or rings surrounding the body (figs. 20,21 ;) by degrees, however, the wrinkles or furrows become manifestly deeper and deeper, in the still elongating body, and at the same time the superior margin of the projecting portions which are separated by the furrows, becomes more and more elevated and presents eight distinct lobes or divisions, which are placed 
exactly in the same line, one above the other in each annular division, so that the series appears to form eight longitudinal bands extending from end to end of the body (fig. 22.) In proportion as the contractions become deeper, the lobular portions acquire greater mobility, and at the same time an independent vitality, and it seems that the animal is capable of division into as many independent, cup-shaped bodies, as it formerly possessed divisions. And, indeed, this finally takes place as we shall now see.

The subsequent development consists in fact in this, that the divided portions so often referred to, and which are placed one upon and in the other like a pile of cups, are actually separated one from the other, while at the same time they are elevated one above the other by an alternate motion of contraction and extension (fig. 23,) their lobular appendages increasing in length at the same time.

In consequence of the movements exerted by each portion and by which the whole stem or pile acquires a vermicular motion, the connexion between them is much loosened, and at last completely dissolved. The separation commences with the upper ones, and close observation then shows that they are actually superimposed one upon the other, like piled-up cups, and without the existence of any organic connexion between them.

After the complete separation of the cup-shaped bodies from each other, they swim about with the usual peristaltic motion of the Medusa, and resemble those animals in every respect, and as is the case in them, a quadrangular extensible mouth depends from the centre of the inferior concave surface; when this mouth is fully extended, the animal bears no inexact resemblance to an umbrella or parasol. Occasionally the disc is reverted or turned inside out, so that the upper surface becomes concave, and the lower convex, and in this condition, on superficial observation, the mouth would appear to project perpendicularly from the dorsal or upper surface. Al- 
though these animals, whose remarkable origin we have just traced, must be considered as Medusa, still they will be found to differ in many respects from the Medusce whose offspring they are, (vid. figs. 29 and 25), especially in the form of the border of the disc and of the prehensile tentacles or marginal filaments attached to it; in the extent of the vessels of the disc, and in the shape of the stomach. But on continuing to observe their growth, we in a short time witness the disappearance of these differences as they approach nearer and nearer to the form and relations of the full-grown animal (figs. 25-30.) During their growtl, for instance, the eight segments or separate lobes of the margin increase but very little in size, whilst on the contrary the intervals between them enlarge very much, and thus the lobes or segments become gradually much depressed (fig. 29.) In the fissures of the lobes, exactly at the point where the ocelli, as they have been termed, or coloured specks are placed, as well as in the middle of the interspaces between the lobes, are seen, proceeding like rays from the middle of the disc, canals, or vessels, which are connected with each other towards the border of the disc by a set of circular or annular vessels, arranged in small arches which ascending slightly from the extremities of the radiating canals proceeding to the interspaces of the lobes towards those going to the edge of the body form segments of circles, smaller in proportion to the less size or age of the animal (vid. figs. $27,28,29$, and $31,32,33$.) As the arches and interspaces alter, certain organs begin to appear on the external side of each arch, between it and the edge of the disc. The formation of these organs commences with the appearance of a vesicle with opaque contents, at the middle of the arch, and similar vesicles are afterwards formed successively on the sides of the first one.

As the number of these vesicles increases, those first formed become larger and gradually project from the substance of the disc, at first as short protuberances and 
afterwards as growing filaments, and in this way while the interspaces continue to increase, the border of the disc becomes furnished with long, pendent, prehensile tentacles, which are very flexible and in continual motion in all directions (fig. 30); and it is in this way that the tentacles are formed. Simultaneously with the appearance of these organs, the vessels of the disc become more numerous, since from the arches or from the annular canals formed by the arches, cæcal vessels shoot out into the substance of the disc, which increasing in length, inosculate with each other, and terminate in the radiating canals which pass from the marginal corpuscles of the lobes. (figs. 31-33.) At this period, the disc externally, exactly resembles the full-grown Medusa.

The mouth, which even in the youngest detached animal allows of being greatly extended and protruded, is quadrangular, and presents four extensible angles. These angles grow more rapidly than the four-sided oral tube, so that in the more advanced animals, the mouth appears during the growth, to have been divided or split into four lobes. The minute serratures which appear on the edges of these lobes are the commencement of the lobes and fringes which are observed on those organs in the adult animal.

Our small Medusa, of about an inch in diameter, correspond in their form, in all respects with those which are fully grown; as they increase in size, the internal organs are developed, especially those destined for the function of reproduction; and their development is completed late in the summer, when the ova in the female are fertilized, from which the infusoria-like fry proceeds, which affixes itself, and assumes the polype form; whence a new series of Medusa-larva, \&c., and the whole of the above-described development is repeated in the course of the year.

After having considered the particular course of development of these Medusa, (and of the Medusa in 
general,) it will not be uninteresting to trace the history of those researches which have thrown light upon this obscure department, in the account of the development of the lower animals. As already observed, we have, in this respect-to thank chiefly, the Norwegian naturalist M. Sars. In a short work 'Beyträge zur Naturgeschichte der Seethiere,' (Bergen, 1828,) this observer described two remarkable animals, Scyplistoma, a polype with a four-sided extensible mouth, and Strobila which resembles a pine cone, and is constituted of a series of Acaleplice or Medusce, placed one within the other. In his later celebrated work, 'Beschreibung und Beobachtungen einiger merkwurdigen oder neuen im Meere an der bergenschen küste lebenden 'Thiere,' (Bergen, 1835,) he states, that the Scyphistoma is not a distinct animal, but the younger state of the animal, which he had formerly named Strobila, and communicates particular observations on this subject, especially with regard to its growth, and the development of the acalepha-like creature. He gives also a description and figure of some free marine animalculæ, which must be referred to the genus Eplyyra (Eschr.), and which he looked upon as the adult state of S.robila. These observations contained a paradox, which could scarcely be believed, yet no one ventured to deny their truth; they were unparalleled as it would appear in the course of nature, as known at that time. Ehrenberg, in his well-known work 'Acalephen des rothen Meeres,' explained the Strobila to be a Lucernaria, on the point of undergoing transverse division.

M. Sars continued his observations on these remarkable forms, but from want of time, his researches net with no attention at the meeting of naturalists at Prague, on which account he published a series of preliminary notices in 'Wiegman's Archiv f. Naturg,' (1837, iii Jahrg., s. 436,) in which he stated, that having pursued the. further development of the Strobila, he had discovered that the free, acalephoid animalculæ, were metamorphosed into the commonest of our medusæ (Medusa aurita,) and 
consequently that the genus Strobila, which was in fact only an early stage in the development of a known animal, and probably also the whole genus Ephyra (Esch.) should be abolished. The observations themselves with the illustrative figures, although dating from March 1837, were first published in 'Erichson's Archiv,' (1841-ersten Heft.) In them the development of the young Medusce after their liberation from the egg was described, and their gradual transformation into the polypoid form of the Strobila proved, from independent observations made in September and October 1839. In which year, long after his treatise had been already designed, Sars received the 'Beiträge zur Naturgeschichte der Wirbellosen Thiere,' (Danzig, 1839) of Siebold, in which that naturalist clearly proves the truth of the assertion made by him in 1837, that the Medusa are generically divided, and also describes the development of the ova of Cyancea capillata, and the history of the infusoria-like fry proceeding from them, until it assumes the form of attached eight-armed polyps.

Sir Graham Dalzell has at different times communicated observations on the same subject (The Edinburgh Philos. Jour., vol. xvii and xxi, extracted in Oken's Isis, 1838); but these observations are not only filled with matters of which he has taken a false view, but also contain phenomena which he has misunderstood, and they have consequently been of no utility in science until now that other fundamental researches have allowed of their being correctly explained.

What is particularly to be observed in the above description of the development of the Medusa aurita, and what will scarcely have escaped the reader, is the remarkable circumstance, that it is not the, at first, infusorialike creatures proceeding from the ova, which are transformed into the perfect Medusa, but that each of them passes into a polypiform creature (Scyphistoma-Strobila,) the apparently detached portions of which after their 
complete liberation, present themselves as free and independent animals (Ephyra) of the Medusa family. In the polypoid animal which as it were includes the series of piled-up Medusa-larve, (if they may be correctly so called which are a younger stage in the development of the Meduse,) such an advance to the perfect form has never been observed; and that it should attain the same perfection that the larvæ do, is, in consequence of the size it has already attained and its relations, altogether improbable; that it might reach this goal by following another course of development is so much the more improbable as we see in the rest of organic nature, like pass only into like.* What the nature of this creature consequently may be, is a question now to be solved, but we require to enable us to do this, in the first place, a precise knowledge of its structure. Sars declares that this polypiform animal simply incloses an internal cavity of the same form as the exterior of the body; it is closed superiorly by an annular membrane, which is placed within the circle of tentacles, and which can be so contracted as completely to close the opening, or so expanded as to form one, equal in size to the diameter of the body. This opening in the annular membrane, which is the entrance into the internal hollow of the bell-shaped body is termed by Sars the oral orifice, but certainly erroneously so. Of internal organs Sars has observed only four roundish prominent, longitudinal ridges proceeding at equal distances from each other, from the bottom of the bell to its border, and the extremities of which, when they reach the annular membrane at the mouth of the bell, appear like four small round holes in it, (vid. Sars in Erichson's Archiv, Ister H. Tab. i, fig. 31.) But here I beg leave to add some remarks and observations which $I$ made during a long

* That they have the power of again affixing themselves, and that a new series of medusa-larve should a second time be developed from them can be the less supposed, since Sars has shown that even the youngest individuals which have become detached, before the transverse wrinkling has taken place, can only under extreme necessity re-affix themselves, and then very loosely; and all of them are not able even to do this. 
residence in Iceland in the spring of 1840 , on some individuals in that stage of development which was originally named Scyphistoma by Sars, and which were apparently of the same species as those observed by him, or at least corresponded entirely with his description of their external form (in his work of 1835.) The ferw specimens referred to were taken outside the so-called battery near Keikevig, and under rather unusual circumstances, for they occurred at an inconsiderable depth affixed on the internal surface of some Modiolus shells and not on algæ. This circumstance afforded me the advantage during the time I kept them in fresh sea water, of being unimpeded by the mucus with which the vessel in which they are placed is immediately filled, when it contains some of the plant also, and of being able to detach thin laminæ of the half-disintegrated shell with the animals adherent, for the purpose of microscopic observation, without disturbing or injuring them in the slightest degree. The number of tentacula was 28-30. The usual form of the body varied from that of an inverted cone, to a cup or bell shape (fig. 35.) The mouth of the bell was surrounded by an extraordinarily moveable lip or annular membrane which passed round within the circlet of tentacles, and allowed of such expansion that the mouth of the bell could be rendered equal in size to the diameter of the body; it was also capable of contracting so as to close the bell completely and of being extended, so as to equal the length of the tentacles, in which condition it was always quadrangular. When the annular membrane was extended in this way (fig. 40,) it could be readily perceived that a vessel or rounded canal ran down each of the four angles; that these four vessels were connected at the border of the opening with a circular vessel; and that they were also united at the base by another and larger circular canal, which ran along the circle of tentacula. Into this larger circular canal, and opposite to the four longitudinal canals of the annular membrane, the four ridges which were observed on the 
inner surface of the bell, directly opened. Midway between these four canals, under favorable circumstances and with a good light might be observed some fine lines, which I looked upon as smaller canals of the same kind.

During the first few days in which the animals were under my observation, I perceived no other internal organs; but at a later period, I observed at the bottom of the cavity of the body, a four-sided projection (figs. 36 and 38 ,) in which there was a hollow, usually square.

Frequently, when the bell and the annular membrane around its orifice were extended, I have seen this quadrangular organ which is toothed at the extremity, become elongated and project as far as the orifice, being placed in the middle of the cavity like the clapper of a bell. At other times, when the body has been much depressed, so as not to be more than a quarter of its usual height, and has presented at its circumference, as it were, four lobes, this organ has projected more than half its length from the mouth of the bell (fig. 37;) on which account, I could no longer in any way doubt, that it was really an oral opening and cesophagus, such as we find in the Medusa, as for instance in the maternal animal, the Mecusa aurita. But besides this point of resemblance we actually find also a vascular system, consisting of annular canals, connected by radiating vessels, and resembling that system of organs in the full-grown animal, together with a number of tentacula, which are produced gradually and in a definite order, like the tentacula of the self-developing $M e d u s a$, in a word we recognize in this apparently polypoid animal, an actual Medusa, but which is fixed.

These polypiform Meclusa thus enjoy a mode of development peculiar to themselves before the period at which Medusa-larve are formed in their abdomen (if such a term may be here applied,) and there is no observation to show that they undergo any further development after the formation and detachment of the larve; on the contrary, it has been observed that when the larvæ approach the complete term of their growth, the trunk or stem is found without such polypoid animal upon it. 
We must, consequently, as far as we at present know, assume that the function of these individuals is fulfilled when the larvæ have reached a definite development, that their whole existence has for its object the perfecting of a series of beings of the same species, towards which they stand in the relation of not simply a precedent preparative generation, or brood of feeders, but, inasmuch as they nourish the beings intrusted to them, not by independent and special acts, but by their life and from their bodies, in that of foster parents (ammende): and I shall, consequently, in what I have to say afterwards, designate them by the short name of Ammen (altrices, "nurses" or fosterparents.)

Since, according to the observations of both Sars and Siebold, only animals which have the power of affixing themselves proceed from the ova of Medusæ, all of which become in the way so often described, polypiform " nurses," which nourish the Medusæ-larvæ from their bodies, a considerable anatomical and physiological difference clearly exists between them, which are all of one sex, and the perfect Medusce which are of two sexes. Here, however, we observe a great natural harmony; since wherever we find the fostering of a brood or fry to be committed to special individuals, these are always of one sex, and indeed females in whom the sexual organs of germination remain in an undeveloped state, whilst in consequence of this abortion in the development of these parts, the instinct or nisus serving for the preservation of the species takes a peculiar direction.

This representation of their essential sexual relations is not affected by the fact frequently observed by Sars, that the " nursing" individuals increase by gemmation; in which mode of increase, something more probably can be perceived than the immediate multiplication of the nurses. *

* Thus it is very remarkable that every part of the body of the "nursing" animals, without distinction, is capable of throwing out gemmæ. May not, however, the objection be made, that an ovum might occasionally contain several embryos, one of which has become developed at the expense of the 
This mode of development it is true has been observed only in Medusa aurita and Cyancea capillata, two of our most common species of Medusa, in which the earlier circumstances of development so entirely correspond, that it cannot be determined whether any given nurse belongs to one or the other; but in all probability a similar mode of development occurs in all true Medusa. It is, however, sufficient for our present purpose that researches have shown this mode of development to occur in certain genera of the family.

But with respect to the relation of the periods of development to the seasons of the year, it should be remarked, that it is in the latter months of summer that we meet with Medusa containing mature ova; and that the researches of Sars on the origin and affixing of the fry, were made in September and October, whilst the detachment of the Medusa-larve has been observed in the spring months of March and April. In the first half of summer, and until the beginning of July, I found in the Atlantic, solitary, free swimming individuals of from $\frac{2}{3}$ "' to $3-4{ }^{\prime \prime \prime}$ in diameter. If to this we add the general observation made before, that the smaller specimens of Medusa are usually met with in spring, and the larger in summer, we shall perceive that the development of these animals, like that of the rest of the organic world, is intimately connected with the periodical motions of the globe.

others, which make good their individuality at a later period? May not several of these gemmæ originate in the same brood, which has attached itself to an individual already affixed a short time previously. 


\section{CHAPTER II.}

THE DEVELOPMENT OF THE CLAVIFORM POLYPES.

(Coryne, Syncoryne, Corymorpha, Campanularia.)

Tab. I. figs. $41-57$.

I HAVE perhaps occupied much time with the $M e$ dusa, but I have thought it necessary to do so in that instance, where the facts present themselves in greater abundance, in order that the basis upon which they are established, and the deductions to be made from them, might appear with all the distinctness which they seem to me to possess. In this chapter, in which I am desirous of proving the existence of a similar course of development in another perhaps not less numerous family of marine animals, I am unfortunately compelled to be more brief. What I have been able to collect in this instance, will probably be regarded with respect to the object I have in view, as very little; I think, however, that even in this little, as in the sketch of a picture not yet filled up, what the whole probably may be, will be not indistinctly discerned, when the necessary parts belonging to it, and as yet deficient, are supplied.

The creatures which I am now considering are the claviform polypes (Coryne) and the forms allied to them. These animals have afforded much ground for speculation to naturalists, especially with regard to the real nature of the bodies, at first tubercular and afterwards bell-shaped, which arise at the base of the more or less clavate polype head, (fig. 41.) 
Professor Ehrenberg was the first to view these bodies, as distinct individuals and even as of distinct sexes. He considered the club-shaped polype-head to be the male, and the bell-shaped bodies, sessile or dependent at its base, as females. This representation has since been generally followed. I propose to alter it a little.

In April and May (1840) in Iceland, I frequently observed on empty shells of Balani and other hard substances taken from the bottom of the sea, coryniform animals (fig. 41) fully half an inch long, and consisting of a slender, membranous stem, which supported a rather slender polype head furnished with a few (5 or 6) tentacula. From the base of this head, four bell-shaped quadrangular bodies hung down; which being placed at right angles to each other formed a cross, and together with the erect central head, the whole bore a considerable external resemblance to a Fritillaria, and I entered it consequently in my note-book, under the name of Coryne fritillaria. These bell-shaped bodies, which I do not hesitate to consider with Ehrenberg as individual animals and not as organs, strikingly resembled the figures which Sars has given of those in Corymorpha nutans and Lovén in Syncoryne Sarsii. They were four-sided and the angles moderately acute. The lower edge of the bell was cut off obliquely, so that one edge was longer and descended lower than the other or opposite and shortest one. The longer edge was slightly enlarged at its inferior angle and furnished with a darkish-coloured knob-like organ, the real nature of which we shall very shortly see. At each of the four angles of the bell-shaped body, there was situate near the edge a triangular reddish coloured spot, which, agreeably to common usage, must probably be considered subservient to vision. Around the mouth of the bell was a rather wide annular membrane by which it was partly closed.

From the bottom or arch of the concave body a foursided free stomach, ciliated at the end, hung down. The bell-shaped body depended under the base of the polype 
head, from a slender peduncle, and its motions were vigorous during its contraction and extension, by which the water was as it were pumped in and out, and at the same time the annular membrane surrounding the mouth was alternately drawn in and pushed out. After being observed for a longer or shorter time, the fully-formed and lively campanulate bodies became detached, and swam about in the water as free Meclusa-like creatures; and they lived thus for several hours in the sea water in which they were kept; a few surviving to the end of the day. Nevertheless I do not entertain the least doubt of this separation being quite natural, and that it takes place when the animal is in its natural condition at the bottom of the sea; partly for the reason, that they did not appear to suffer in consequence of their being detached, since after becoming so, their motions were more lively than before, and those which were not detached from the polype ceased to move after the lapse of the same time as the others; and partly because in the same places whence I had previously obtained specimens of my Coryne fritillaria from the bottom (viz. below Oerfarsey, an island in the bay immediately off the town of Reikewig, I met with a Medusa-like animal near the surface of the water, which I considered to be a full-grown, free, bell-shaped Coryne precisely of the same species (figs. 43, 44, 45.) These individuals so exactly corresponded, both in their external form and internal configuration with those animals, except in size, that I can adduce as the only difference, the presence of a lobate organ attached to the longest angle. This organ, which in the campanulate body of the Coryne, is represented by a wart-like protuberance, in these presented at its broader base, two lateral lobes, and at its more slender extremity one smaller lobe, which appeared to be cut off. It was at the same time filled with cells or globules, and two very long marginal filaments sprung from its base, which under a high power appeared to be beset with minute vesicles arranged nearly circularly. 
The movement of these animals was altogether similar to that of the detached bell-shaped Coryne, that is, they propelled themselves backwards by a rhythmical pumping in and out of the water, whilst the long filaments hung behind them, waving about in all directions. Since these individuals allowed the course of the organs to be more easily perceived, I will here also remark, that at each of the four angles of the bell a very delicate vessel ran down very nearly to the extreme edge, beyond which I was unable to follow it. 'The four external angles were of a milk-white colour, and formed in a peculiar way. In each of the larger cells, of which the white lines or edges of each angle were constituted, was situate a very minute globular cell, which lay half in and half out of the membrane, (stinging organs ?) (fig. 46 ;) I discovered a similar structure in a white line which passed down from the lower edge of the bell, and formed a ring, connecting the other four lines together. The triangular ocelli resembled those of the Coryne, but were larger. At some distance from the longer edge, but otherwise perfectly parallel to it, two slightly zigzag lines (canals a) proceeded downwards to the peculiarly formed, lobed organ.

An organ developed in such a peculiar and striking manner, must necessarily have a definite and essential object, and since it is developed at so late a period, and is as it seems filled with globules or cells, I can only look upon it as connected with generation.

What I am convinced of with respect to this mode of generation, namely, that, at least in this species of $\mathrm{Co}$ ryne, the bell-shaped individuals detach themselves from the club-shaped polype and swim about towards the surface of the water in the form of small Medusa, is no more than what R. Wagner, Sars, and Lovén have conjectured, with regard to the form and rhythmical motion of the bell-shaped bodies of other species of the family; and if ny memory does not deceive me, Sars, either by letter or orally, also communicatcd to me, that he last year observed the detachment of the campanulate bodies. 
Compare also, on this subject, R. Wagner's researches on Coryne aculeata, which were carried on in the Adriatic in the year 1832. (Isis 1833, p. 256, tab. xi.) That the bell-shaped animal frequently produced ova, and consequently are females, has long been remarked, for which we may refer to Lovén's excellent memoir on Syncoryne ramosa of Sars, in 'Svenska Vetenskaps Akademiens Handlingar, (Aar 1836,) which also appeared in 'Wiegman's Archiv für 1837,' (s. 322, tab. vi,) and to R. Wagner's figure of Coryne vulgaris, in his 'Icones Zootomic :' (1841, tab. xxi, fig. xvi.)

Still more, however, do the conditions of Sars' new animal, Corymorpha nutans recall what is exhibited in my Coryne fritillaria. In order to compare them, I have placed Sars' figure of the bell-shaped bodies of the former, next to mine (fig. 47.) Sars expressly remarks, that the four angles terminate in as many knobs, and that one of these is always larger than the rest, and supports a smaller rounded protuberance. In this description will be easily recognized the lobated generative organ present in the detached form of the animal.

The notion promulgated by Sars (Beskrivelser, s. 25, ) and referred to by Lovén (l. c. p. 322,) that the bellshaped body detaches itself and becomes a Coryne or clubshaped Polype, and that the above-described tubercle at one of the angles is lengthened into the stem of the polype, will certainly be shared in by no one, and no longer maintained by Sars himself.

Any transformation of the bell-shaped into the clavate form, or into a Coryne, I must consider as altogether impossible, from considerations of the structure of each, and of the facts we have already obtained on the subject, although a direct observation of a former period would appear to show that it does occur.

O. F. Müller, 'Zool. Dan.' (p. 3, Danish edition, p. 13,) for instance, asserts, that the detached capsules are developed into new polypes. According to my opinion the bell-shaped individuals are full-grown and fully-developed 
animals, which are destined for the propagation of the species, and that there are probably both males and females among them. In Syncoryne ramosa, Sars (Lovén, l. c.,) and Coryne vulgaris (R. Wagner, Icones Zootomicæ, l. c.,) the ova are seen to be formed in the bell-shaped individuals while still attached to the polype; in Coryne fritillaria, and probably in Corymorpha nutans Sars: the ova are not formed until the bell-shaped animals have become detached, and have acquired their perfect development into the form of medusa-like creatures. Agreeably to the conclusions at which I have arrived in the preceding section, I see in the Coryne itself only a previous generation of preparative " nurses," which are so far asexual, inasmuch as that their generative organs are not developed.

I cannot here forbear remarking upon a Meclusa $p a$ pillata observed by Abildgaard near Heligoland, and figured in 'Zool. Dan.' (tab. cxl,) as being an acalephoid animal exhibiting such a close similarity with the bellshaped bodies nourished by the Coryne, that one would be readily inclined to look upon it as such. If this figure be compared with that by Lovén of the more globular campanulate animals attached to Syncoryne Sarsii, Wiegman's Archiv, (1837, tab. vi, fig. 25,) the resemblance will be found very striking.

Should future inquiry determine, what, however, I by no means doubt, that the whole family of claviform polypes in the genera Coryne, Syncoryne, Corymorpha, is only a stage or generation in the development of forms, which when perfect closely resemble Medusce without it being possible to arrange them together, all these genera as such must be abolished, since they include forms or individuals, which do not represent the perfect state of the species to which they belong. The more perfect forms, however, notwithstanding their resemblance to Medusæ, must still occupy the systematic place of the claviform Polypes or Corynæ, as animals closely allied to Tubularia, Sertularia, \&c. 
For observations and researches on the genus Campanularia which have enabled us to institute this comparison, science is obliged especially to Rapp, Grant, Lister, and Lovén.

I will here, as briefly as possible, give the results of the observations of the last-named Swedish naturalist, but for the observations themselves, must refer to the sources whence my abstract is drawn, namely the ' $\mathrm{Kgl}$. SvenskaWetenskaps Akademiens Handlingar,' (1835,) and 'Wiegman's Archiv. f. Naturg.,' (1837, s. 249-262, tab. vi, whence I have taken the figures $(48-58)$ given in tab. I. of this work, which afford us a striking example of cyclical development, and throw a clear light on all the neighbouring families both above and below.

Fig. 48 represents a Campanularia geniculata or bellshaped Polype very slightly magnified. It is evident, that the individuals, which, surrounded by cells or cups, shaped like inverted cones or bells, constitute one of these polypes, have cells of three kinds, each of which has a determinate position. The most numerous are the smaller cells (individuals) placed at the extremities of the stem and branches (fig. 48 a a.) In the angles between the branches and the stem are situated the axillary cells, which are always longer and nearly twice as large, (fig. $48 b \mathrm{~b}$, ) and upon these are placed the third kind of cells which are globular (fig. $48 c c$,) and the smallest of all. The relation between the three groups of individuals or cells differing thus in form and position, becomes clear, only when the development of the whole polype is traced, and a moderately high power employed for the purpose. The minute vesicular individuals (fig. $48 c c$ and fig. $53 a$ and $b$ ) which are placed upon the larger and longer axillary cells, contain two, and rarely three moderately large ova, which exhibit the essential parts of an ovum, and the individuals in which they are contained, are thus to be considered as, in reality, females.

When the thin membrane of the ovum bursts asunder, 
there issues from it an oval somewhat elongated embryo, (fig. $53 a$, and 54, ) the whole of whose surface is covered with cilia, by which it is enabled to move about in the water in all directions, whilst at the same time it contracts and elongates its body, which is sometimes more of an oval or even pear-shaped form, and sometimes longer and attenuated posteriorly. Lovén distinguished in this embryo, an interior cavity, containing an opaque fluid, and circumscribed by two membranes, of which the internal is opaque and the outer one as transparent as glass. He was unable to discover any oral orifice, and it is hardly probable that one should be formed at this stage of development.

After swimming about freely for some time, the little creature attaches itself to any large object, as the frond of a fucus, becomes contracted, and assumes a circular figure. The cilia cease to vibrate and the membrane upon which they are situate forms a narrow, nearly transparent border around the animal, in the centre of which an opaque spot is visible, which is formed by the close aggregation of the minute granules contained in the fluid (fig. 55.) Over this opaque spot the surface becomes slightly elevated into a rounded projection; this is the commencement of a polype stem, which rises gradually in a vertical direction from the circular, expanded disc, the substance of which contracts at the same time, and is divided into four lobes (fig. 56, which, according to Lovén, are the first traces of the offsets most usually put out from the stem of the polype. By the alternate advance and stopping of the growth, the circular contractions are caused which give its annulated aspect to the stem of the polype. Fig. 57 shows the stem at the beginning of its growth; its interual cavity, filled with the finely granular fluid which circulates within it (which may not inappropriately be compared to a nutritious matter or chyle, ) rises in a conical or spherical form, distending its two containing membranes. The convex surface of the external membrane secretes a delicate epi- 
dermis, which is at first very soft, but afterwards becomes firmer and horny, and it is in this way that the external horny sheath or tube around these polypes is formed; and at the same time the spherical extremity of the growing stem from the afflux of the contained fluid is constantly rising, and thus forms a new ring or circle of the sheath, above those already formed. When the stem has attained a certain growth, the motion of the granules contained in the fluid becomes more active and the distension greater, and a so-called cell or cup is formed, which is in fact a polype in a cell. The dilated part is so much expanded as to become, as it were, annular, and it secretes from its inferior surface a horny membrane which forms a partition between the cavity of the stem and that of the cell now in process of formation.* This formation commences by the gradual ascent of the annular portion, which, as it increases in size, secretes a horny membrane from its outer surface, and forms the wall of an inverted conical cell. When this cell has attained its full size (fig. 50) all the soft parts recede from its walls, and form a column in the centre; and it is at this time that the tentacula begin to be formed and the oral orifice to appear (fig. 51.) The animal now pushes against the flat covering or lid of the cell, protrudes its tentacula, and becoming independent, seizes its food which consists of Cyclops and other small crustacea; and the nutritious particles, circulating in the interior cavity (or so called intestinal tube), become more abundant. This is followed by the shooting out of one branch after another at regular distances from the completely formed polype, which is effected by the interior soft substance (the intestinal tube) gradually accumulating at certain parts of the sheath or tube, and causing a rounded projection on it, which projection continues to grow from the stem in the same way that the latter grew from the discoid expansion on the fucus. As soon as the branches have acquired a certain length, a cell or polype is

* It is probable that the so-called intestinal canal has never any connexion with the cavities of the cells. 
developed at the extremity of each, exactly like that at the extremity of the stem, and which follows the same course of development. In this way we witness the gradual formation of all the individual cells ( $a$ a a a a, fig. 48, ) of the first form, on the compound polype which originated in one of the minute ciliated creatures.

When the cells and polypes of the branches are fully formed, other cells, much larger and differently shaped, spring up in the angles between the stem and branches (fig. $48 b 6 b$, and magnified fig. 52.) They are formed exactly in the same way as those first described, but are always nearly sessile and provided with an arched operculum, from which the softer annularly expanded, substance does not shrink (fig. 52 ;) consequently the animal does not complete its tentacula, nor protrude itself from the cell. On the contrary, other and still more interesting phenomena are exhibited; for new individuals are generated between the outer and inner membranes surrounding the so-called intestinal tube, upon which are now formed small elevations (fig. $52 b$, ) at which the granules of the interior fluid appear to be detained. These projections increase in size and become rounded, and their commexions with the intestinal tube more slender, though never entirely destroyed. External to these vesicular projections, some perfectly spherical bodies are visible (fig. $52 f$ ) of an opaque substance, but presenting a clear round spot like an included vesicle (fig. 52 g) on their external side. The globular bodies, two of which are placed on the external aspect of each vesicular projection of the central tube, are inclosed in a delicate transparent membrane (fig. 52 h) on the outer side of which is a circlet of minute tubercles (fig. 52 k.) During the continued development, which always takes place from above downwards, so that its successive steps may be observed in the series of vesicular elevations ranged one above another, the uppermost transparent sac with its contents approaches the operculum of the axillary cell and breaks through it, without, however, losing its connexion with the central tube. The succeeding 
sacs then follow the same course, until the whole series is exhausted, in consequence of which, the polype of the axillary cell seems to shrink; but it is constantly again covered with a flat operculum or membrane, which adheres to the border of the cell, and surrounds the slender connexions of the sacculi with the central tube. Meanwhile the apparent sacculi open (fig. 53 b); and a circlet of about twelve irregularly-toothed tentacula projects around the opening, and it is now seen that the sacculi are in fact globular individuals, in which four longitudinal vessels proceeding from the base of the tentacula to the bottom of the body, represent the four vessels met with in the more fully-developed coryna.

Thus these globular individuals are completely developed females, and the opaque globules contained in them, ova, in which the clear spot is the germinal vesicle (vesicula Purkinji.) When the embryo is fully developed, it ruptures the delicate membrane of the egg and escapes, remains for some time within the parent animal, through whose opening, however, it afterwards passes into the water, attaches itself to a fixed object, and becomes the origin of a new compound polype, in which the same process of development is repeated. The parent animal dies off or withers, having fulfilled its function.

Upon reviewing this sketch, it can hardly be considered to present an instance of metamorphosis, since it is not the same individuals which in the course of time exhibit various forms, but we see here also, a series of generations whose succession in a definite order is necessary to the complete development of the species. The ciliated embryos which, by their adhesion lay the foundation of the polypes, originate only from ova, which are developed in the females. These latter are generated between the inner and outer tunic of the polype in the axillary cells, which polypes may consequently be considered as the " nurses" or foster-parents of the female individuals, whilst they are themselves, on the contrary, derived from a previous generation of polypes of a different form, 
which occupy the extremities of the branches, are of the same shape as the polype of the stem, and must be regarded as of the same kind, although they appear to arise from it by what is called gemmation.

Numerous observations already recorded justify us in assuming that the account of the development of these animals, displayed in the foregoing exposition, applies not only to Campanularia, Plumularia, and other Tubularia, but also to the Sertularia. But how far the aggregated Coralline polypes may be explained in a similar way, namely, by supposing them to be a colony of imperfectly developed individuals, whose aggregation has for its object the complete development of individuals of the same species, must be determined by future inquiry. 
CHAPTER III.

THE ALTERNATE GENERATION OF THE SALPE.

(Proles Gregata, Proles Solitaria.)

IN the preceding chapter it must certainly have occurred to every one, that phenomena would also be presented among the Mollusca, particularly in the Salpa, analogous to those exhibited in the development of the Medusce and Corynce. These animals have attracted the notice of all voyagers, by the extraordinary circumstance, that numbers of individuals, 20,40 or more, are united into very long chains (Salpa chains) in a peculiar manner and by means of special organs of attachment. All the individual Salpe composing these chains, are of the same form, and are opposed to each other in the same direction; they move with great uniformity, and keep as it were the same time, by which movement the whole chain progresses in a serpentine manner, below the smooth and tranquil surface of the water ; for, like other gelatinous and transparent marine animals, they approach the surface of the sea, only in fair and calm weather. Besides the Salpce which are thus united in chains, there are also other individuals which are not so joined, but swim about separately. Some of these exhibit evident traces of their having previously been united, since they possess the organs by which they had been attached, and their shape exactly resembles that of the associated animals; but in others, all trace of their having been 
formerly connected is absent. Thus the Salpe may be divided into two classes, the associated and the solitary.

With regard to these strange creatures, Chamisso* made the curious observation, that the solitary Salpee, though never themselves forming parts of a chain, yet always contain a progeny resembling those which do, and that each separate embryo is linked together, like the individuals forming the Salpa chains, and very closely resembles them in figure; but in the associated Salpa on the contrary, he found young, resembling the solitary ones. This was usually a single pedunculated foetus, situate in, and attached to, the wall of the respiratory sac of the parent animal, and resembling the solitary Salpe in its shape. In only one associated Salpa (Salpa zonaria) there were always found four such pedunculated distinct embryos. Now, as examination of the free swimming individuals, which presented marks of having been disjointed from a chain, proved that these also contained only solitary pedunculated embryos, Chamisso concluded from his observations, that all solitary Salpa, produced associated ones or chains; and on the contrary, that all the associated Salpe were parents of solitary ones, and these again of the associated and so on.

The generations of the Salpa consequently, are alternately solitary and associated, so that a Salpa mother, to use Chamisso's familiar expression, is not like its daughter or its own mother, but resembles its sister, its granddaughter, and its grandmother. Against this theory of the alternate generations of the Salpa, its intelligent author had many attacks to sustain, and the more so, on account of the considerable difference which exists between individuals of the associated and solitary Salpe, and because no example of such alternate generation was known in the rest of nature. Thus it was no wonder, that endeavours were made to subvert this theory, partly by seeking to weaken the force of the observations upon

* Chamisso. De animalibus quibusdam e classe vermium Limmanâ. Fasc. I. de Salpa. Bcrolini, 1819, 4to. 
which the theory was founded, and partly by interpreting them in another way.

The former was attempted especially by Meyen,* who in his voyage round the world was so unlucky as not to meet with a single solitary salpa containing a chain of embryos, although, free swimming salpa-chains in many places surrounded the ship in masses. He consequently attempted to make good the assertion, that the free swimming salpa-cliains and the associated embryos, which Chamisso had observed in the solitary Salpa, were to be explained in entirely different ways, and had no relation to each other. His observations, which were without doubt superficial, led him to conclude that the association of the Salpa was a voluntary act, and that they had the power of reuniting themselves, after having been once separated.

The opposite course is followed by Prof. Dr. Eschricht, in a copious memoir lately published in Copenhagen, $\uparrow$ in which he industriously tries to give another explanation of the phenomena : on which account we must subject his labours to a strict examination. In the first twenty sections, he adduces numerous anatomical relations, and reviews them with as much accuracy as the examination of specimens preserved in spirit will allow, and in the twentyfirst and following sections comes to the question, the solution of which is the true object of the essay, namely, the real nature of the associated embryos and Salpa-chains. The examination of Salpa cordiformis, a solitary Salpa, and of Salpa zonaria, an associated one, led Eschricht to the conclusion, which agrees with the views of Chamisso, that every Salpa chain originates in the embryo (p. 378,) and consequently is born in the associated form, because it is certain that the catenation of several Salpa commences

* Meyen. Beiträge zur Zoologie, gesammelt auf einer Reise um die Erde, Iste Abth., über die Salpen; Nova acta Acad. Cæs. Leop. Car. natur. Curios. tom. xvi, pars prior. 1832.

$\uparrow$ Anatomisk-physiologiske Undersögelser over Salperne, af Dr. F. Eschricht, in den Schriften der Königl. Dän. Ges. der Wissench., naturh. og mathem. Abhandl. viii. 1841, p. 297-392, tab. 1, v. 
in their embryo state, because also, there is no reason for assuming any other mode of association in the Salpe than that which originates in the fotal state, and becuuse no certain observations tend to show, that the connexion of these animals is ever restored after having been once dissolved, the impossibility of which is evident from the structure of the organs of adhesion, as figured by Prof. Eschricht. For he found in his specimens of Salpa zonaria, which. all presented indubitable marks of the rupture of a previous union, the four pedunculate bodies, which as it is known, eventually form four solitary embryos, just as Chamisso, and more lately Quoy, Gaimard, and others have found them, and besides this, he observed in the case of the Salpa cordiformis, that each enbryo constituting the embryo chain, while still inclosed in the body of the mother, presented distinct traces of younger solitary embryos; Chamisso's observations, which bear all the stamp of truth, are thus confirmed by those of several others, as well as by the anatomical researches of Prof. Eschricht, who, however, considers them as insufficient for the foundation of such a theory as that of Chamisso mentioned above, althongh that accurate observer himself asserts, that he had traced the whole course of development in one species, viz. in Salpa pinnata " hac unicâ in specie, fatemur nos integrum metamorphoseos cyclum, hiatu nullo, ommibus suis momentis absolutum persecutos esse oculis." (l.c. p. 10.) For Prof. Eschricht objects, that it does not appear from Chamisso's observations, that the associated Salpe produced from their solitary congeners, continue throughout to produce only solitary young; it may be possible, that the associated Salpe become detached after the birth of their first offspring; may lose their organs of attachment; may assume the solitary form, and afterwards produce a later generation of (associated) embryos. And he goes on to observe also, that it is not proved by Chamisso's observations, that the solitary Salpe which produce chains of embryos, and are thus the parents of associated individuals, are 
identically the same solitary Salpe which had been produced by the associated ones. Thus, according to Prof. Eschricht, they may be born in the associated form from solitary parents, and after producing a solitary progeny, may themselves become transformed into solitary Salpe, and in this condition may produce young in the associated form. As long as these objections are unanswered, it would be prudent, according to Prof. Eschricht, to assume another mode of explaining these extraordinary facts, " and which would accord better with the general laws of development," and he ventures to propose for further inquiry, the following theory of the propagation of the Salpa:

"The Salpe in their younger state produce solitary embryos, and in their older, associated ones. They do not necessarily undergo any metamorphosis; the single (solitary) embryos assume, while still within the mother, their permanent form; but the embryos forming chains, are slightly anomalous in figure owing to their union, and this form afterwards changes into that which is permanently retained." It is vain, however, to look upon this as a natural explanation; and, even if some observations of my own of analogous phenomena, and the information afforded by the observations of others upon similar subjects, had not led me to consider Chamisso's theory as not unnatural, still I should feel myself compelled in the name of Nature, to protest against that of Eschricht, when it demands to be considered a natural one, either absolutely, or in comparison with that of Chamisso.

Eschricht has referred his theory to "a closer examination;" to which we will now subject it. "When young, the Salpe produce a solitary progeny, and when older, an associated one." This expression assumes in the first place, that one and the same animal, at two different times or periods of its life can produce young differing in no slight degree in their organization. It is true, that bir'ds when young lay fewer and smaller eggs, and when older more and larger ones; that probably certain rep- 
tiles at one time bring forth eggs, whilst at another, the shell of the egg is ruptured at an earlier period, and living young are produced, \&c.; but notwithstanding this, the young from the eggs and those which are born alive, entirely correspond in their organization. In the humblebee and wasp, we also know, that larvæ are produced from the first deposited eggs, which only attain a definite and lower degree of development, whilst the larvæ from the ova which are deposited at a later period by the same females, attain another and a higher stage; but so far as we are at present acquainted with their nature the larvæ from all the ova, are indebted for the degree of development which they respectively attain, whether higher or lower, only to the adventitious and extraneous care which is devoted to them; and I believe it would be very difficult to find in the whole of nature, anything analogous to that which is supposed by Eschricht.* Inasmuch as that in an organization in other respects similar, we must always presume that organization or state of development to be the higher and more complete which exhibits the greatest degree of independence, and the existence of which is connected in the least degree with the coexistence of another similar organization, and as in this respect a free swimming form must be considered as more highly de-

* This first objection, which is not exactly the same with the only one made by Professor Eschricht to his own theory, namely that the embryos never resemble their mother, but that the young of a sotitary salpa, in their form, invariably resemble the associated, whilst those of an associated salpa always assume the solitary form, loses none of its weight from the assumption of Professor Eschricht, that the reason of the difference of form which exists between the associated and the solitary salpa-embryos lies especially in their connexion. For the circumstance that the individuals of the one generation of embryos are connected by peculiarly developed organs, whilst, on the contrary, the other generation wants those organs and consists of unassociated embryos, is much more essential than a slight difference between the two generations, in the ontlines of their external figure, and in the relative extent of certain organs, which besides are common to them both. Still it by no means follows, that the reason of the difference in form between the associated and solitary salpa should exist simply in their connexion; for there is some common, internal, fundamental principle concerned in the nccessary occurrence of such an intercommexion, and of the organization conducive to it, which it would be vain to attempt to demonstrate with our present amount of knowledge. 
veloped, than one which is fixed or not free in its movements, so we are certainly justified in considering, that the solitary Salpa are superior in their development to the associated; and this is even admitted by Eschricht, when he allows, that though late, eventually the associated is changed into the solitary form. But, in the second place, this expression implies that an animal in its younger and less developed condition, produces young more highly developed than those produced by it when it is itself older and has reached a higher stage of development; and if the different generations or forms of the progeny are now compared, not with each other, but both generations with the parent animal, the above hypothesis will be found also to imply, thirdly, that a young animal produces a progeny of a form and organization which is attained by itself, only at a later period, and that when it has attained its full development, it should only be able to produce young far inferior to itself, and which by progressive transformation alone, afterwards attain to the degree of development of the former generation and of the parent.* But the worst conclusion to which this

* In meeting the objection, which he himself has made to his own theory, Professor Eschricht declares: "that it is certainly extraordinary that the fotus while still within the mother, should present a form at which the mother itself does not arrive till asterwards; but the wonder will in a great measure be removed, when it is remembered that the difference of form (described in Sect. 15,) depends on the relations which the animal assumes in its connexion with the others, and not on necessary gradations in the progress of its growth towards completion, and it consequently possesses no analogy at all with what is termed metamorphosis." (At Formsforskjelligheden beroer paa Forholdene i Kjoededannelsen, ikke paa nodrendige Gradationer i Uddannelsen, altsaa aldeles ikke ere analoge med de saakaldte metamorphoser. I have here assumed the words "ere analoge" to be an error of the press, and "Formsforskjelligheden" to be the subject of the proposition. But nevertheless the sense of the passage is still obscure.-Germ. Trans.) Probably there is here some error of the press or of expression, which prevents a clear apprehension of the author's meaning. I willingly grant him, however, in the meanwhile, that in one respect no metamorphosis does occur; for I am convinced that the associated salpa never become other than associated, and are never solitary. But on the other hand, it appears to me that Professor Eschricht, who maintains that the associated salpa assume in process of time, though late, the solitary form, will find it difficult to show that such a transformation is brought about in any other way than by a sudden transition, that is by a metamorphosis, from the circumstance that the associated sulpee retain for so 
hypothesis of Prof. Eschricht leads, in my opinion, still remains. He confessedly assumes, " that the embryos forming the chain," change at a later period from their somewhat anomalous form into the permanent one, (that is, into the form of the solitary,) and at the same time he supposes, as he is compelled to do both by the observations of living nature of Chamisso and others, and by his own anatomical researches, that they, while still in the first or associated condition, produce embryos (the form of which is here immaterial) and then, afterwards assume another and permanent form. On the contrary, however, I must, fouithly, object, that it is opposed to all natural considerations, to all known natural phenomena, and to all physiological principles, that an animal should be able to propagate itself before it has attained its perfect form and development. Although Professor Eschricht may assume, that the first three assertions of his hypothesis are not contrary to nature, the last, at least, must be considered so.

Having thus shown that the proposed explanation of the phenomena attending the propagation of the Salpa, from whatever side it is viewed, is not the less unnatural, we return to Chamisso's theory, which is founded upon the observation, that the first generation of these animals is solitary, and the second associated, or, in other words, that all Salpa chains are produced from solitary Salpe, and all solitary Salpe on the other hand, from the associated. This conclusion may at first sight appear extraordinary ; I am, however, convinced that every attentive reader will find something similar displayed in the two

long a time, and so characteristically, the form they possessed during foetal life. It can scarcely be imagined that the extermal and internal conditions, tab. iv, fig. 18, of an animal of the size of the Salpa zonaria should be changed without metamorphosis into those of the Salpa cordiformis (tab. 1.) Thus, according to the hypothesis of Professor Eschricht, the full grown solitary salpe must have a double origin, viz., partly as solitary from young individuals, and partly as associated from older ones, and which at a later period assume the solitary form; but this also appears very unnatural, that what was at the beginning dissimilar, should afterwards be developed and become similar. 
preceding sections, and especially in the phenomena observed with regard to the propagation of Medusa aurita. This free swimining Medusa always produces a progeny which is polypiform, and destitute of the power of locomotion, but which on the other hand after attaching itself to various bodies at the bottom of the sea, brings forth a progeny consisting of free swimming Medusa, which never assume the polypoid form; and this alternation is constant. The fact may be thus expressed: that each second generation is affixed and polypoid, or that the free swimming hemispherical Medusa always produce a polypoid offspring, and that the polypoid Medus $a$ are always the parents of the free swimming hemispherical ones, \&c. I have consequently no hesitation in expressing my belief, that the alternate generation of the Salpa, from solitary and associated individuals, is to be explained in the same way as that of the Medusce, and that the first generation of these animals serves as a series of foster-parents, whose object is, by their furthering the development of the second generation, to conduce to the perfection of the species. I am, however, prepared to admit, that this kind of explanation does not enlarge our knowledge with regard to the propagation of the Salpa; I only think, that the phenomena ahready known, will have a clearer light thrown upon them from the analogy. Some doubt even must still remain, on the circumstance whether the solitary or the associated Salpee are the foster-parents. In my opinion however, it is the solitary form rather than the other which should be assumed to be that of the "nurses." *

* From a remark in Sar's Memoir on the Medusa (Erichson's Archiv, 1841, H. i, p. 29, ) I perceive that that excellent observer has instituted researches on the development of the salpee, and promises to communicate them at another opportunity (which it is much to be desired should occur soon.) Although in the above place he does not state anything precise, with regard to the result of his inquiries, yet we may gather from what he says that Chamisso's views and remarks are in the main correct. "The salpe correspond in this with the medusa, that it is not their larve which are developed into the perfect animal, but the progeny of the larve; it is not the individual, but the generation which is metamorphosed." 
The Salpe have always been placed near the Ascidice, and the more accurately the structure of both these families is known, the more evident does their relationship become.

For this knowledge, we are recently indebted to the last memoir* of Milne Edwards, on the compound Asciclice, or those which are regularly grouped in large masses or colonies, (Asciclia composita.) This excellent naturalist has pointed out a peculiar circulation of the blood, common to all the Ascidia, whether solitary (Ascidice simplices,) or in small groups (A. sociales, M. Edw.,) or closely aggregated and for the most part regularly grouped in larger masses or colonies $(A$. composite; $)$ and a similar circulation has also been discovered in Pyrosoma which may be considered a swimming colony of ascidians, and in the Salpa. $\dagger$

What, however, the more justifies us in delaying a moment with the compound ascidians before quitting the consideration of the series of the animal kingdom, to

* Milne Edwards, Observations sur les Ascidies Composées des côtes de la Manche, 1841. Avec planches, gr. Svo.

+ In this circulation the blood is carried from the heart, and back again to it through the same vessels. The heart, which is always placed close to the generative organs, and usually in the inferior part of the animal, is moderately extended, contracts with an undulating motion, and propels the blood in the same direction with the undulations ; for instance, if these are directed from below upwards, the blood ascends in a stream along the auterior surface of the abdomen, within a wide thoracic or abdominal vessel, from which a number of contiguous transverse canals proceed, which are connected by mumerous smaller longitudinal vessels, and form the four-sided vascular network on the walls of the branchial sac. All the transverse canals open into a large dorsal vessel, which receives thus all the blood which has passed through the vessels of the branchial sac; but besides this some blood is also received by it which has not passed through the respiratory organ, in consequence of the great dorsal vessel being connected at each extremity with the great thoracic or abdominal vessel, by two considerable annular vessels. The blood returns downwards from the dorsal vessel through a canal lying: on the dorsal surface of the abdomen (dorsal canal) to the opposite end of the hcart. After the lapse of a few minutes the heart begins to undulate in the contrary direction, which is necessarily followed by the blood; which now flows upwards during the same space of time through the dorsal canal and dorsal ressel, traverses the branchial sac, and passing through the great abdominal ressel along the anterior surface of the abdomen again reaches the heart. In this way the blood flows alternately in opposite directions, according to the direction of the movements of the heart. 
which the Salpa belong, is their mode of propagation as confirmed by the observations of Milne Edwards. Although all the Ascidice are affixed, yet their young swim about freely, and to this end their oval obtuse bodies are provided with a special organ for swimming, or sort of tail which they move about in the same way as tadpoles and Cercaria. At all events, this appendage has been observed in all the Ascidise which are aggregated in smaller swarms, or which form larger colonies, in which latter, the individuals are so closely connected together by means of a common, gelatinous, or membranous substance which surrounds them (enveloppe,) that one is inclined to consider them as immersed in it. In several allied genera, moreover, we find more or fewer individuals of the same form and size arranged in a very regular manner, 6, 8, 10, such being grouped on each side of a straight line or radiating around a common central point, (as for instance, Botryllus, ) and forming a hollow or pit common to all, and to the construction of the sides of which all the Ascidice fixed around the common centre contribute, and in which are situated the anal and generative openings, so that in consequence of this structure, the mature ova and young ones must be collected in the hollow or pit before they escape into the water. It is very probable, that the young remain some time in this receptacle, in order as it were to be hatched, before they swim about; at least, great numbers of them are frequently retained in it.

That the progeny when it quits this receptacle, does so in the form of caudate free swimming animalculæ, was observed as far back as 1828, by Audouin and Milne Edwards, and independently of them, by Sars (Beskrivelser og Jagttagelser, 1835,) and the observation is confirmed by Dalyell, (The New Edinburgh Philos. Journal, January 1839.) But for our first clear idea of the complete development of these free swimming animalculæ in their earliest period, we are indebted to the above-mentioned larger memoir by Milne Edwards, and the observations made by him in 1834 and 1839. After 
the hatching of the young fry, Milne Edwards observed their development at periods of four hours, and has given figures for each of these periods which represent the changes undergone by the animal in the intervals.

The young animals, as it was correctly stated by Sars, present externally a delicate, lax integument, hanging round them in sacculated folds in consequence of the retraction from it of the soft internal parts; which are otherwise of the same shape as the external sacciform case, only that there proceed from them anteriorly several cylindrical prolongations, dilated at the end into a sort of knob, by which they are in contact with the external tegument, to which they are the more closely united, the shorter the time since the escape of the embryo from the egg. These organs, thus placed with considerable regularity within the integument and around the anterior extremity, misled Sars into the supposition that it was not a single embryo which was contained in the egg, but a whole circle or star-shaped assemblage of them. Milne Edwards, however, shows that these dilated extremities serve as suctorial discs, which are employed by the animal after it has swam about for some hours in the water, to attach itself by to larger objects, in order to become fixed like the parent animal. At this period a change in the development begins to occur. The processes, which support the suctorial discs, and the interior caudal tube become absorbed, and the substance of which they were composed gradually enters into that composing the bulk of the soft parts, that it may be formed into new organs; and in about ten hours from the time of its affixing itself, the animal is contracted into a globular mass within the wide, dead, caudate integument. In twenty hours, the situations of the future mouth and heart become evident; on the next day the oral orifice is completed, and water begins to enter the respiratory sac; on the third day the pulsation of the heart is observable, and the outward form of an Ascidia recognizable, and within a few days all the organs are formed, except those 
of generation, which are not distinct till the end of the second week.

Excepting slight differences in the length of the intervals in which the animal arrives at the varions stages of its development, the same mode of development takes place in all the compound Ascidice, and in all of them consequently, the progeny consists of solitary individuals, which grow up into solitary Ascidia.

With regard to the mode in which the colonies are formed, especially when they are composed of individuals distributed in regular groups as in the genus Botryllus, \&c., the question, as it appears to me, has been far too lightly treated by M. Edwards. For he has observed, that among the Ascidice composite, and sociales, individuals occur which propagate themselves by gemmation as it is commonly termed, since from the lower end of the animal peculiar processes arise, which gradually become irregularly or dichotomously branched, whilst the enlarged extremities of these branches are, at a later period, formed into Ascidice. Since in this way from a single individual several Ascidice may originate, M. Edwards supposes that the colonies owe their origin to solitary individuals, which have multiplied themselves by gemmation, and from which new individuals successive gemmations again take place until the whole number is formed, which we find constituting a given mass or group. To this it may be fairly objected, that although in the ascidian groups or colonies, the separate individuals are able to multiply themselves by gemmation, and although it may be admitted as in some degree analogous to this, that it is possible that the solitary Ascidice, into which the caudate young produced from the egg of the aggregated Ascidia are changed, may throw out similar gemma-(although, so far as I know, this has not been observed)-still, individuals of equal size and similar form, do not spring at one and the same time from such gemmation, and still less, do groups of individuals, arranged in a definite number around a common centre or central line, as in Botryllus, \&c.; which 
latter mode of grouping is quite unintelligible and inexplicable under the liypothesis of M. Edwards.

It occurs to me that the regular grouping of individuals in Botryllus, \&c., bears the greatest resemblance with the catcuation of the Salpa, and may best be compared with it; and I consequently consider, until observation proves the contrary, this grouping to be a foetal condition, and assume that the Botrylli are born in this state of organic connexion. In accordance with this supposition, I am inclined to consider the solitary Ascidice, whose development into perfect animals has been so beautifully shown by M. Edwards, to be the animals which produce the aggregated ones, just as the solitary Salpe bring forth Salpa-chains. It may be sufficient to have expressed this opinion, since observations are wanting: to enable our advancing further in this direction than to a probable hypothesis.

I now proceed to another class of the animal kingdom, the EnTozoA, with respect to some of which I can rely upon observations which will serve to illustrate some of their relations, which have been hitherto obscure. 


\section{CHAPTER IV.}

THE DEVELOPMENT OF THE TREMATODA.

The best known form of the numerous family of the Trematoda is the fuke or Liverworm (Distoma hepaticum,) an entozoon which inhabits the livers of sheep in particular situations, and, especially in wet years, causes much sickness among those animals. Similar forms are met with in almost all animals of the four higher classes, and among the lower, the Mollusca are equally infested by them.

It might almost be said, that in these classes every species of animal is inhabited by its own fluke; in several animals also, several different species of these parasites have been found, which inhabit either all the organs of the animal indiscriminately, or are exclusively confined to one, (Liver, Kidneys, Bladder,) or to a definite part of an organ. Several of these Trematoda, as we shall also see, when young are not connected with any organ, but enjoy the power of free locomotion in water externally to the animal which in their future state as entozoa they infest. In this condition they are provided with a locomotive organ, usually a tail of moderate length, by the waving movement of which the creature propels itself through the water, like a tadpole, to which in its external form it is not dissimilar, except that it is much smaller, and almost microscopic. In this larval state, the Trematoda are known to naturalists under the generic name of Cercaria. 
It was well known that this form was not a permanent one, but we were ignorant of the changes which it underwent. As I have been so fortunate as to trace these changes, I will now detail them.

\section{(a) Cercaria echinata? Siebold.}

\section{(Tab. ii.)}

I cannot determine with certainty whether the Cercaria which I have figured in tab. ii, fig. 6 , be really the $C$. echinata of Siebold, or a very nearly allied species; I however, think they are identical, from the description given in Burdach's ' Physiology,' (2d edit. ii. s. 187.)

This species has of course the usual character of the Cercaria; a body formed entirely like that of a Distoma, but which is prolonged posteriorly into a long, transversely striated, extensible tail, not a vestige of which is presented by the Distomata. They are found by thousands, and frequently by millions in the water, in which two of our largest fresh-water snails, Planorbis cornea and Limnaus stagnalis, have been kept. The body is usually of a more or less elongated oval form, which, however, it is constantly changing, assuming, during the continual movement of the animal, every outline, from the circular figure which it has in the fully contracted state, to the linear figure which it possesses when extended. During its various contractions it is more or less evident that a shallow circular depression exists at the anterior part of the animal, which might almost be termed a neck, as it separates that portion which is nearest the mouth from the rest of the body. This depression or neck is partially overlapped by a delicate overhanging collar, by which the head (if the portion beyond the contraction and containing the mouth may be so called) joins the depression. When the creature depresses its head close to the body, this collar stands almost straight out from it, and when the animal in this state is viewed laterally, the collar appears like a small tubercle on each side; but when it turns itself, or is 
turned round on its axis, it is then easily seen that the collar is constituted by a fold or border of integument, and that it descends rather lower on the abdominal than on the dorsal aspect, and also that it is deeply incised in the middle of its abdominal portion. The sharp border of the collar is more or less regularly serrated, and the small teeth formed by these serratures have given rise to the name echinata applied to this species, under the supposition that it is the same with that of Siebold, and that the above described organ may be designated as " a circlet constituted of blunt spines around the mouth." Under sufficient illumination, and when the part is slightly compressed between slips of glass, there may be distinguished in the substance of the collar and within the integument numerous spiculæ or spines, which form as it were in the collar a circle around the oral orifice. These spines are placed with their thicker ends towards the mouth, alternately near it and further off, in two concentric circles, and the opposite and smaller extremity of each spine passes into one of the teeth of the collar. The position of the oral orifice, in consequence of the various contractions of the body, seldom coincides with the most anterior part of the animal, but is usually placed somewhat below it on the abdominal surface; the margin of the mouth can be so much protruded, as to appear like a suctorial acetabulum surrounding the orifice. There is also a sort of pharynx, but it does not appear to be muscular. A little behind the middle of the body, is seen a rather larger sucker (the abdominal) which is somewhat depressed in the centre, and the margin of which can be expanded in various ways. Close to the root of the tail is a transparent spot, surrounded by an abrupt dark coloured border, and appearing like an interior cavity with contractile walls, it is in fact however, only the root of the tail which is seen through the body. On the other hand, close before this there is a much smaller circular spot, which is an opening or pore. Of the internal organs which are visible through the semitransparent integument, 
one is especially remarkable, large and vesicular, which commences close to the edge of the collar, passes downwards as far as the abdominal acetabulum, and thence sends down a branch on each side of it, almost straight to the posterior border of the body. As this organ is composed of vesicular sacculi which do not open into each other, nor form any common canal, but on the contrary appear to open into a cavity situated beneath them, I have looked upon it as a liver. From the oral orifice a canal may be seen passing to the anterior end of this organ, but not to enter it; since this canal must be an oesophagus, I am compelled to assume that a stomach passes under the liver-like organ, and is conformable to it. Other winding organs, whose real nature is not yet clear to me, descend on each side of the body; they are partly filled with numerous very minute equal sized globules or cells. I have only casually been able to trace their course upwards as far as the sucker; whether they terminate here, or whether it is that they form a canal, which under certain conditions of illumination may be observed, as a transparent slightly winding streak, between the branches of the liver-like organ, and which appears to terminate in the caudal cavity, I must leave undetermined. In the upper part of their course they contain small globules, and form as it were several reticulations, and also as it appears constitute a ring around the pharynx.

The tail is very long, being about the same length as the body, to which it is attached in a very shallow depression. It is extremely moveable, contractile and extensible, and presents on the sides alternate depressions. It is formed of several membranes or tubes placed one within the other, of which the outermost is a very transparent epidermis, under which is a tolerably thick membrane furnished with transverse muscular fibres or stria, and between each pair of these transverse fibres is placed a globular vesicle which appears to be a mucous follicle or gland; the innermost tube is opaque and of firmer consistence, it contains the longitudinal muscular fibres, and 
is usually reticulated on the surface. Through the centre of these tubes there passes a slightly narrower canal, which becomes very small torvards the extremity of the tail.

The existence of the same layers in the body itself of the Cercaria, can easily be demonstrated; but the transversely striated layer is here not so much developed.

The swimming movement of these Cercarice is very characteristic; in performing it, the animal curves its body together into a ball, by which the head is brought near to the caudal extremity, and at the same time the elongated tail strikes out right and left in innumerable sigmoid flexures, so that sometimes it presents the appearance of a figure 8 behind the animal. In this way they may be seen swarming about the water snails in great numbers. The reason for their keeping chiefly in the neighbourhood of these animals is self-evident on placing a few snails in a glass of water containing a number of the animalculæ. After swimming about the snails for some time, they affix themselves by means of their suckers to the slimy integument of those animals; and all their movements upon it are readily perceived with a good glass.

They frequently detach themselves, roll about in the water in their peculiar way, then return and reaffix themselves and remain still, attached only by the sucker, and extend both the anterior part of the body and the tail in the same direction; in this position, from the great number affixed at the same time, they give the snail a sort of flocculent appearance. This quietude ordinarily lasts but a very short time; they soon begin to move about with a leech-like motion in all directions on the surface of the snail ; but after they have wandered about in this way for a short time, as if to set themselves right, they attach themselves again by the sucker, and remain more quiet. On examining with a sufficient magnifying power a portion of the skin of the snail with several of the Cercarice adherent to it, it will be perceived, that all the efforts of these creatures are directed to the inserting 
of themselves deeper into the mucous integument, and to the getting rid of the tail, which is no longer of any use to them as an organ of locomotion.

For this purpose they contract the body into an oval form, and lash out the tail forcibly on both sides, upon which the body is again slightly moved, whilst the tail is kept still, but only that it may be again lashed about with greater vehemence than before, when the body has acquired a point d'appui for its further contraction, and for the more strenuous movements of the tail. These repeated efforts end at last in the casting off from the body, of the tail, which becomes a lifeless and irregularly contracted mass, and at the same time the tailless animal itself assumes so completely the appearance of a Distoma or fluke, that it could not fail of being recognized as belonging to that genus, in case it were met with in this condition in the viscera of other animals. However it undergoes a further remarkable transformation before it becomes a true entozoon in the common acceptation of the word.

In various Cercaria a copious mucous secretion is observable on the surface of the body, even before the loss of the tail, and this secretion apparently increases during the efforts of the animal to cast off its appendage, and especially during the strong contractions of the body.

As soon as the tail has been got rid of, the Cercaria begins, by extending and contracting itself, partly to move about, but partly, and in fact chiefly to turn itself as it were round and round in the same spot. By this sort of movement it makes for itself a circular cavity within the mucus, which gradually hardens, and forms a tough, nearly transparent case around it. This is the noted pupa state of the Cercaria, observed first by Nitzsch * and afterwards by Siebold. The tailless Cercarice lie concealed under their transparent case, which is arched over them like a small, closely-shut watch-glass *

* Nitzsch. Beitrag zur Infusorienkunde, oder Naturbeschreibung der Zercarien und Bacillarien. Halle, 1817. 
(fig. 7.) This has inclined Siebold to doubt whether a proper pupa case is formed. I think the animal really casts a very delicate cuticle; and in this opinion I am supported, chiefly by observing that after the assumption of the pupa state all the internal organs are more distinctly seen; for instance, through many pupa cases, the formation of which I have watched under the microscope, the above-described circlet of spines in the collar might be readily seen, which before the pupa condition had been assumed were distinguishable only with great difficulty. The position of this circlet of spines necessarily varies very much according to the position and motions of the animal within the pupa case. Compare the figures $7 a, b, c$, the last of which represents a pupa under the highest power of my microscope.

The number of pupa which may be found assembled on the cuticle, and especially on the mantle over the back of the snail, is very remarkable; and I have several times observed the skin of these animals, in the greater part of its extent, as thickly set with the pupæ as is represented at fig. $7 d$. It must, however, be remarked that this pupa condition is also assumed before the eyes of the observer, in water and on a slip of glass, without the addition of any of the mucus or other substance from the snail, and it takes place likewise in the interior of the snail (when Cercaria occur there in a way which we shall soon see) in the water-chambers or reservoirs of water, betweeen several of the organs of the snail, in which the Cercarice are frequently obliged to swim, instead of in the water external to the animal.

This was the extent of our knowledge as regarded these creatures.

The expression of the helminthologist Siebold, that "what becomes of these pupa Cercarice is at present an enigma," applies, as far as my knowledge of science extends, as well to these as to all the other species of Cercarice. I hasten, therefore, to solve the riddle. How long they remain in the pupa state, I am unable to say 
exactly; but that they do so for a long time, not many weeks only, but for many months, I will hereafter prove. I will here only state that the above observations on the Cercuria and their pupe were made in the months of July and August, and that during this time, even when I met with individuals which had assumed the pupa state at an earlier period, there could not be discovered the slightest difference between the larve taken from the pupa cases, and those which had become pupe a short time before, so that it might be supposed that a still longer time was required before they would escape from their cases. The same conclusion resulted from observations repeated in September.

The first sign .I observed of the animal quitting its pupa case was in January, in some snails which I collected by degrees from a ditch, where in the autumn I had remarked a great number of Cercaria. These snails I had placed in vessels in a warm room. I had previously observed in various pupe that the larva contained in them was a little changed; for if I caused one of the pupa cases to burst, by sudden compression between glasses, a convoluted animalcule escaped from it, which had the form of a Distoma (fig. $8 a$,) with a very prominent acetabulum under the abdomen, and a number of pointed spines situated on the upper surface of the collar. At first the creature gave but little sign of life, and bent itself slightly on all sides, but afterwards stretched itself straight out, and commenced very lively movements. The figures $8 b, 8 c$, and $8 d$, exhibit this Distoma or fluke, as I observed it many times in the winter months, either immediately beneath the skin or in the water passages near the skin in the Limnaus stagnalis, many hundreds of which I kept in large vessels. Fig. $8 b$ still exhibits the circlet of spines, from which it would seem the animal had but just escaped from the pupa case. The fissure in the middle of the collar on its abdominal aspect, and the spines which in the neighbourhood of the fissure cross each other, were very distinctly seen; at 
the same time, I observed very clearly that the surface of the abdomen was hollowed out in a broad line, extending from the collar to the discoid acetabulum, between which and the posterior end of the body I noticed in several individuals a spot composed of transparent globules or cells, within which again were two contiguous clear specks, the whole of which I could only look upon as the transparent ends of the forked intestine, surrounded by the hepatic substance. The animals represented by fig. $8 c, 8 d$, are more advanced. In fig. $8 c$, the spines had recently fallen off, leaving evident traces of their attachments on the upper surface of the collar; fig. $8 d$, on the contrary, had lost all trace of the spines, and its collar was much smaller. The abdominal acetabulum was also smaller, and had lost its cup-like form. The liver-like organ, and the cæcal prolongations of the digestive cavity surrounded by it, were in all these individuals of unusual width.

Finally, figs. $8 e$, and $8 f$, represent this fluke as I met with it, to the number of $10-12$ individuals in the liver of some snails (Limnaus stagnalis,) on the 6th of August, 1841. These snails had been taken in a place much exposed to the sun, at a sea sluice near Gräse.

The Distomata differed from those described above, which I afterwards found beneath the skin of the snails, especially in their greater sluggishness of motion and the more homogeneous, parenchymatous consistence of the substance composing the body. No external trace of longitudinal or transverse muscular fibres was visible, although the individuals figured in $8 c$ and $8 d$, presented distinct and regular transverse ruga, and performed very lively movements during their contractions.

Thus, the deeper these creatures had penetrated into the body of the snail, and into the substance of the individual organs, the more of their own organization did they appear to lose. Both the oral and abdominal acetabula became proportionably smaller, although from the sitnation of the animal it was not possible that their size should 
have allowed of alteration by contraction and expansion. The digestive organs occupied their usual position; but through the integument they appeared only like a uniformly coloured, structureless material filling a forked cavity, at the upper end of which might be observed a pore, surrounded with a distinct border. The organs containing globules, situated on each side of the middle line, could at this time be traced upwards towards the mouth, only for about half their length.

We have now seen, that the Cercaria echinata is developed into an actual fuke or Distoma. When I first became acquainted with these remarkable creatures, I had no doubt of the identity of the fucke, (fig. $8 e$ and fig. $8 f$,) with the Cercaria echinata (fig. 6 ;) but it was not till the last winter that I met with individuals which having just quitted the pupa cases, were abont to penetrate into the body or glandular organs of the snail (fig. $8 a b c d$ ). Those in the condition represented in (fig. $8 e$ and $f$,) occurred only in the liver, and indeed in that portion which occupied the ontermost whorls of the shell.

The further advance of this fluke to a fully developed animal, as we know it, may perhaps be determined from consideration of the other Distomata and Monostomata, in which the first stage of development has been shown by the observations of Siebold and others. Our present information would lead us to conclude that it deposits ova, from which, either within the maternal body or without it, oval-shaped young proceed, which move about briskly in the fluid contained in the interior of the snail, or in the surrounding water, and bear no resemblance to their parent. In what way this progeny is transformed into a fuke, or as we now know into a Cercaria, is as yet an unexplained mystery; but that this change can and does take place throughout, only by the intervention of several generations, may be assumed as beyond doubt; and if we examine attentively what is taught us by Bojanus, Baer, and Siebold, respecting the development of the Cercaria, 
and interpret the phenomena thus presented in a natural way, we may to a certain extent penetrate the obscurity which involves the solution of this enigma, although we shall not arrive at its complete elucidation.

Thus if we are desirous of tracing the whole series of development in this species of fluke, in the absence of all observations upon its ova and their progeny, we can only recur to their earlier stages of development, and try whether we cannot trace them up to the egg, or at least as near as may be to that point.

Whence comes then the free swimming Cercaria, afteruards a pupa, viz. the Cercaria echinata?

This question is answered by the observations of Bojanus, who states, that this species is the same with those he saw swarming out from the "ling's-yellow worms" ("konigsgelben Würmern") described by him, and which occur in great numbers in the interior of snails, especially of Limnceus stagnalis and Paludina vivipara. It is, consequently, in these yellow worms, which are about two lines long, that the Cercarice which are the larve of the actual flukes are developed; and since we now know that the flukes are perfect animals, which themselves undergo no transformation and are propagated by ova, we are reduced to the conclusion that the progeny is indebted for its origin and development to animals, which in external form and partly in internal organization, differ from the animals into which that progeny is afterwards developed; in other words it may be said, that we here again meet with generations of "nurses," and that the yellow cylindrical worms of Bojanus which inhabit the snail, are the "nurses" of the Cercarice and Distomata. That the Cercarice are actually developed in the abovementioned yellow worms, any one may be easily convinced who will take a dozen large specimens of Limnaus stagnalis from small stagnant pools which have been exposed to the sun; the worms will be very readily found. 'They are situated not so much in the viscera themselves, (the liver and reproductive organs, as in the membranes 
covering them, and their long bodies will be found half floating as it were in the fluid, which occupies the space between the organs and which appears to be pure water, entering through the aqueducts or water-passages. Fig. 4 a represents two of these " their great difference from the Cercaria, and still more from the flukes is very apparent. Fig. 4 a shows a similar individual more highly magnified, and also slightly compressed between slips of glass, which renders the vast number of Cercarice within it more distinct. It is not only the ontlines of this brood of Cercaria, which are seen in the " nurses" thus compressed, but several of their internal organs as well, as for instance, the forked intestine and the liver.

As regards the external form of these worms, it must be allowed that it is usually alike in all, unless they have suddenly contracted themselves, in consequence of some external irritation, and owing to which contraction they are sometimes scarcely recognizable from the alteration in their shape. However, the number of these creatures is so great, that they are crowded together on the walls of the water-passages, or in the cellular tissue surrounding the liver, kidneys, \&c., and on this account it not unfrequently occurs that, even within the snail itself and before the worms have been touched, such contracted misshaped individuals are met with, recognizable only by the oblique projections on the posterior half of the body.*

The " murses" usually present the appearance given in fig. $4 a$ and $b$. The body is cylindrical, and is furnished in most instances with a spherical, contracted head, which includes an oral cavity with very muscular walls, and a small circular mouth. Below the head is a sort of collar which abuts upon a depression, which according to the greater or less state of contraction of the animal, is nearer or further from the mouth. When the head is drawn towards the depression, the collar projects straight out

* Baer has figured one in this condition. Nova Acta, Acad. Nat. Cur. tom. xiii. tab. 31 . 
like a broad fringe surrounding the body, and frequently appears as if it were folded, and consisted of two laminæ. At some distance posterior to the middle of the body are situated the two characteristic oblique processes, and which, as well as the part of the trunk posterior to them, which I designate a tail, are simply local dilatations of the cavity of the body. Of internal organs there is only to be seen an undivided sacculated stomach, very small in proportion to the size of the animal, and into which the œesophagus opens, (see fig. 4 b.) The whole rernainder of the very large body is filled with the brood of Cercarice. In the instance figured at $4 b$, all the embryos have simultaneously attained their full development, which is but very seldom the case, since, in the same individual, Cercarice are found in all stages of development.

The whole series of forms which the Cercarice pass through within the body of their foster-parent, is represented in (fig. $5 a-5 \mathrm{~m}$.) At first the germs from which the Cercaria are developed are nearly spherical, and appear to be formed of numerous vesicular globules or cells, which are pretty clearly seen to be all surrounded by a very delicate common membrane. These spherical germs afterwards increase in length as they are formed into embryos, and during this growth one end becomes much more dilated than the other. This unequal development continues in two opposite directions, so that the more slender end gradually forms the tail of the embryo, and the thicker its body. Thus the body and tail are at first not merely united very closely, but form externally one whole, and so long as this is the case, very weak motions are observed in the embryo, for instance, when it is irritated by any foreign matter, such as acids, \&c., but it is not entirely inanimate. As its growth continues, the embryo begins to wriggle about with a worm-like motion, and the more slender portion shows externally a disposition to separate itself from the thicker part ; but no very lively motion is observable until the depression between the tail and head is so marked, that the former can be 
moved at all angles with the latter; on which account the more the tail is developed, the more lively are the motions of the embryo within its foster-parent; at the same time the body has become more flexible, contractile, and extensible, and the abdominal acetabulum which was indeed visible as a depression anterior to the root of the tail, assumes now the distinct appearance of a suctorial disc, but this organ like the tail does not attain its full activity until the embryo has left the " nurse," although it is frequently very prominent and expanded, as shown in fig. $5 \mathrm{~m}$, in which it is also seen how much the abdomen is hollowed out, before the animal begins to move about upon it. None of the internal organs are evident before the embryos are fully grown; but at that period, some organs are more distinct than in the free swimming individuals which have escaped from the " murses," viz., the organs filled with minute cells, which in several instances of embryos taken from the "nurses" themselves, were clearly seen to be the two branches of a canal which ran the whole length of the body between the branches of the digestive organ, and appeared to open into the cavity within the tail. The collar itself is formed the last. Some doubt exists as to the mode in which the Cercaria quit their "nurses," since it has been observed under the microscope that there are two places at which they come away, viz., from each side of the body in the depression under the collar, and from the abdominal surface between the two oblique processes, but they escape from the latter situation only when the animal has been slightly compressed between the glasses; and from the former on the contrary when no pressure at all has been employed. It very often appeared to me that there were two openings in the cervical depression, which were surrounded as it were with elevated borders. That the "nurses" are able to discharge their brood of Cercarice without external aid, is shown by the great number of those creatures swimming about free in the internal cavities of the snails; but that the contraction of the 
snail itself, probably also exerts a considerable influence in this respect is evident, from the swarms of Cercarice which appear in the water when the snail is compelled to contract itself forcibly within its shell. It would appear that the Cercarice are expelled from the internal cavities of the snail (the aqueous chambers, which extend between the viscera and are partly bounded by them, and to the walls of which the "nurses" especially attach themselves) through the same minute canals, by which the water enters those cavities. It is very rare, however, that all the Cercaria come away; some of them are retained and swim about, as has been said, in the aqueous chambers, and assume the pupa state on their walls when they have found a fit spot, and there undergo the same transformations as the individuals which have made their escape into the water outside.

Siebold frequently found pupæ in the snails, as I have often done myself; Baer has also seen them, but not understood what they really were, for he did not conceive that the phenomena observed by Nitzsch in connexion with the supposed death of the Cercaria was their entering into the pupa state, but assumed that a single cercaria was placed in each of the cases under the same conditions as those to which a number of cercaria are subjected, in the particular forms to which I have above given the name of "nurses."

There is one organ especially in which above all others the pupæ of the Cercaria are met with, viz., the auricle, in which if there are any pupæ in the animal they are sure to be found, and usually in considerable numbers.

In Planorbis comeus and Limneus stagnalis I found pupæ even in the month of August, and afterwards throughout the autumn.

In Paludina vivipara, in the auricle of which Baer so constantly found the pupæ, both of the Cercaria echinata (Sieb.?) and of another species, the Cercaria ephemera (Nitzsch,) especially the latter, that he states them to be peculiar to that part, I have, in the winter and beginning 
of the spring of this year, always met with the pupæ of the species here clescribed, but also, only in the auricle, although they occurred frequently in considerable numbers.

In some of the snails there were only from two to five pupæ; in most of them from ten to twenty, and in several even many more than thirty. Among the individuals observed, the number of which far exceeded a hundred, only about ten were met with, in the auricles of which, none of these creatures were found; but of Cercarice themselves or their " murses," I did not, during these months, meet with the least trace. I have convinced myself by examinations repeated almost weekly, that pupæ all retaining the same condition, occupy the auricle even after the first ten days of June; if, however, the pupa cases are opened during this period, the inclosed animalcules appear to be on the point of leaving them, for they are unusually brisk in their movements, (much more lively than those which I observed in the spring months, after they have newly escaped from the pupæ, have assumed the appearance of fukes, and at least some of them, even before leaving the pupa case, have lost their circlet of spines.

From this it is evident, that the Cercarice remain for a long time in the pupa state, probably from two to nine months, as might also have been conjectured from the observations of Nitzsch upon Cercaria ephemera, " according to which it is not improbable, that when left wholly to themselves and to natural circumstances, they pass from the pupa cases into a new form, which differs in some respects from that which I have previously described and figured from individuals which have been hatched as it were by artificial warmth from the pupæ contained in

* Nitzsch (Beitr. z. Infusorienk., od. Naturbeschreibung. der Zerk. und Bacill.,) says (s. 17) that his specimens of Cercaria ephemera lived three months after the bodies had assumed the pearly aspect (that is, had become pupæ,) and regrets much that, as he expresses it, he was so foolish as to throw them away, under the supposition that they would become nothing more than they were, although their fresh condition would have induced the suspicion that they retained the germ of a new life. 
snails, which had been exposed for several months to a degree of temperature unusual to them, and not been furnished with their natural food. The individuals which remain within the aqueous reservoirs, and undergo their transformation in the interior of the snails, are specially destined for the multiplication of the Distomata witlin those animals; and on the contrary, those Cercarice which are expelled through the water-passages, serve to propagate the species on other snails, although some of them may enter into the pupa state on the surface of the same snail from which they had been expelled, and in the interior of which their foster-parents had lived.

Let us now leave the consideration of the destiny of the Cercaria which are not expelled from the animals infested by them, and return to the "nurses," in order through them to come at the origin of the Distomata. For this purpose, we must seek for the smallest individuals of that class, and endeavour to discover their primitive form, so that we may be the better able to obtain a glimpse at their origin. Here, however, we are met by the difficulty, that although they may be found of a certain degree of smallness, yet that we can never get beyond this, and find them still smaller. However, they may always be met with of such small size and imperfect form, that it is impossible to suppose they could have originated in the transformation of Cercaria or full-grown Distomata. Fig. $4 d$, represents a very young individual, about the youngest form I have been able to meet with in the viscera of the snail, in the large masses of " nurses" which so often occur there, and which have received from Siebold the name of "Cercaria nests." These younger individuals are distinguished from the older ones by the proportionately larger size of the head and collar, and the greater length of the ventricular cavity, which reaches almost as far as the oblique processes. When visible germs of embryos are present, they occupy only the posterior portion of the cavity of the body, and do not surround the stomach. It may also be remarked, that in 
all these young individuals the skin was readily seen to be composed of glandular, circular, nearly equal-sized cells or vesicles.

I will now explain this origin of the very young " murses." Siebold expresses his surprise at seeing them, (which he does not look upon as independent animals, but only as living organs of generation, and with Burdach designates as "living germ-sacs") developed from germs, which are always contained in other creatures corresponding with them in outward appearance (germsacs); but he seems to have seen this very seldom. I had certainly had thousands of "nurses" under the microscope before I saw this phenomenon, and I freely confess, that for a long time I believed Siebold's observation to be founded on some illusion. In July, August, and September, I also saw no instance of it; but in the winter it constantly occurred in some of the snails taken from the same places as the others, that they harboured only entozoa, which liad the outward form of the "nurses," but which contained a progeny consisting of actual " nurses," in all stages of development. This was the case only in some, and those rather young snails, whilst all the others were at the same time inhabited by "nurses," whose progeny was true Cercaria, and I, consequently, cannot doubt but that it is normal for the "nurses" to originate in creatures of similar appearance, and which are thus the "nurses" of "nurses." These "parent nurses" (abaltrices) notwithstanding their great external resemblance, were not difficult to be distinguished from the common ones; the stomach, for instance, in the fullgrown "parent nurses" filled with their progeny of embryo "nurses" was longer and wider than in any even of the youngest " nurses," (compare fig. $2 a$ and $2 b$ with $4 c$ and $4 d$.)

In figs. $2 c$ and $2 d$ are seen the "parent nurses" in their younger form. The embryo "nurses" are contained only in the posterior part of the bedy, between the two lateral processes, which is the same situation as that 
occupied by the germs of the Cercarice in the " nurses" themselves, and it cannot be doubted that the germs are always collected in that situation as in a distinct organ (uterus?), and that by the development of these germs into embryos and the growth of the embryos, this organ is enlarged, and consequently the whole cavity of the body of the "nurse" distended and filled. In the same way that the Cercariae within the "nurses" attain their full development only by degrees, the " nurses" also within their parents do not reach their full growth simultaneously, whence it must be assumed, that they, like the Cercaria, are not all born at once. The series in the development of the " nurses" from perfectly spherical germ granules is represented in figs. $3 a-3 p$, and will afford when compared with the development of the Cercarice given above, and notwithstanding their great resemblance, evident sigus by which it may readily be determined from the appearance of the embryo itself, whether a Cercaria or a "nurse" (altrix) is about to be formed from it.

That the oral orifice and the head of the "nurses" and "parent murses" are identical with the parts of the same name in the Cercarice; that the constitution of the collar is the same in all three forms or generations; that the lateral processes of the " nurses" and "parent nurses" are the projecting borders of the posterior part of the body, on each side of the root of the tail in the Cercarice; and finally, that the tail, although the Cercaria lose it, is also the same organ in all three generations, are points to which I surely need scarcely direct attention; and all conjectures, ${ }^{*}$ as to whether or no either the whole of the " nurse" or "parent nurse," or some of their organs, may have a different object, must in my opinion cease of themselves.

We have thus followed the Distoma to its third stage

* As, for instance, the common opinion among the Germans that the "nurses" arc only vitalized generative organs; Siebold's supposition that the lateral processes may possibly perform the function of organs of nutrition, \&c. 
in ascent, and I have not been able to detect any more generations; and am, consequently, not in a condition at present to trace the origin of the Distoma further back. I entertain, however, the not unfounded supposition, that the "parent murses" do not arise from other similar creatures, but that they proceed originally from ova; for, as is stated above, (p. 61,) it must be assumed that the full-grown fuke, like all other species of this genus or family, is oviparous. I will afterwards exhibit the reasons which induce me to believe that it is the third generation, or the "parent nurses" which are produced from the ova; whilst I will also prove, that animals such as those which I have named "murses" and "parent nurses," belong to the series of development of the Distomata, and derive their origin from ova, which have been produced by the Distomata themselves.

With regard to the link which is deficient in the development of the "parent nurses," and for want of which we are unable to deduce their immediate origin from the full-grown Distoma, so that all the generations here leferred to would constitute a complete cycle (cyclus), we may form a tolerably correct notion of what it is like by help of the observations which were published by Siebold some years since, in the first number of 'Wiegmann's Arch. für Naturg.'

Monostomm mutabile is an entozoon of the trematode family, which inhabits several of the cranial cavities limed with mucous membrane in certain water birds, and is one of the small trematoda, the embryos of which are fully developed in the ova, while still in ntero. The young embryo is frequently hatched before or just as the ovum is expelled, and in this case, the Monostomum mutabile is ovo-viviparous. The newly-hatched young (fig. 16 ) are elongated, oval, furnished at the anterior extremity with some short lobes, which the animal is able to protrude and retract, and its whole surface is covered with vibratile 
cilia, by aid of which it moves readily in the water. In the anterior portion of the body are two quadrangular spots which are inclined obliquely towards each other, and can scarcely be regarded as anything but eyes. The posterior two thirds of the trunk are occupied by a slightly transparent, whitish body (g), which it might be supposed was an organ as Siebold thought it to be, if it were not that after a time, and some rather vigorous motions, it becomes detached, ruptures the body of its parent, and presents itself as an independent animal of entirely different appearance to that in which it lay concealed, and was already developed (fig. $1 a g$,) whilst the latter was still within the ovum.

Now, since this inclosed animalcule is constantly present in the ciliated young Monostomum, and as there is always but one animalcule in each individual, and always in the same situation, there must necessarily be some organic connexion between the two, and one entirely different from that which it has been supposed could be explained by styling the one a necessary parasite of the other. If one animal is, organically speaking, necessarily connected with another, so that each can be developed only in or around the other, they must belong to one and the same unity, or constitute such a unity, and this is doubtless the case with the animals we are now considering.

Fig. $1 b$, represents the embryo Monostomum recently born, and possessed of sufficient locomotive powers to enable it to seek out a fit habitation; when it has met with this, the ciliated integument, and the eyes now useless, are thrown off by the animal stripping itself of the whole of its skin, together with which it loses also its external form, and becomes the sluggish creature (fig. $1 \mathrm{c}$ and $1 d$,) whose motions are confined to a vermicular wriggling. The first form of this embryo is not unlike that of the common ciliated progeny of the Trematoda, as they have been known to us in many species for a long time, from the observations of Mehlis, Nordmann, and 
Siebold, and it might at first sight be taken for one of the polygastric infusoria of Ehreuberg, which also move by means of cilia; * whilst in the next form which it assumes, the young Monostomum bears an undeniable resemblance to those animals which I have termed "murses" and "parent nurses," in that species of the Trematoda which is developed from the Cercaria eclinata. In this second or altered form (the necessary parasite) the animal, according to Siebold's figure, appears to have a mouth at the anterior extremity, within which there seems to be a muscular oral cavity. At a short distance below the mouth there is an evident depression, indicating as it were a short neck (fig. $1 d$,) resembling that in the "nurses" and "parent nurses;" at the posterior part of the body there are two lateral processes, and behind these a shorter, moderately thick tail or prolongation of the body, which in like manner correspond to the same parts in those creatures.

If objection be made to the view which does not regard the change from the active state represented in fig. $1 b$, into the sluggish animalcule fig. $1 c$, as a metamorphosis, I will with respect to this point further remark, that the mode in which these two apparently different animals lie one within the other, recalls completely the conditions under which the sluggish short-tailed Brachyurus lies within the active long-tailed Macrourus, and the form which it has on escaping from the ovum, but which it afterwards loses. $\dagger$

Now, since the progeny of the Monostomata - a family

* I believe also that it may be regarded like the other Polygastrica, as possessing many stomachs; and it appears to me, that the dispute about the many stomachs of the Polygastrica may carry us further than to assertions which are merely opposed to each other, if the analogy or want of analogy of these infusoria, with the earliest fotal conditions of several forms of animals, is followed out.

$\dagger$ An abridgment of my observations on the metamorphosis of the Crustacea (sand-crab, Hyas araneus; and the hermit-crab, Pagurus Bernhardus ;) and on the various regions in the water imhabited by the young ones in the various stages of their development, is given in Oversigt overdet kongldanske Videnskabsselskabs; Forhandlinger for Aaret, 1840; and in Valentin's Repert. 1840. 
closely allied to Distoma, changes its form in this way, and by doing so acquires a remarkable similarity to the " nurses" and "parent nurses" of the genus Distoma, the course of whose development I have endeavoured to exhibit, and since this progeny in consequence of its metamorphosis rather becomes more unlike the form of the parent animal than approaches it, it will surely not be considered too bold to assume, that the animals which are the immediate result of the metamorphosis, do not by another transformation become actual Monostomata, but that they develop the germs which do eventually become perfect Monostomata, or in other words, that these metamorphosed young ones are to be considered as " nurses."

If we now introduce a link such as we have presented to us by the Monostomata, into the series of development of the Distomata given above, the whole cycle will be completed, and as I should hope organically completed or nearly so. Several examples of the same kind will be presented in what follows.

\section{(b) Cercaria armata, Siebold.}

(Tab. iii. fig. 1-6.)

As I am obliged by want of space to be as brief as possible, I shall refer as much as I can to the figures and to the communications of Siebold respecting this species,* as I have no doubt but that the one I have before me is the same with that described by himalthough in this case, Wagner's figure referred to in Oken's 'Isis,' (1834, ii, tab. 2,) is not quite correct,- and because I think that figures will give a much more correct idea of the animal than a lengthened description.

This Cercaria is scarcely half the size of the former one, but is equally lively and active in all its parts; though it has not the power of rolling itself into a ball when swimming in the water, and the tail does not on

* In Burdach's Physiologie. 2d cdit, tom. ii, p. 187, scq. 
each stroke form the same 88 or SS figures; but the body and neck undulate alternately while the animal is swimming. On fixed objects in the water the creature's motions are more leech-like, in which case it makes use of the abdominal acetabulum; I have seen hundreds of the Cercarice creeping in this way on the slimy cuticle of Limnaus stagnalis and Planorbis corneus, whilst thousands were swarming about every snail in the glasses.

Their incredible numbers frequently made the water turbid, and I have not unfrequently observed the same thing to occur naturally in stagnant pools in the neighbourhood of Copenhagen and Sörö (in the marsh Flommen, in which these animalcules were swarming. This observation, in conjunction with another, that they always keep as it were in whole swarms around the snails, appears to me to be not unimportant with regard to the mode in which they are conveyed from one animal to another.

Of the internal organs, which are visible through the more than half-transparent integument, the most striking is the minute, linear-pointed, hard spiculum, placed above the oral cavity, immediately under the skin, and which projects so much with its pointed extremity from the skin, that the species has been rightly named armata; besides this, there is an elongated organ which commences at the anterior extremity of the animal on each side of the spiculum, and passes down along the sides of the body; but to the middle of which I have been only occasionally able to trace it, and at that point a clear spot, surrounded with one or two darker rings, indicates the situation of the abdominal acetabulum and its borders. Before the root of the tail, as in the former species, is situated a clear spot, capable of being expanded and contracted, which from long examination of several species of Cercaria, I believe to be nothing but the transverse section of the tail where it is attached to the trunk, seen through the skin. The body is slightly excavated posteriorly, to receive the tail, and the lateral portions which 
embrace its root are of somewhat firmer consistence than the rest of the trunk, and appear during the continual motion of the animal to be used by it as a pair of stumps or feet to push itself forwards with. The tail cannot ever be extended so far as to cause the disappearance of the depression in which it is inserted, or of the lateral folds; its internal cavity reaches as far as the body, but $I$ have not been able to trace it further. The whole animal is covered with an extremely delicate transparent cuticle, beneath which the skin, which is highly glandular, secretes a viscid, yellowish-white slime, which hardens under the water, and is of considerable importance during the further development of the Cercaria.

The fact that this Cercaria, like the former, assumes a pupa state, has been already observed by Siebold, who has described the phenomena attending that change, in Burdach's ' Physiologie,' t. ii. I will now only add, that it crowds about the water snails in much larger swarms than the preceding species, and attaches itself to their uncovered portions in such numbers as to give the surface a flocculent appearance, and that after crawling about for some time, it assumes the pupa state. It is during this creeping about on the cuticle of the snail that the Cercaria exhibits the thrusting or piercing action which is seen to attend its motions on the object-stage of the microscope. Attaching itself by means of the abdominal sucker, and pushing itself as it were by the projections on each side of the root of the tail, it thus thrusts the fore part of the body and the spiculum placed on its anterior extremity, with considerable force against the skin of the snail, which is in this way apparently perforated, for immediately afterwards the Cercaria is seen to be sunk or buried in it, and covered with its slime. If the tail has not previously been detached by the vigorous movements during the alternate attachments and creeping about of the Cercaria, it now becomes so ; and since by this separation of the tail its internal cavity is divided, a new opening is produced at the postcrior end of the 
body, through which a fluid containing numerous globules is expressed. I must suppose with Siebold, that this is the proper excretory organ of the Distoma, which thus obtains an exit. For it cannot be doubted that the fluid secreted and contained in this organ is of an entirely different nature in the Distoma to that in the Cercaria or its "nurses" and "parent-nurses," since in the former it is rejected, and in the latter retained in the body.

When the Cercaria is buried in the skin of the snail, it apparently secretes from its whole surface a very large quantity of slime, in which the animal, which we recognize as a distoma-larva, is in continual motion around the same point; and as the mucus gradually hardens, a case is as it were formed around it (fig. $4 b$ ). The walls of this pupa case appear to be thickened by a delicate membrane, which is shed doubtlessly from the body of the animal itself, since the spiculum mentioned above is always found to be cast off, and to be stationary at some part or other of the walls of the cyst, although during the circular movements of the larva within the case it had been carried round from side to side together with it. The detached spiculum is afterwards covered over, and walled off by a distinct layer of mucus. (Compare $\ddot{o}$ in figs. $4 d, 4 e$, and $4 f$.)

In a few hours after the larve or Cercarice have affixed themselves to the skin of the snail, nearly all of them have assumed the pupa state; and the oval pupæ may be placed so close to each other on (the back [nacken] and edge of the mantle of the snail) that a portion of the skin viewed under the microscope resembles, in miniature, a pavement composed of oval pebbles; and this is the case not only in snails which have been kept in glasses and in a small quantity of water, and consequently exposed to great numbers of their enemies, but also in those taken from pools of water in the natural state. After entering the pupa state, the animal appears to shrink away from the sides of the case, so as to leave a 
small interval between it and the cyst, but it continues its movement not the less for many weeks, though perhaps with diminished activity.

I conclude that a long time elapses between their becoming pupæ and their quitting that condition, partly because I have had pupæ under observation for several weeks, and partly because I have examined in a state of nature, hundreds of pupæ which clearly showed that the animals had lain for a long time in that condition. I have several times endeavoured to preserve a considerable number of pupæ in the living state between slips of glass, but have only once succeeded in keeping them alive until some of the animals crept out, which occurred in about ten days from the commencement of the experiment. All the rest remained in their previous condition, until at last, by imprudently wetting them with cold water, I killed them ontright.

Several of the external and internal organs are visible through the transparent pupa case, which without great difficulty may be referred to those of the Cercaria, since during the act of the creatures assuming the pupa state, we have the opportunity of tracing the metamorphosis of at least some organs, and the position of these may then throw some light upon the others. The most prominent of these is of a horse-shoe shaped figure in the hinder part of the pupa; this marks the position of the semicircular lateral projections which surround the root of the tail, and which have apparently become thicker and larger in consequence of the contraction of the body. Between the two arms of the horse-shoe $(t)$ is situated the opening of the proper excretory organ (vide $4 d, 4 e, 4 f, 4 g$ ). A more or less circular spot or ring in the centre of the animal is the acetabulum $(u)$; a three-lobed organ, which when regularly contracted is shaped like a trefoil leaf, is without doubt a digestive organ or stomach, with its club-shaped lateral prolongations, for immediately anterior to the central lobe of this organ, under favorable circumstances, an opening or mouth may be perceived on 
the anterior edge of the animal, and a delicate canal passing down from it to the central lobe.

Besides these, I clearly distinguished a tolerably large double organ ( $x$, fig. $4 f$, and $4 g$,) the two branches of which, proceeding from the anterior extremity of the animal, and passing in a curved direction around the stomach, unite in the mesial line behind the acetabulum, and appear to be comnected with a rounded swelling, which is seen like a circular clear spot in front of the horseshoe-like outlines of the posterior borders of the animal. The situation would render it not improbable that this double organ is connected with the function of reproduction.

The animal does not appear to creep out of the pupa case through any regular opening, for close to the individuals above referred to as having just left the pupa cases, I observed the latter irregularly crumpled up, and scarcely recognizable. Fig. 5 a represents an animal newly escaped from the pupa case ; several of its internal organs were still apparent for the first hour or two through the integument; its changed condition, however, afterwards prevented their being distinguished. The organs marked $s, t, u, v$, are the same with those similarly lettered in fig. 4, and I suppose it is the same with that marked $x$, though I am unable, in the pupa, to discover a commexion with the organ marked $v$, as in the animal. The figures $5 b c d$, represent, for the purpose of comparison, individuals which I obtained at the same time from pupa cases, either by opening them or bursting them by compression between slips of glass. They are evidently true Distomata. The most important changes which are observed during the growth of these animals consist in the very powerful contraction of the body, the shape of which changes from the broadly lanceolate which it is normally, to an obovate or pyriform, in consequence of the anterior extremity constantly increasing in breadth (fig. 5 e $f g$ ). Simultaneously with this change of form, the activity of the animal diminishes, and becomes at last 
so much impaired, that it may be looked at for a long time, without giving certain signs of being a living creature. In this full-grown state they are covered by a very thick cuticle, appearing as if they were enveloped in a thick layer of inspissated albumen; and this albuminous cuticle is a great obstacle to observations, in consequence of its elevated spherical surface refracting the rays of light.

This Distoma, as it is represented in figs. $5 e-h$, occurs frequently in the liver and generative organs of two of our larger fresh-water snails, Limncus stagnalis and Planorbis corneus, and in some snails, in assemblages of 10-50. In this condition it would scarcely be taken for the same animal with that which we have previously been considering as Cercaria armata. At first sight there is visible beneath the thick cuticle only an irregular network of canals, filled with a fluid containing minute globules; a closer examination shows us, in a sharply defined circle in the centre of the animal, the acetabulum or sucker; in two semicircles turned towards each other, we perceive the wider ends of the digestive cavity; and in depressions and tubes which pass through the thick integument, we see both the mouth and the anus, the latter being recognizable by the fluid loaded with cells which it emits, and by its situation between the posterior horseshoeshaped borders, which serve as a sucker.

It is not difficult to comprehend in what way the $D i s$ tomata, after leaving the pupa case, enter the nobler organs of the snail, since we saw them buried in its skin whilst assuming the pupa state. I have very seldom been fortunate enough to meet with them in the skin soon after their quitting the pupa state; they were at that time very active in their motions. I have also found them $\frac{1}{2} " \prime$ and $1^{\prime \prime \prime}$ under the skin, on their passage inwards, and have no doubt at all that they afterwards chiefly follow the course of the aqueous canals, and thus enter the animal much in the same way as when, in the form . of Cercaria, they came out of it. 
I have, however, satisfied myself that very far from all the individuals reach the organs mentioned above, viz., the liver and generative organs; for I have observed great numbers of them full-grown which conld not be distinguished from those in the liver, occupying the cavity in the head and anterior part of the body which is filled with a slimy fluid, and in which the nervous ring of the pharynx is situated, in the cavity around the heart, and in several other situations, so that this Distoma is not one of those species whose full development is restricted to one organ of the animal infested by them.

We have thus again traced a free swimming Cercaria or Distoma-larva, until it is deposited as a true entozoon Distoma or fuke, deep in the organs of the snail; we shall now see that it has previously inhabited, also, the interior of a snail, although not of the same one. The observations already referred to of Bojanus, Baer, and Siebold, have proved that all Cercarice occur in sacciform bodies in the interior of snails, and the sacs in which these animals are situate have been described by Siebold, in Burdach's 'Physiologie,' l. c. The figures $1 f$ and $1 \mathrm{~g}$ represent sacs of this kind, containing numbers of developed and undeveloped Cercarice; and if one of these sacs is opened, the whole series of forms through which the Cercaria pass can be readily followed (figs. $2 a-g$,) from the globular gemmules to the perfect forms, which as soon as they have quitted the sac, can no longer be distinguished from those swimming free in the water. It may be soon ascertained that the whole course of development entirely corresponds with that of the former species. The parts which are completed last are the frontal spiculum and the double tortuous organ, which passes down on each side of the body.

By the first inquiries it was soon determined that all Cercurice originate in the sacciform bodies, and that these always contain Cercarice, and grow and are de- 
veloped along with them; but the earlier observers conceived an erroneous notion of the true nature of these sacs, since they even denied that the present kind enjoy independent existence and vitality. Siebold for instance says, that the sac is " a pouch closed on all sides, and possessing neither intestine nor mouth, colourless, and exhibiting no sign of life." 'This is not altogether untrue with respect to the sacs when they occur in large clumps and masses in the liver, kidneys, or other internal organs, under circumstances when their great numbers have prevented their free development; for then, certainly, no sign of motion is perceptible in them, and should any be perceived, it is impossible to distinguish whether it be referrible to the sacs themselves, or to the Cercarice swarming within them. But, if smaller, that is, younger sacs, or above all, sacs containing only a half-developed progeny of Cercarice, and which lie free, or scattered on the surface of the organs, or what is still better, attached to them by one end only, and with the whole body hanging out in the surrounding water passage be observed, an evident twisting and winding, vermicular motion will be perceptible in them. I have even met with solitary sacs on the walls of the water passages, in which a few slow movements were perceptible, which besides the usual rolling or turning on the axis, consisted in a contraction and extension, which at other times has been very seldom observed. In these solitary sacs it was also manifest, that the surface by which they adhered to the organs of the snail, formed a sort of acetabulum, which however had already lost all power of motion, and was scarcely capable of again affixing itself by suction when once detached.

I have also witnessed something like this in sacculi which had been immersed in luke-warm water, and very carefully separated from the heap or mass which was often deposited as thick as a swarm of bees upon the branch of a tree, around and in the organs of the snail.

In the smallest sacculi which I could find (fig. $1 a, b$,) 
and which, as it were, filled every snail with their thousands, such a depression was never wanting at one end, and at the opposite extremity I could always distinguish another smaller depression or opening, the skin over which was sometimes elevated in a vesicular form; in these I was certainly unable to detect the germs of the future progeny; but before they had doubled their size, and while still not so large as the bodies of the Cercarice afterwards to be developed in them, I could very plainly distinguish the germs in the form of rounded granules. The whole alteration undergone by these sacculi during their growth (figs. $1 a-f$ ) may perhaps be conceived in this way; that the supposed sacculi are not hollow in their earliest state, but consist throughout of a mass of globules and vesicles; that while they are still extremely small, a minute cavity is formed within them, in which the germs of the future Cercaria are situated; that, normally a simultaneous increase goes on of the germinal cavity, and of the supposed sacculus itself, the walls of which evidently consist of numerous round glandular vesicles. The independent motions which are observable in them in this condition cease altogether when the embryos approach the cercaria form, and the whole integument is then clistended into a thin membrane in which any organized structure can with difficulty be distinguished.

Now, as these presumed sacculi, at least at one period of their existence, are capable of spontaneous motion, and are only in appearance destitute of organization, since they are seen to grow or increase in bulk by organic means, we must certainly consider them as animated beings, and according to the observations adduced in the preceding pages, even as animals which stand in such intimate relation with the Cercaria, that these latter occur only in the sacciform animals, and on the other hand the sacciform animals always contain Cercaria more or less developed. They must consequently both be necessary parts or links of one and the same unity, and I have no hesitation in placing the sacciform individuals in the same 
species with the Cercaria inclosed within them, or with the Distoma into which the Cercaria are transformed after passing through the pupa state. They are thus individuals which remain stationary at a particular stage of development, not much higher than that at which the Cercaria commence, and which have undergone as it were a retrograde metamorphosis, in order to promote the perfect development of the brood of Cercaria committed to them; in other words, they are individuals of the kind which I have in the foregoing pages denominated " nurses." The existence of such " nursing" animals within a species can no longer be considered singular, when the facts adduced in the preceding sections are brought into comparison ; and their origin can also no longer appear mysterious when it is remembered, that sluggish creatures resembling the " nurses" or "parent nurses" of the Cercaria echinata arise from the metamorphosis of the active young of $\mathrm{Mo}$ nostoma mutabile. In the following pages I will relate precise observations, to show that these saccular and apparently altogether lifeless " nurses" originate directly from very lively animalcules; but before proceeding to these observations, I will offer some considerations on the subject of the " mursing" animals now before us.

In the earlier researches upon the Cercaria, the supposition is sometimes directly broached and sometimes understood, that the "nursing" animals, the supposed sacculi, were probably only the smaller and distended bodies of the Cercaria, from which, consequently, they must have originated through a kind of metamorphosis ; but I believe that this opinion is confuted by what has been stated in the preceding observations, and that there is no doubt but that the "murses" are developed from very minute oval corpuscles or germs, and that thus they and the Cercaria contained within them, pass through a parallel series of developments, and that there is no room for supposing that any metamorphosis or transformation occurs from one series to the other.

It seems as if the earlier observers could not under- 
stand how the Cercarice which had attained their full growth, escaped from the close-shut sacculi which the "nurses" appeared to them to be; and when the whole swarm of Cercarice is seen moving about within the containing cyst, it certainly seems as if they were endeavouring to find an outlet. I have no doubt but that the animal is provided with such an outlet, since I have been able to demonstrate in the younger "nurses" at least two openings, without however being able to determine the precise function of each; and I have besides so often seen a series of Cercaria one after another escaping from the orifice at the free extremity of the " nurse," that I have been induced to consider that opening as their natural exit. The correctness of this opinion would further appear from the fact, that the above phenomenon is always observed to occur in the same spot, even when the animal has not been subjected to the slightest pressure. That this birth, if such an expression may be used, most frequently occurs when any circumstance promotes the expulsion of the brood from the "nurse" is natural, and its occurrence is readily explained by a phenomenon which is at first sight surprising, that thousands of Cercarice will suddenly be seen swarming in a glass of water, when a snail placed in it is compelled in some way or another to withdraw itself quickly into its shell. As has been previously remarked, when the "nurses" are compressed in this way by the surrounding organs, the progeny is expelled and carried together with the water forced out by the contraction of the snail, through the canals, into the surrounding water, in which we found them when we began to trace the history of their development.

That such a half natural, half artificial birth is not the lot of all Cercarice is evident, even from the observations of Siebold, who has sometimes noticed within the " murses," and among half developed Cercaria, some individuals which having already cast off the tail, were in a condition to assume the pupa state. I have had numerous opportunities of confirming this observation and even of 
extending it, having seen them sometimes as perfect pupe in that situation. Hence it necessarily follows, that the Distoma proceeding from one of these pupe will be found within the "nurse," and would be as it were an entozoon to it rather than to the snail. Such an occurrence as this is represented in fig. $6 a$, where a Distoma-like individual lies under the creeping multitude of Cercarice, and has already attained such a size as certainly to prevent its exit, except by rupture of the "nurse." I have witnessed this interesting sight in only about twenty or thirty individuals, amongst thousands of "nurses" which I have had under the microscope ; an entirely different circumstance, however, which occurred in some snails is not to be comprehended in this account. These had all their internal organs nearly full of large " nurses," of which every fifteenth or twentieth individual had one, two, or three full-grown Distomata lying under the remaining half or fully developed brood; two even had more, the one four and the other five flukes or Distomata (fig. 6 b.) In these the mode of arrangement by which they occupied the smallest possible space was very evident; this was effected by their being placed alternately with the broader and narrower end towards the same side, and this regularity of position occurred even when there were only two or three within the "nurse." It would not therefore be extraordinary, if we should here and there meet with " "ursing" organisms, containing only full-grown Distomata and no Cercarice at all; since it is evident from what is stated above, that even the whole progeny may possibly attain their full development within the " nurses." Thus we are furnished in this case with an instance of the $\mathrm{Cer}$ carice becoming pupae, and of their emerging from that state within the bodies of the " nurses;" the Cercaria also frequently enter into the pupa state within the cavities of the snail, especially in the aqueducts, the walls of which are occasionally seen covered with pupa, and by this means the number of the entozoa infesting one and the same snail is of course very remarkably increased. 
(c) Cercaria ephemera, Nitzsch, and Distoma DUPlicatum, Baer.

It has been shown by the development of Cercaria echinata and $C$. armata, that both these species enter the snail from without, become pupe upon and within them, and after quitting the pupa cases, penetrate, as forms of the genus Distoma, into the internal organs, which they inhabit as true entozoa, so that it is no longer a mere hypothesis, but an ascertained fact, that at least some entozoa enter the animals infested by them from without; we have further seen, that both these species of Cercaria are developed only within special organisms, which must be considered as independent creatures, and as individuals of the same species as the Cercaria themselves, but which as regards their form differ very widely from the latter, in consequence of some of their organs having been developed at the cost of others, in order to contribute in the greatest degree possible to the development of the germs of the Cercaria.

These animalcules, which, on account of the office they fulfil have been termed " nurses," derive their origin, as regards the one species from nearly similar animals, in the bodies of which they were developed from gemma, and which in all probability, and according to all analogy had originally proceeded from the ova of a distoma in the form of ciliated embryos, and had afterwards undergone metamorphosis.

With respect to the second species $C$. armata, my observations have not yet shown a similar development within "nurses" of a second generation, or "parent murses" as I have called them, although I have occasionally seen several " nurses" of this species which were inclosed as it were in a common membrane, which might be supposed to be perhaps the delicate integument of the "parent nurse." 
However, in order that the observation that the species of Distoma which is developed from the larva of Cercaria eclinata does not attain its complete form till the third generation, should not stand alone and unsupported by analogy, I will state some observations on another species of Cercaria, although it must be done with great brevity, and I am not able to give any figures illustrating their development.

Cercaria ephemera (Nitzsch) was the first species of Cercaria intimately known to naturalists, and indeed only through Nitzsch's curious observations of the phenomena attending their becoming pupa. More lately, Baer so commonly noticed their pupa in the auricle of Paludina vivipara (without, however, knowing any more than Nitzsch, that they were really pupce,) that he termed them a species of Cercaria peculiar to the auricle; and Siebold, (l. c.) has again observed and described them in the pupa state. "I also have had several opportunities of becoming acquainted with them, and will only add as regards these animals themselves, that I have obtained several Distomata from the liver of Paludina vivipara, which from their external form I am compelled to regard as the species into which the Cercaria ephemera is metamorphosed from the pupa; however, the want of individuals newly come out of this state, prevents proof of this assertion being given. The " nurses" of this species have, on the contrary, as far as I know, been described only by Siebold, and as far as my observations themselves extend, they correspond with those of that helminthologist; they may for instance be compared with the " nurses" of Cercaria echinata; like them they are elongated, cylindrical animalcules, having vermicular motion; they have a wellmarked muscular mouth; and a very long and wide digestive cavity, which causes a protuberance in the middle of the animal, and reaches even to its posterior extremity; it has no lateral processes. The Cercaria ephemera lies, in all stages of development, between the digestive cavity and the skin, but never in great numbers; as soon as it 
is little more than half developed, the two opaque ocelli, characteristic of this species, appear through the skin. Siebold remarks, that he has found these "nursing animals," or germ-sacs, within other similar "nursing animals," or other germ-sacs, and thus it appears evident to me, that the Distoma into which the C. ephemera is metamorphosed, must be removed at least three generations from a Distoma like itself, or in other words, that from its ova complete distoma-forms do not proceed till the third generation.*

* Since I have ventured to explain Siebold's expressions a little in accordance with my observations, it will be proper to give my reasons for doing so; what he says with respect to the development of the "nurses" is thus expressed:- "I have here and there met with a 'germ-sac' (keinschlauch), in which I have observed among the Cercaria germs one, and sometimes two, or more oval, colourless bodies, furnished with a distinct pharynx and a simple crcal intestine. These bodies were of nearly the same sizc as the bodies of the Cercarice. The intestine was much convoluted, and occupied nearly the whole cavity of the body. Similar oval bodies, which were evidently to be regarded as young 'germ-sacs' (since in those which I discovered in the 'germ-sacs' of Cercaria echinata I could clearly distinguish the two posterior processes as small tubercles) presented themselves, on some occasions, also in the same situation in a young Cercaria (cercarien geniste); there might likewise be observed, by aid of the microscope, between these smallest germ-sacs and the full-grown sacs filled with embryos, some of every size, so that their growth could be accurately traced, and the gradual completion of the yellow, granular vesicular bodies, and of the germgranules clearly observed." (1. c. p. 190.) It is clear that Siebold met with "germ-sacs," as I had with "nurses," in all stages of development, and even within other "germ-sacs," which, moreover, he could not distinguish from them; but in these they are placed among the Cercaria germs, one, two, or more together, in the form of oval, motionless bodies, of about the same size as the bodies of the Cercaria. It must consequently be believed either that murses and cercarice are developed together in one body, or that one and the same creature ("germ-sac") develops both murses and Cercarice, and even simultaneously, which in my opinion would be erroneous. For it is seen that the "nurses" of both species, C. ephemera and C. echinata (Sieb.) present the same phenomena; now since I have observed in hundreds of the " nurses" belonging to the latter species, that they are developed from germ-granules in other "murse"-like animals, ("parent-nurses") in the same way as the cercarice, but that these latter never contain anything but germs of "nurses," I must suppose that it is the same with the former, and am encouraged in this supposition by Siebold's having met with extremely minute embryo "murses" in them; and he expressly says that they lie not among Cercarice, but among their germs, and a confounding of "nurse"-germs and Cercaria-germs may occur very readily, especially when it has not been remarked that the "nurses" are devcloped from germ-gramules, as probably Siebold had not happened to do. 
In order to place in the clearest possible light that which, in the development of the Distoma, is effected through several alternating generations, I will adduce as an observation precisely to the same point, that a minute oval animalcule which moves by means of cilia, and in that respect resembles the offspring of the ova of the Distomata, becomes in the third generation a Distomalike animal. There is found for instance both in the internal organs, and in the external mucus of our common fresh-water muscles (Anadonta) an extraordinary quantity of animalculæ, appearing to the naked eye like minute oval points, transparent, with milk-white extremities and having a peculiar rotatory motion. Under the microscope they appear reniform, very flat, with opaque extremities, and as it seems are covered with vibratile cilia, so that they call to mind a Paramacium or Colpodium, to one of which genera they might not improbably be referred, had we sufficient means of determining the point. I cannot avoid supposing, that the figs. 7, 8, 9, tab. 73, (Zool. Dan.,) refer to this animalcule ; and it is certain, that it is these animals which Baer, in his memoir on Distoma duplicatum mentions, under the name of Paramacium, and describes as a "chaotic swarm" in the interior of the Anadonta.

These paramacium-like animalculæ, crowd about in the aqueducts, both in the mantle and in the foot and internal parts of the muscle, (as for instance in the kidneys;) many of them may be observed in the same situation, and it is then readily perceived that they are not all equally active; for some possess all their cilia, whilst others have lost them, and in consequence remain quiet, or are seen to be adherent, and their substance has become parenchymatous. There are also met with, especially in the muscles inhabited by these Parancecia, other more parenchymatous, and more or less regularly oval bodies, which are slightly depressed and adherent. It is not difficult, among the numbers which are usually present, to show the complete change in every respect of these 
oval bodies into the adherent, sluggish Paramacia, so that I have been unable to distinguish between them, and I consequently see in the whole series of changes, only the passage towards the metamorphosis of the ciliated animalculæ into motionless parenchymatous bodies. Although motionless, they must not be considered as lifeless, since their continued growth may be readily followed, and is evidently the effect of nutrition, and not an expansion caused by the substance distending them from within. From a length of $\frac{2}{30}$ '" they frequently attain that of $\frac{8}{30} " \prime$; and the size of a transparent spot indicating a cavity, increases in the same proportion. When the animalcules have attained the size of $\frac{8}{30}$ " their internal cavity is evidently filled with minute oval or spherical corpuscles, which are germs, and which now commence a remarkable development. As the animalcules increase in size, they become more and more parenchymatous and friable, and their external substance is broken by the slightest pressure, nothing remaining then but a strong internal membrane which incloses the cavity in which the germs are contained. This rupture occurs especially when they have attained their full size of $\frac{2}{3}$ "' or even of 1 '", at which time the largest of the successively developed embryos have acquired the length of $\frac{5}{30}$ '" and lie inclosed merely by a saccular integument, in which the metamorphosed Paramcecium-like animalcule is scarcely any longer recognizable.

The included embryos, which, like the Cercarice or their " nurses," occur in all stages of development within the sac, present usually a short neck-like prolongation at one end, and on the other a distinct depression, which may probably be an oral orifice or suctorial organ, by which they can affix themselves when they have in some way or other, most likely by bursting it, escaped from the sac; they are then found of the size mentioned above $\left(\frac{5}{30}{ }^{\prime \prime \prime}\right)$ in the internal organs of the muscles. If some of these embryos extracted from the sac or newly escaped from it are allowed to rotate on their axis, under the mi- 
croscope, it will be seen that their transverse section is perfectly circular or very slightly depressed, and that their integument, and, it might almost be said, their whole substance, is composed of a mass of regular, nearly equalsized, closely packed, globular cells or vesicles, (glandfollicles?); and that this substance incloses an internal cavity of nearly the same shape as the body externally. In this cavity a series of globular germs is distinguishable, and as the body in which they are contained which though motionless is yet living, increases in size, until it is more than a line in length, these germs also increase and become active cercaria-like creatures, that is to say animalcules with a distoma-like body, and a long moveable tail; but the tail in this instance is both thick and clavate, and the fully-developed animal is the Distoma duplicatum of Baer.*

The course of development of these Cercarie within the parent receptacle, corresponds entirely with that of the true Cercaria, and after quitting their " nurses" it would appear that they necessarily undergo also the same change as those, as they shortly afterwards cast off the thick tail, and move about as Distomata; but it has happened to me as it did to Baer, that they died before becoming pupe, notwithstanding which, however, I have no doubt at all that they do enter into that state, but probably only under peculiarly favorable circumstances. As multitudes of these Cercarice occur in many muscles within their sacculi, and also occasionally out of them, and as they are sometimes present in some, and even in many muscles by many thousands, it might be expected that they would be met with plentifully in the form which they finally assume. This is not the case however, and although Baer and several others have examined the muscles with great care in order to find entozoa, no true distoma has been discovered in them; we are made ac-

* Baer's memoir upon Distoma duplicatum will be found in the series of his other memoirs upon the Cercarice and other entozoa, including Planaria, in 'Nov. Act. Acad. Leop. Car. Natur. Curios.' xiii, tab. 28. 
quainted, however, by the researches of Baer with a remarkable entozoon of the Distoma family, Aspidogaster conchicola which occurs only in the ventricle of these molluscs. Upon comparing the form of this worm with that of the body of the distoma-larva with clavate tail, I cannot help supposing, from what I know of the change consequent upon metamorphosis in this family, that the D. duplicatum of Baer is the larva of Aspidogaster conclicola (Baer.) There is certainly a remarkable discrepancy between this view and the fact that Baer has found only one or extremely few specimens of Aspidogaster in each muscle, whilst on the contrary the animals from which I suppose them to proceed, occur by hundreds and thousands in each individual; this only proves, however, that certain favorable conditions are pre-requisite for the complete development of the entozoon, and how much nature compensates by an inexhaustible fertility, for the inevitable loss sustained in consequence of the absence of such favorable conditions. This discrepancy, moreover, is not greater than that which exists in the case of the Cercaria eclinata, of which many thousands have been observed, while it seems that the full-grown Distomata have been noticed only in the few individuals mentioned above.

Whether my supposition, that the Cercaria (Distoma duplicatum Baer) is changed into Aspidogaster conchicola (Baer) be correct or not, still it is certainly a larval form, and clerives its origin in the third remove from a ciliated, free-swimming animalcule, which is afterwards metamorphosed into a sacciform "nursing animal," which, in accordance with the terms used before, must be called a "parent-nurse" (grossamme); whilst the progeny developed in it, which, from their absolute and relative size, and their possessing a cavity containing germs, can in no wise be Cercaria, constitute evidently the same step in development, as the true "nurses," and from which is produced the next step in the series, the $D$. duplicatum, which can only be compared with a true Cercaria; which in fact it is. 
(d) The Development of other Trematode Animals.

Thus, if we trace the ciliated trematode embryos in their progress towards a perfect Trematode, or if we proceed in the other direction and go back from the Trematode itself, and endeavour to get as near as possible to its origin, the same phenomena will be presented to us, since the species must, from the egg upwards, necessarily pass through several generations succeeding each other in a definite order before it appears as individuals, which both externally and internally resemble those from which the course of development commenced, and which are capable of propagating the species anew by the generation of ova. That all trematode animals are developed in this way, that all are obliged to undergo such alternation of generation cannot be directly affirmed from the facts adduced; these, however, are sufficient to warrant the supposition that this is probably the case. I will here only recall the general observation made with regard to the ova of the Trematoda, that there always proceeds from them a more or less active ciliated animalcule which has not the slightest resemblance to the parent animal, and consequently, under all circumstances, must undergo a remarkable change or metamorphosis. It might, on this account, with great probability be assumed, that its progress and course of development corresponded with those of similar creatures, and that it was metamorphosed into a "nursing" individual, as is shown by Siebold's observations on Monostoma mutabile, and mine upon Distoma duplicatum. If such a course of development be supposed, there must be as many forms of "murses" as there are species of Trematoda, and since such " nursing" animals have not been observed, it would certainly be extraordinary that all the search after entozoa, which has been made, should not have brought to light animals, 
which might with some probability be supposed to play that part; I must, however, remark upon this, that no search has as yet been made for them with this view. Secondly, that they may occur in such situations and under such forms as would be least imagined; and, lastly, that they may have remained concealed by their extreme minuteness. It should be remembered that the "nurse" of the Medusa, Cyanea capillata is only a few lines long, and remains at the bottom of the sea, while the full-grown $C$. capillata which has been indebted to it for its nourishment, is a million times larger, often spans a space of several fathoms, with its tentacula, and swims about freely in the ocean.

There are not wanting, however, farther examples of the occurrence of the same mode of development in other Trematoda, besides those related in the above observations. In Baer's memoir, so often quoted, we meet with mention of several, sometimes lifeless, (that is, motionless,) sometimes living, "germ-sacs" containing Cercarice in all stages of development, and which, consequently, I am obliged to look upon as so many species of "nurses."

Here belong also the cysts or so-called hydatids in which Baer found completely developed Distomata; as for instance, $D$. cirrigerum in hydatids in the muscular substance of our common river crab (Astacus fluviatilis,) another Distoma in our smallest fresh-water snail (Ancylus lacustris, ) and lastly, one which inhabits an active "germ-sac," resembling the "nurses" of C. echinata, but like those of $C$. ephemera, wanting the lateral processes. The extraordinary entozoon Leucochloridium paradoxum found by Carus in the swollen tactile horns of Succinea amphibia, and in which there were numerous developed Distomata, is also only a "nurse." I cannot therefore agree in the opinion of that ingenious naturalist, that it might have originated by equivocal generation from the metamorphosed cellular tissue of the mollusc; I even believe that $I$ have discovered its true origin, in finding in the tentacles of this snail in the early months of summer, 
some oval, very active, ciliated animalcules, which were not unlike the Opalina ranarum of Ehrenberg. *

The Distomata thus undergo their complete metamorphosis within these last-mentioned " nursing animals," as is the case with that Distoma which, as we have seen, results from the larva of Cercaria armata when it has not had the opportunity of quitting the "murse" at the proper time. Consequently, when the larvæ of this species are not destined to swim about freely, we cannot expect that they should have the form of a Cercaria, that is, that they should be provided with the tail, which is the principal swimming organ of those creatures, and thus the larvæ of the different species of Distomata which inhabit the interior of the allied fresh-water snails, would even not have that form; still less should we expect that the Distomata of other classes of animals should have it, and we may even with greater probability suppose, that the cercaria-form will be found only in the Distomata of the snails, since, at present, the Cercarice have been observed only in water, in which fresh-water snails have been. $t$

I must here, however, refer to an observation which although it proves nothing respecting the alternate generation of the Trematoda, yet makes us at least acquainted with an interesting metamorphosis which some of the forms undergo, and shows us where, in all probability, the larve and pupe of a whole genus of Trematoda are to be sought for. Nordmann's discovery of the occurrence of entozoa, and especially of those belonging to the trematode family in the eyes of fish, particularly of freshwater fish, in such numbers that their presence in these delicate nrgans may almost be considered as normal, caused at first, as might be expected, great astonishment,

* An animal which swarms in the rectum of the frog in thousands, probably to the end that one of the many may reach a situation favorable to the development aud propagation of the species. Baer's Bucephalus polymorphus is probably also to be here considered a "nursing" animal.

$t$ A proof that entozoa may enter animals which they do not usually infest, is derived from this, - that I have once found the pupa of Cercaria echinata on the heart of an Anadonta. 
but the fact is now as generally recognized, as it is readily proved.

Thus it is not at all wonderful that I should also have found numerous trematode animalcules in the eyes of our fresh-water fishes; but it was very instructive that I should meet with two of these trematode forms in the eyes of the pike and perch, which differed in size and appearance, but nevertheless were so much alike externally and internally, that I could scarcely doubt that they belonged to the same species, and that the one was an earlier condition of the other; besides these, I found sometimes in the same, sometimes in other eyes, situate here and there, minute watch-glass-shaped capsules, which inclosed trematode animalcules resembling both forms, but especially the larger, and examination soon rendered it certain that this was the pupa state, intervening between the two forms noticed. This interested me so much the more, that I sometimes found these pupce on the internal surface of the cornea, and at the same time noticed a finely granular, unorganized streak, which passing through the cornea to the pupa clearly indicated the way by which the animal had penetrated previous to becoming a pupa. That these animals had entered from without, was shown also by some pupce which were situated in the skin around the eye, or a little beneath it, or even on the muscles of the globe, (and in this situation, the pupe doubtless correspond with the encysted parasites, whose occurrence on the muscles is mentioned by Prof. J. Müller, in his memoir on the Psorospermata.)

I was surprised that I could not recollect, that Nordmann had remarked this form of development, but when I afterwards obtained his celebrated work,* I saw that he was well acquainted with, and had described and figured it all, but only that this interconnexion between them was unknown to him. Two of the forms, for in-

* A. v. Nordmanm, Mikrographische Beiträge zur Naturgeschichte der wirhellosen Thicre. Berlin, 1832, 4to. 
stance, represented the two divisions of his genus $D i$ plostomum, and the third, that of Holostomum; so that his Diplostomum clavatum is the larva, Holostomum cuticola* the pupa, and Diplostomum volvens the full-grown Tirematode.

Now since we see (1. c.) that Nordmann has observed fifty-eight species of entozoa in the eyes of different fish, which belong principally to the two genera named Holostomum and Diplostomum, and that he has formed two separate groups of the latter genus, the one claviform, corresponding with D. clavatum, and the other broader and flatter, with $D$. volvens, I am certainly much inclined to assume that the one group is the larva condition of the other ; and Nordmann's own words appear to support me in this supposition, since he was himself inclined to consider them to be connected as younger and older forms, if only the transition form between them had been discovered. We cannot expect to meet with such if a pupa state forms the intermediate link, and on this account we may preliminarily regard the encysted Holostomum as a pupa. According to the remark, p. 102, it appears that most, if not all Holostomata in fishes are thus encysted, and consequently that they are pupe. Now if we assume, as our present knowledge would seem to justify us in doing, that these forms (of Distoma) are peculiar to the eyes of fish, as they have not been observed in other organs, and if we allow its proper weight to Nordmann's observation that the pupce or encysted Holostomata are frequently found over the whole skin of the fish, either immediately under the epidermis, or imbedded in the most external layer of muscle, we shall again perceive a ready explanation of the fact that many of these animals must necessarily fail of being developed even though they have reached the organism at the expense of which they are destined to live,

* In his description, the Holostomum cuticola is represented as of a larger size than my pupa, but the form is the same. Holostomum brevicaudatum of Nordmann, which was not found in a capsule, much resembles an individual which has just quitted the pupa case, and remains in a contracted state; its size corresponds exactly with this. 
unless they also reach the organ or situation, which affords the requisite conditions for their future development. 'There is no doubt at all from what precedes, that another animalcule described and figured by Nordmann is also a pupa, viz., the Distoma anmuligem, (tab. i, figs. 5, 10 ;) it also inhabits the eye of the perch, but Nordmann has invariably found it only in the pupa state.

Having thus, as I hope, shown in what way trematode animalcules also enter fish from without, and penetrate into their organs, and immediately as it seems whilst undergoing a metamorphosis, I will now only add an observation which renders it probable, that the Trematoda of the higher animals, at least of the Batrachians, likewise make their entrance into them from without; I have, for instance, found immediately under the skin of the common frog (Rana temporaria) small cysts, which from my previous kuowledge of the transformation of the entozoa, I necessarily considered as mupe, and the correctness of this supposition was established when I opened them; for they invariably contained a trematode animal, viz., an Amplistomum, and since similar entozoa are rather frequently met with in the rectum (A. clavatum, and I usually observed the pupe on the mesentery, and even in the cellular tissue surrounding the intestinal canal, I was obliged to conclude that the individuals within the intestine originated in those pupa, and had entered through the integument. It will not, however, be long before observation will prove it to be a universal fact, that the greatest part of these parasites penetrate through the skin by the shortest route into the internal organs.

When a metamorphosis occurs so extensively, or is even universal in one division of the entozoa, the question naturally arises, whether with respect to the other divisions of that class, it is probable that a similar transformation is effected by a single metamorphosis, or 
whether even they probably do not attain their development through a series of alternate generations, and exist at first externally to the organisms with which their life is afterwards inseparably connected. Although I cannot commit myself to a precise reply to this query which is rather beside the especial object of these pages, yet I cannot help giving a few hints on the subject. The Nematoidea, which in their adult state often pass from one individual to another, also probably penetrate from without and as embryos, the organism they infest; they do not appear to undergo a true metamorphosis, but to change their skin : I am also unacquainted with any observation which would justify the supposition, that there is in this group any fostering of the young by precedent generations, unless the genus Sphcerularia, a parasite of the Hymenoptera, which Siebold refers to this division of entozoa be a "nurse"; at least it much resembles one, appears to be nearly powerless to perform spontaneous movements, and contains a numerous smooth-skinned progeny, which move about very actively within their parent, but bear no resemblance to it.* The cystic entozoa on the contrary, betray in many ways that they are a " nursing" generation, and especially in the singular circumstance of their being frequently inclosed like boxes one within the other. Probably the full-grown animal of this division is quite unknown, and it is not unlikely, that in course of time, it may happen with them as it has with the whole division of the "asexual" Trematoda of Siebold, viz., Cercaria, Leucochloridium, \&c., that they must be rejected from the system as being earlier forms of development, or earlier generations of other animals. The Echinorhynchi present several phenomena which are interesting with regard to our object, viz., the remarkable incubation or

* See Siebold's Abh. von d. gesehlechtsl. Nematoiden, in Wiegmann's Arch. 1838, B. iv, h. 1, s. 305 . Further researches will show the nature of the so-ealled asexual Nematoidea which inhabit eases or cysts; they inspire the more interest since Creplin, in his remark upon Siebold's memoir, referred to above (Wiegmann's Areh. 1838, B. iv, s. 373,) alleges that there is no known instance of the encysted Nematoidea possessing sexual organs. 
breeding which takes place between the skin and the viscera, and the inclusion and incipient development of the ova in the so-called "loose ovaries," during the continued growth of the latter. I must confess, that I look upon these oval bodies much rather as individuals which will never quit the parent animal, than as "ovaries;" and till their true nature is known I shall regard them as such, and consequently consider most of the Echinorlyynchi hitherto known, as "murses." It is confessedly uncertain whether the Echinorlynchi spend part of their life externally to the organism which they inhabit as full-grown animals, or not; it is however very probable they do so, as the embryo attains no real development in the ova so long as these are in the Echinorhynchus; and the ova are met with in the mucus of the stomach and in the excrements, by thousands, in the same condition, so that the development of the young in the ova and their escape from them, certainly occurs very long after the ova have reached the water.*

With this I connect the remark, that in the months of February, March, and April, I have often found in the mesentery and cellular tissue about the liver and intestine of the sole, very minute individuals of from $\frac{1}{2}{ }^{\prime \prime \prime}-\frac{2}{3}{ }^{\prime \prime \prime}$ or sometimes even $1^{\prime \prime \prime}$ in length, all of which were inclosed in a thick membranous cyst, of a more or less regular oval form. When these cysts were opened (fig. $a$, tab. iii) there came out of them a very much contracted Echinorlynchus (fig. b) whose organ of attachment, furnished

* A remarkable exception must be made, however, in the case of a species of Echinorhynchus examined by Professor Eschricht, and in which he observed innumerable ova, in which the embryo was so much developed, that at first the egg membrane escaped his notice, and he believed the embryos had been hatched. As this observation was made on an Echinorhynchus of the common haddock of Copenhagen, and as the Echinorhynchi of this fish, as well as of the sole, which appear to be the same species, have been examined by many, it is the more remarkable that this condition was not earlier noticed; I have myself, during several months, examined the Echinorhynchi of our common sole, but there has been no trace of an embryo in their ova, although the latter were passed by thousands in the excrement. [May it not then probably have bcen an ascaris or some other nematode which Professor Esclnicht had bcfore him?] 
with hooks, was deeply retracted within the animal, and which after some time it began to extend, - and finally protruded as its armed proboscis (fig. c.) Whether the animal lay in this cyst as in a sort of pupa condition, I I must leave undetermined, but such appeared to be the case. This observation corroborates the opinion of Prof. Eschricht, that the Echinorhynchi probably penetrate the fish; for he found in the summer months, in the flesh of the Copenhagen haddocks numerous Echinorhynchi which he could only regard as young ones, in the act of passing through the skin and fiesh to the intestinal canal, their proper abode, and in which situation only, are they met with, as adult, or nearly adult individuals, so that the helminthologist Siebold has never yet met with Echinorhynchi so young, that the so-called "loose ovaries" were not developed in them, and has never even met with individuals which he could altogether call " small," " on which account the encysted individuals mentioned above as occurring in the abdominal cavity, are not without interest.

Lastly, with respect to the metamorphosis of the Cestoid worms, we have an example of it presented to us in Miescher's interesting memoir $†$ on the forms which

* Vide Burdach's Physiologie, $2 d$ edit. tom. ii.

$\dagger$ I am acquainted with this memoir only through the reference to it made by Siebold in the Report of Contributions in the province of Helminthology during the year 1840, given in Erichson's Archiv, 1841, s. 301-304; but I must remark, that it is rather bold to assume that the encysted Filarice piscium are transformed into claviform cysts, wherein is found at first a trematode animal, which is afterwards developed into a Tetrarhynchus. These encysted Filaria piscium, which occur so abundantly in the haddock, \&c., and whose description by Siebold has already been once mentioned in this memoir, betray, as it appears to me, but very little similarity with the at first tubular, afterwards clavate cysts which I have found loose in the abdominal cavity and on the viscera of Esox belone, and within which there is always a Tetrarhynchus, with spirally contracted hooked tentacles, capable of being extended to an extraordinary length. The earlier condition, so far as I have been able to judge of the tube, certainly has the form, but none of the structure of a Filaria. The contracted animal inclosed in the knob-like cysts in which the Tetrarhynchus is developed, resembles, as far as its substance is concerned, a very young cestoid embryo. All the developed Tetrarhynchi within the cysts lad the appendix to their bodies which is mentioned by Miescher as being present in those which he met with in the cavity of 
the genus Tetrarlynchus passes through; but which also in fact includes nearly all we know about them; whilst the great work of Professor Eschricht, upon the genus Bothriocephalus of this family, has given an entirely new view of those animals, constituted of almost innumerable joints, so that they are to be regarded according to his anatomical investigations, not as single but as compound animals, viz., compound Trematoda or fukes, so that each joint is to be compared with a distoma,- - a view of their nature to which Baer had some time before alluded, and which had also struck Creplin and Mehlis, on account of the resemblance of the sexual organs, but which is now for the first time entitled to the greatest attention, having been rendered probable by so many anatomical researches. However, I cannot for my part entirely coincide in this view of the Cestoid family of worms, for in whatever way the joints and their reciprocal connexion are considered, compound animals are presented, whose construction is entirely different from that of all other animals. The tapervorm is certainly not a single individual, but consists of several; that is, it is constituted of the head, which is an animal, and of the progeny derived from it. This view is much supported, it is even proved by the fact, that the offspring (joints) in a state of progressive development, never actually become animals similar to that from which they spring (the cephalic joint,) which alone remains dissimilar to all the rest, never acquires any developed sexual organs, and consequently never generates any ova, which the others produce in great abundance; whilst the cephalic joint is furnished with a mouth and suctorial acetabula, proceeds from an egg, and is the animal upon which the development of all the rest depends, and is thus in fact one of those animals to which we have in the preceding pages given the name of " murse."

the thorax and around the heart, and which in his opinion were on their migration to the exterior of the animal, (might they not rather be on their migration to the intestinal canal within?) For the rest, I must lament that other occupations prevented my availing mysclf of the opportunity which was afforded me of making more accurate researches into the development of the Tetrorluynchi. 
If this view be correct, which time will determine, it will be seen that the Bothriocephali, just as all the other animals mentioned in this Essay, which are developed through alternating generations, present quite another and more significant resemblance to plants, than that set up by Prof. Eschricht. The individuals which are fostered by, and appear to proceed from the head by the so-called transverse division, * thus attain such a degree of perfection, that the ova are fully formed in them even before they become detached from the "nursing animal"; and, as defensive cases for the ova, they are passed in the natural way from the animal which they have infested, in order probably to reach, eventually, another similar animal, under another form, and as other individuals. $\dagger$

* The head of the Bothriocephalus, with all its successive joints, appears to me aptly comparable with the Scyphistoma strobila; but no one has as yct termed that a compound animal, nor has the term been applied to the connected series of Naida, although their condition is a very similar one. It has been said of all three forms, that they are multiplied by transverse scission or division, expressions which I should not venture to use without prefixing "the so-called," for the relations which obtain in these instances are entirely different from those which would be implied by the separation or abscission of a definite portion of a whole from the other portions of the same whole, in order that the separated portion should itself become another similar whole. I have never been able to meet with Naide so small, but that it was quite evident that several individuals, in various stages of development, were ranged one after the other, and that the one animal was never developed from joints which had previously belonged to another individual.

+ The development which the ova of the Cestoidea undergo must obviously occur under very peculiar circumstances. Professor Eschricht remarks upon this subject, that the ova, collected into masses and encased in a thick slime or mucus, are passed from the joints packed np, as if they had to make a long and difficult journey. I was also much surprised to see the separate joints of the tapeworm of the sheep and dog passed, each by itself, with the ova, and as it were in a definite proportion with the evacuated fæces; in a lamb which was much infested with this worm, I was even struck by the regularity with which each joint of the worm passed through the rectum with four or five balls of the fæces, so that I necessarily concluded that the object of these little masses was probably not merely the conducing to the development of the germ in the ovum, but also to the transference of the embryo to new organisms. As matters stand also, I cannot doubt that the Entozoa in certain stages of their growth, or in certain generations, have a geographical extent and distribution in nature (e. g. in water) externally to the organisms which they infest at other times. We could not otherwise easily imagine how the Entozoa of man or of domestic animals, especially in certain races, should occur as they do, dispersed in regions far remote from each other, 


\section{CHAPTER V.}

CONCLUDING REMARKS ON THE ALTERNATING GENERATIONS AND THEIR REAL NATURE.

THe mode of development by means of "nurses" or intermediate generations, is thus seen to be no longer an isolated phenomenon in nature. The circumstance of an animal giving birth to a progeny permanently dissimilar to its parent, but which itself produces a new generation, which either itself or in its offspring, returns to the form of the parent animal, is a phenomenon not confined to a single class or series of animals ; the vertebrate class is the only one in which it has not yet been observed.* It would consequently appear that there is something intrinsic in this mode of development, and that it occurs as it were with a certain necessity ; on which account it will undoubtedly soon be recognized to a greater extent and more generally. It should no longer be considered as something paradoxical or anomalous (as we have hitherto been too much inclined to deem both it and the phenomena in which it is exhibited,) it must be in harmony with the rest of development in nature, in which the fundamental principle of this course of development must also be elsewhere expressed, although it may be displayed in a form under which we shall less readily perceive and recognize it. This is seen when we trace the mode of

* To the instances adduced in the foregoing pages, we might add the - cyclical development of the vorticellee, as it has been described by Ehrenberg. 
development in question more widely through nature; and whilst contemplating it through the phenomena in which it is manifested, we comprehend it in its true light.

If we collect and regard in one view, the whole system of development by means of " nursing" generations, as it is exhibited in the bell-shaped Polypes (Campanularia,) the Claviform Polypes (Coryne,) Medusce, Salpa, Vorticella, and Entozoa, it appears as a peculiar and consequently as an essential feature in this course of development, that the species (that is, the species in its development) is not wholly represented in the solitary, full-grown, fertile individuals of both sexes, nor in their development, but that to complete this representation, supplementary individuals, as it were, of one or of several precedent generations are requisite. Thus, the distinction between this course of development, and that which is generally recognized in nature, in which the species is represented by the individual (of both sexes) and its development, is the want on the part of the individuals of a complete individuality as representatives of the species, or of a specific individuality, if I may so express it. If now we agree to regard such an incompleteness in the individual, as the essence of this development, we shall comprehend its significance in nature when we thoroughly consider this course of development in its various periods, throughout the above-mentioned families, how it begins and advances, so that at last we discover to what it tends. I believe also, that we might trace, even now, this development by means of precedent, preparatory generations of " nurses" in its peculiar course and advance, notwithstanding the paucity of instances adduced in the foregoing pages, and the many gaps in the series of observations. Thus we see the greatest incompleteness and the highest degree of mutual dependence in the Campanularia and similar polypes, in which the generations representing the unity of the species are very unlike each other, and in which all the individuals, are fused as it were into an outward unity, or into a set of polypes. . 
'I'hey exist, organically connected with each other, and are normally free only in their first generation, and indeed only in their earliest stage of development, and only for a short time, since the free-swimming ciliated embryo swims about in the water at most for some hours, in order to find a suitable place for the foundation of a new polype stem. In the Coryna or claviform polypes, the organic connexion between the individuals and generations is rather more lax ; the perfect gemmiparous or ovigerous individuals are usually quite free, often even at an early age (Coryne fritillaria, Corymorpha,) so that they do not attain their full development until after their separation from the "nursing"-generation. In the Medusce and Salpe, the generations which are connected together into one whole, become more like each other; the first generation of the Meduse is still fixed but more active and mobile in its parts; the individuals of the perfect generation, leave the "mursing" animal while still very small, and undergo remarkable changes after they have become free and are swimming freely about; both generations of the Salpa, finally, are free and free swimmers, only the individuals of one of them are organically connected with each other; they have, however, no common organs (in the full-grown state,) and if my explanation of the alternate generation of the compound Ascidians is correct, we have in that instance precisely the development of the Salpe at a somewhat lower stage ; the individuals of the one generation are organically connected, without having a common organ; but both generations are fixed.

In the class of Entozoa a similar progressive attempt at becoming free and accomplishing a perfect growth appears evident to me.

In the Cestoidea the generation of perfect individuals, constitutes externally a unity; they are only successively detached from each other as the term of their existence approaches, and their whole existence is throughout connected with the "nursing" animal. In some of the Trematoda, the later generations remain within the earlier, 
until they have attained their full development ; in others they forsake them in an earlier condition, are free and free swimming, and undergo a complete metamorphosis ; in some of these latter, the earlier generations are transformed into motionless and as it were lifeless cysts, whilst in others, they remain free and active, (the " nurses" and "parent nurses" of Cercaria ephemera and C. echinata,) but retain during their whole life a form, which, at most, resembles the larvæ of the more perfect generation. In this way an advance in a certain direction, may indisputably be observed; at first, all the generations constitute a unity, not merely as regards the interior, but also with respect to the exterior; they form a stationary colony; after which, the generations are detached more and more from each other, and become at the same time more free; and finally, all the individuals constituting the generation are separate from each other, and acquire the power of free locomotion; in this latter stage, or that of freedom and perfection, we found the development of animals which are certainly no longer attached to imanimate objects at the bottom of the sea, but live buried in other animal organisms, and belong not to the sea, but to fresh water. In a still higher and more free stage than this, we observe the development of animals, which do not belong to the water, but to the air, as in that which occurs in the Aplides. The propagation of these creatures through a series of generations has been already long known. In the spring, for instance, a generation is produced from the ova, which grows and is metamorphosed, and without previous fertilization, gives birth to a new generation, and this again to a third, and so on, for ten or twelve weeks; so that in certain species, even as many as nine, such preliminary generations will have been observed; but, at last, there always occurs a generation consisting of males and females, the former of which, after their metamorphosis, are usually winged; fertilization and the depositing of eggs takes place, and the long series of generations recommences in the next year, and in the same order. All 
the individuals are free and enjoy the power of free locomotion, and undergo a metamorphosis; here, however, we have before us aerial animals, and which are no longer parasites inluabiting other organisms; at most they are only externally parasitic, and on plants alone ; the phenomena of this mode of development are no longer exhibited by Entozoa, but by Epiphyta. Nevertheless, the course of development is in itself similar; but in the external, more free, and nobler form in which it is now exhibited, the endeavour to attain something higher is manifest; each link or generation certainly brings its offspring nearer to the perfection aimed at; but this approachment towards perfection is effected only by means of the " nursing" by special animals, and is committed to the still and quiet activity of an organ, without the nursing animals themselves being conscious of it; it is a function merely and not an expression of the will. In all parts of the animal kingdom we see instances of the still, quiet, and unconscious activity of the animal, being developed into voluntary actions, which are undertaken by it from an internal, obscure, and irresistible impulse (or artificial impulse,*) as is the case in this instance. The development and mode of feeding or nourishing the young exhibited in its course, of Bees, Wasps, Ants, and Termites affords a direct example of the mode in which the care of the young is provided for, by the voluntary action of numerous individuals devoted to that object. Those of the young which are to be developed into the more perfect, fertile individuals, are not protected in the body of the foster-parents, nor is their nourishment secreted by one of their organs ; both protection and food are afforded them by means which are brought about by the conscious activity of the "feeders." The wasp, for instance, or the wild humble bee, which has been impregnated in the autumn and has afterwards sought a shelter to protect itself against the cold of winter, prepares a solitary habita-

* Or instinct to produce compound effects resembling human art (Kunsttrieb.) 
tion, in which it builds cells and deposits its eggs ; from the eggs proceed larva, but the insects into which these larva are metamorphosed are not fertile; they are barren, and all their faculties are directed to the assisting of the parent animal in the better nourishing of the future brood, to which end, some of their external organs are transformed, and to the erection of a better habitation and cells into which they convey the eggs of the female, and the food of the larva to be developed from them. Other cells, which contain a better sort of food, are erected for a later and less numerous progeny of eggs; and again in others, which are more roomy and provided with the best kind of food, but of which there are only a few, is the last brood of the female deposited. From the first kind of cells, proceed the barren individuals, from the second the males, and from the third the females; after undergoing a metamorphosis, the males and females fly away, impregnation takes place and the males die; the females, however, return, and the whole multitude of barren individuals, which at the same time perform the duty of feeding the young, build cells for their various progeny of eggs, and nourish the three forms of larvæ which proceed from them. In this way the inhabitants of the colony become very numerous; nevertheless they all die off in the winter; the fertile females alone remain alive, and propagate the species the year following, under the same development of alternating broods, the earlier of which is always by far the most numerous, and assists in the development of the later. In the colonies of Bees, Ants, and Termites, the same thing occurs ; the many thousand individuals which constitute one of these colonies, are principally "feeders," or individuals which have originated in the precedent divisions of the eggs of the females, and in these is exhibited, even with greater precision, a more marked division of labour in the feeding of the progeny. So that, out of the various precedent divisions, individuals apparently arise which assist in the development of the more perfect progeny in various ways. Thus 
there are in a hive of bees, individuals which are employed almost wholly in the feeding of the larvæ (Fütterer, foragers,) whilst others do scarcely anything else than collect wax and build cells (workers.) In anthills, one set of the feeders is constantly employed in conveying the larvæ from one place to another, according as they require a greater or less degree of warmth, \&c., whilst others are engaged in building the passages or earth cells, and in making excavations around the habitation. Among the Termites also we are acquainted with several forms of "feeders," constituting particular tribes or classes; the description of labour however, which each of these classes performs, is unknown; it is known, however, that a form with a large head and strong jaws, is always posted at the entrance of the artificially constructed dwelling, and keeps guard there as soon as any disturbance is remarked, and thus constitutes the safeguard not only of the young but of the whole community.

Now, in the cases in which the more perfect develop. ment of the progeny is promoted, . either by means of " murses" * or of " feeders," + (under which latter term, we understand special individuals devoted to the actual care or nourishing of the young, which office they fulfil by a conscious activity,) we see that nature always has in view the production of a multitude of individuals to whose life or care is then committed the perfecting of a later generation or progeny, consisting of less numerous individuals. This previous or preparatory multitude seems to consist, invariably, of females, the males being apparently excluded from any participation in the office, on which account the males of all the animals among which the system of "nursing" or of "feeding" obtains, constitute a very subordinate number. That the "nursing" should be committed to females alone appears to us very natural, since we are acquainted with an organ in them whose natural function would be

$$
\text { * The "nurses" (amme.) † The "feeders" (pflegerinne.) }
$$


to perform that office. The generative organs are, indeed, in perfect (female) individuals, divided as it were into two parts of very distinct natures; the ovarium for the preparation of the germ and the production of the egg, and the oviduct and uterus in which the ova are as it were incubated, and the germ and embryo sufficiently developed to allow of its being born. Now, it is actually the case, that no true ovary has been discovered in the "nursing" (ammen) generations ; on the contrary, the germs, as soon as they are perceptible, are situated in organs which must be regarded as oviducts and uteri, as for instance, in the most perfect "nurses" we are acquainted with, the Aphides. In the "nurses" of the trematode larva, Cercaria echinata, I have remarked, that the germs in their earliest condition, are collected into an organ at the root of the tail, which may probably be regarded as a uterus, and that they appear to distend this organ gradually to the size of the whole body. The accurate anatomical researches of Prof. Eschricht on the Salpa, also show in the most precise way, that the associated brood of the Salpa does not originate from ova, but that, as germs which are arranged in a definite manner between the walls of a hollow organ, it is contained in what can in no case be an ovary, and which the author has termed a "germ-tube," (Keimrohre.) This organ lies in a cavity which may probably be considered very nearly a uterus, which is however, always as it were a secondary receptacle for the germs; but in the present instance, it cannot be shown that they have occupied any previous receptacle or place of formation.*

From what we at present know, we may probably

* Accurate researches with respect to these organs of the " nurses" in all the above-mentioned forms of animals, such as have lately been made by Professor Eschricht on the Salpce, would be of extreme interest for the physiology of generation, and would be a task worthy of a competent anatomist. I cannot refrain from again directing attention to the remarkable organ in the Trematoda, the secretion of which in the perfect animal is expelled from the body, but in the " nursing generation," on the contrary, remains within it, as being an organ which probably subserves the function of generation, and favours that of "nursing" in the first generation. 
assume with some degree of certainty, that the "mursing" individuals are never themselves gemmiparous, but that they are born with germs in the organs in which the embryos are afterwards nourished, and from all this it appears as if the female generative organism were always divided in those cases in which development by means of "nurses" occurs, so that as in the more perfect females an ovary especially, is formed, so in the "nursing" individuals a much developed uterus is presented, in consequence of which, they as individualized uteri, have assigned to them as the object of their existence the performance of the functions of a uterus, and their complete formation must thus necessarily precede that of the germs which are committed to their fostering care. We cannot readily perceive the reason, that because all nursing (ammende) individuals must be of the female sex, it should follow, that all those individuals which feed the young (brutpflegende) should also be of that sex, and yet this seems to be the law. Anatomy shows us that the "feeders" among bees, wasps, \&c., and probably those of all insects living in regular societies are females, whose sexual organs remain in an undeveloped state. They present scarcely the vestige of an ovary; the uterus is rudimentary, and all propagation consequently in the material way (materiellen Seite), so to say, is rendered impossible; - the imperfection of the organ does not even allow of their acting as "nurses" (ammen,) and the propagative instinct, in a physical, corporeal sense passes into a will for the propagation of the species, into a nisus impelling to the feeding or nourishing of the young, and the fulfilment of these impulsive duties is favoured by the peculiar transformation which some of the organs undergo at the expense of those intended for propagation, in order that they may become adapted to the bringing up of the young. *

* The jaws of the working ants are stronger than those of the male and female; and the becs also which collect honey and wax are provided with wide mandibles, which together form a pair of forceps. The ovipositor is in them conrerted into a spiculum (defensive organ), \&c. 
Whence it follows that the development of the species in this case does not take place by means of several generations, but through several broods of the same generation. The reason of the great number of "feeders," and for the common good of "workers," so that they often constitute thousands, whilst the fertile individuals scarcely amount to hundreds* may be readily understood, when we consider more closely the regular societies of Bees and Ants, and witness the labour required for the nourishment of the young. But on the other hand, how the development of the species is promoted by the multitude of "nursing" animals (amme) of which we often see thousands for each single fertile one, appears to us difficult of explanation, since, even all of them can only be regarded as animated organs, which do not appear to act for or with each other. It does not, however, seem to me improbable, that even the Aphides, trematode nurses, and other parasites, which are so immediately injurious to the organisms in or upon which they live, are not destined merely to promote the extension of the species, but that they also induce in the organisms themselves, conditions necessarily more and more favorable to a later generation; plants also and animals afford us many instances, that to a certain abundance of parasites there usually succeeds a complete overflow of them.

I conclude with the remark, that, inasmuch as in the system of " mursing," the whole advancement of the welfare of the young is effected only by a still and peaceful organic activity, is only a function of the vegetative life of the individual, so also all those forms of animals in whose development the "nursing" system obtains, actually remind us of the propagation and vital cycle of plants. For it is peculiar to plants and as it were their special characteristic, that the germ, the primordial individual in the vegetation or seed, is competent to produce individuals which are again capable of pro-

* In a hive of bees there are from 2000 to 3000 males, and only one female to 50,000 "feeders" and "workers." 
ducing seeds or individuals of the primary form or that to which the plant owed its origin, only by the intervention of a whole series of generations. It is certainly the great triumph of Morphology, that it is able to show how the plant or tree (that colony of individuals arranged in accordance with a simple vegetative principle, or fundamental law,) unfolds itself through a frequently long succession of generations, into individuals, becoming constantly more and more perfect, until, after the immediately precedent generation, it appears as Calyx and Corolla with perfect male and female individuals; stamens (Staubblättern,) and pistils (Fruchtblättern)(so that even in the vegetable kingdom the grosser hermaphroditism does not obtain, which is still supposed to take place in the animal,) and after, the fructification brings forth seed, which again goes through the same course. It is this great and significant resemblance to the vegetable kingdom, which in my opinion is presented by the entozoa, and all " nurse" generations (amme,) and to which I have alluded in the preceding Essay ; I might almost say, that the condition of continued dependance incidental to the animal life, is, to a certain extent, one of less perfection than that which is presented in the progressive elevation in development effected by the agency of the vegetative life. 



\section{EXPLANATION OF THE FIGURES.}

\section{PLATE I.}

Figs.1-40. The Development of Mechusa Aurita.

N.B. Almost all the figures are taken from the memoir by Sars, in Erichson's Arch., 1 B. 1 H. tab. i-iv, some from a work by the same author, entitled 'Beskrivelser og Iagttagelser over nogle markelige eller nye $i$ Havet ved den Bergenske Kyst levende Dyr, o. s. v.,' (Bergen, 1835.) Figs. 1-19 represent especially the progeny of Cyanea capillata, but according to Sars it corresponds so perfectly with that of Medusa aurita, that in most cases it is impossible to distinguish the one from the other. Fig. 35-40 only are from my original drawings, made in my Icelandic journey.

Figs. 1-19. Show the development of the first generation, which I have named Medusa-nurses.

Figs. 1-4. The ciliated, free-swimming, infusorial progeny of the Meduse, newly escaped from the peculiar receptacles in the tentacles of the female Medusa, in which they undergo a sort of incubation 
for a time. Figs. 1, 2, 3 are viewed from the wider end, and fig. 4 from the narrower. At the wider end is seen a depression, by which they afterwards affix themselves by suction.

Fig. 5. An individual which has already affixed itself at the surface of the water.

Figs. 6-9. Show the way in which the young Medusa after (on the third day) having become attached by the wider end to some fixed object, gradually grow and change their form, until the hitherto slender, projecting extremity becomes thicker, and the body passes through the cylindrical (figs. 7, 8) into the clavate form (fig. 9.)

F1G. 10. A club-shaped individual, seen from above, in which now an actual opening (but no oral orifice) has been formed; this orifice is surrounded by a circular elevated margin, and presents four indistinct tubercles.

Figs. 11-14 represent a similar individual in its advancing growth; the four inferior tubercles are gradually more and more elevated (on the fourth and fifth day) (figs. 11, 12, 13) finally become filamentous and assume the form of tentacula (fig. 14.)

Figs. 15, 16. Individuals at the age of from ten to eleven days; the number of tentacles is increased to eight, four new ones having sprung up between the older ones; fig. 15 is seen from the side, fig. 16 from above.

FIG. 17. An individual which besides the eight older tentacles, exhibits five new ones springing up : viewed from above (on the twelfth day.) 
Figs. 18, 19. Individuals much older, and possessing the full number of tentacles; smaller individuals are seen upon them, as if arising from gemmæ or runners (stolones.)

FIGS. 20-34 represent the development of the second generation (THE MEDUSA LARVE) within the first (THE MEDUSA "NURSEs"), and their completion into perfect MEDUs.e.

Figs. 20-22. Show the commencing development of new animalcules in the posterior part of the body of the polypiform " nurses"; the development causes the appearance of a transverse division of the animal. Fig. 20 is an individual with one transverse ruga. Fig. 21 with more, when several germs lave become developed. Fig. 22 with many; the borders of the new animalcules are now free, eightlobed; they possess the power of spontaneous motion. The whole set (Strobila) is, however, complete, and the "nurse" animal is placed upon the pile of larva, as it may be termed.

Figs. 23, 24. Show how the Medusa-larve detach themselves from the "nurse" animal. Fig. 24 is a bunch or set of larvæ, the "murse" belonging to which has already become detached: (of a natural size.) Fig. 23 is the lowermost part of such a set, and shows how the larva rise up from one another, and are finally altogether separated.

Eigs. 25-30. The free Medusa-larva proceeding to their further development. Fig. 25, a larva of the natural size and recently separated. Fig. 26, an individual rather more developed, and Fig. 27, the same seen from below. Fig. 28, a still larger indiviclual (of 
the size of nature). Fig. 29, one of much larger size seen from above. Fig. 30, one fully developed, but not yet full-grown, with four perfect, cloven, oral tentacles, and numerous outstretched marginal tentacles.

Figs. 31-34. Exhibit in magnified figures, the changes which the edge of the bell-shaped body of the medusa larva undergoes, and show the gradual rising and growth of the marginal tentacula (figs. 31-32-33) in the three stages of development shown in figs. 26-28-29, together with the division of the ventricular tube into four arms (fig. 34.)

Figs. 35-40. May serve to prove, that the polypiform "NURSE" animal is a stationary MEDUSA; all the figures are much magnified.

Fig. 35. A polypiform "nurse" (Scyphistoma) viewed laterally. Fig. 36, a smaller individual, much depressed towards its stem; within the border of tentacles, is seen the mouth of the bell, and within this again the oral orifice. Fig. 37, a similar individual, which has protruded the ventricular tube, through the mouth of the bell and the circle, formed by the reclined tentacles. Fig. 38, an individual viewed from above, in which the tentacles are extended almost horizontally; the marginal membrane around the mouth of the bell is also dilated, and retracted towards the base of the tentacles; four large vessels, appearing like thick-rounded ridges or elevations, descend from the margin to the stomach which is situated at the bottom of the bell. Fig. 39. The outline of an individual whose marginal membrane is almost wholly retracted around the mouth of the bell; in this figure are also seen the annular vessel around the contracted mouth of the bell, the annular vessel at the base of the tentacles, and the 
fort radiating vessels which connect the two former. Fig. 4.0, represents the whole vascular system in comnexion, as far as I have been able to trace it.

Figs. 41-47. The Development of the Club-shaped Polype, Coryne fritillaria.

N.B. (The figures are after my own drawings, from specimens observed in Iceland. Fig. 47 is taken from Sars, $(l . c .$, ) for the purpose of comparison.)

Fig. 41. A club-shaped polype, Coryne fritillaria, of the natural size; it consists of a so-called clubshaped head, which is the original animal, or the first generation; a stem which supports this head, and 3-4 quadrangular bell-shaped bodies (individuals of the second generation) which hang on short peduncles around the base of the club-shaped individual.

FIG. 42. One of the bell-shaped individuals (but very little magnified) which has become detached from the "murse." Fig. 44, a medusa-like, bell-shaped individual, met with swimming free in the sea; it has more than doubled its size since its separation, and particular organs (generative?) have become developed; of natural size. Fig. 43, the same very little magnified. Fig. 45 , the same very much magnified, to allow of a better insight into its structure. Fig. 46, some cells on the edges of the bellshaped individuals, highly magnified, in order to show the vesicles, situated half in and half out of them.

Fig. 47. A young bell-shaped individual of the Corymorpha nutans, Sars, for comparison. 
Figs. 48-57. The Development of the Campanulate Polype,-Campanularia geniculata.

N.B. All the figures (except fig. 48) are taken from the celebrated memoir of Loven on this subject. (Wiegmann's Archiv für Naturgeschichte, 1837. Tab. VI.)

Fig. 48. A specimen of Campanularia geniculata slightly magnified. It constitutes a whole colony of individuals, of somewhat different aspects, and consisting of several generations; first appear individuals of the form a $a$ a they occupy the summits of the branches, and elicit afterwards the larger individuals of the form $b \quad b \quad b$, which are always situated in the axillæ of the branches. Wittin, the second form (the " nurses") is hatched the third and more perfect form $c c c$, which is smaller and globular, and which in a short time is to be seen placed upon the individuals $b b b$, whilst the young proceeding from their ova, make their escape.

Figs. 49-57. Highly magnified, show the relations between the various forms (generations) of the individuals.

FIg. 49. A magnified full-grown individual of the first generation-a "parent-nurse" (grossamme) as I term it-with a branch growing out of it.

Figs. 50, 51. Represent two periods of the successive development of a polype of the same generation, at the extremity of the branch, or of the stem.

Fig. 52. A highly magnified individual of the second generation ("nurses," ammen); on one side of the 
intestinal tube is seen the commencing development of the third generation (the perfect females.)

H'IG. 53. Two perfect females, which are protruded through the operculum of the " murse;" in one of them is seen the fully-developed egg, which may also be distinguished even before the female quits the "nursing animal" (vide fig. 52); in the other, the young are on the point of escaping into the water.

FIGs. 54-57. Show the metamorphosis of the young, and the way in which a new polype stem is founded, together with the origin of the "PARENT-NURSES."

FIG. 54. The oval ciliated, young polype (in the water).

FIG. 55. The young polype, after it has affixed itself and become contracted into the form of a disc.

FIG. 56. The same, rather older; the disc is beginning to divide into several portions, and presents in the centre a small tubercle.

Fig. 57. The same, after this rounded tubercle has increased in height, and has formed the lower part of the stem of the compound polype. 


\section{PLATE II.}

Figs. 1-8. The Development of the Fluke, Distoma PACIFICA.

N.B. All the figures, except figure 1, which is taken from Siebold's Memoir on Monostomum mutabile, in Wiegmann's Archiv. f. Naturg., 1836, are from my own drawings.

Figs. 1-2, Show the first generation in the development of the distoma, - the "PARENT-NURSES."

Fig. 1. First stage in the development of Monostomum mutabile; $1 \mathrm{a}$, an ovum, through the shell of which is seen the developed embryo, which is represented in $1 b$, after it has quitted the egg, and is swimming about at liberty; $1 c$, and $1 d$, are the same individual, after its metamorphosis from an active form into an inactive sluggish creature, which is not itself a mother, but nourishes within it a progeny from which, in the third generation, a parent animal does proceed. I call this a "parent-nurse" (grossamme).

Fig. 2. Animals which inhabit fresh-water snails, as entozoa, and after a few generations become true Distomata, or resemble them; on which account, in the text I have termed them their "parent-murses." From the analogy in the external form, with the creatures which proceed from the ova of Monostomum, and are afterwards metamorphosed, it must be as- 
sumed that those creatures which are produced from the ova of the Distoma in the common embryonic form of the Distomata (compare fig. 16 ) - the first generation-are of an allied nature. Figs. $2 d$ and $2 c$ are individuals, in which is a new progeny in the form of globular germs, and which occupies only the posterior part of the body; $2 b$ and $2 a$ show partly developed embryos, filling nearly the whole cavity of the body.

Figs. 3-4. The second generation in the development of the Distoma. (The "nurses," amme.)

Fig. 3. A series of forms, through which the young pass from the globular germs in the "parentmurses," figs. $3 a-d$; during their growth they become at first oval, figs. $3 e-g$; but afterwards more elongated, and almost cylindrical $(k i k l$,) whilst a small process which is situated at one end is lengthened into a sort of tail, and a depression at the opposite extremity is formed into a mouth and oral cavity. Figs. $3 m n o p$, are older embryos, which exhibit the parts named above more distinctly; a pair of lateral processes at the root of the tail, as also a depression below the head, become more evident; the interior large cavity represented at $v$ is a digestive sac. Figs. $3 o$ and $p$ are fully developed individuals (" murses") in which the germs of another generation (the third) are distinguishable just above the root of the tail.

FIG. 4. The growth of the second generation, the "nurses" (amme) and the hatching or incubation of the third generation (the Distoma-larva). $4 d$ is very young, and has recently quitted its "nurse" -the "parent-nurse" (grossamme); $4 c$ is half-grown, and the germs of the third generation contained in it are partly developed into embryos, and show that 
they will attain a form different from that of the animal in which they are situated (or fostered). 4.6 contains fully-developed embryos, which exhibit the long tail and an internal, bifurcated digestive organ; they fill the whole cavity of the body of the " nursing animal" so that the saccular digestive organ of the latter is reduced into a small organ marked $v$. $4 a$ completed " nurses" slightly magnified.

Figs. 5, 6, 7, 8. The third generation of the Distoma; the embryo, larva, pupa, and perfect Distoma.

Fig. 5. The forms gradually assumed by the young within the "mursing" animals, whilst from germs they are formed into embryos; Cercaria, Distoma larve; figs. $5 a-e$ spherical germs, which are elongated $(g-h)$ and exhibit a trace of life $(i)$ whilst a tail begins to be distinct from the body. In figs. $k$ and $l$ the form of the Cercarice is completed, and several of the internal organs are distinguishable. Fig. $m$ unborn Cercaria viewed from the side.

FIg. 6. A Cercaria which has quitted its "nurse" and swims free in the water. The outward form of the body corresponds with that of the Distoma, as also do the internal organs, but is wanting the tail (vide fig. 8). The head and the collar situated beneath it correspond with the same parts in the two preceding generations of " murses" and "parentmurses" (vide fig. 2 and fig. 4). The lateral processes in these are the lateral portions of the posterior part of the body surrounding the root of the tail; the tail is one and the same.organ in all the three generations.

Fig. 7. Distoma pupæ or Cercarice in the state of pupæ or when they have cast off the tail and are sur- 
rounded in a mucoid case. $7 d$, a portion of the skin of a fresh-water snail, upon which a number of Cercarice have become pupa; slightly magnified. $7 a$ and $7 b$ single pupa highly magnified, and $7 c$ under the same magnifying power as that under which the Cercaria, fig. 6 , is figured. A circlet of spines, which was concealed in the collar of the Cercaria, is at this period very distinct, and presents itself in various positions, according to the motions of the animal within the pupa case.

Fig. 8. The animals proceeding from the pupa; true Distomata; fig. $8 a$, an individual extracted from the pupa case, and in a rolled up position; $8 b, 8 c$, $8 d$, individuals which have spontaneously quitted the pupa cases, and have penetrated a short distance into the body of the snail. $8 b$ still retains the circlet of spines on the collar around the oral orifice. $S c$ has just lost the spines, the marks of which are still evident on the collar, which is diminishing in size. $8 d$ an individual more deeply buried than the preceding ones in the body of the snail; the collar still smaller. $8 e$ and $8 f$ individuals occurring in the outermost convolutions of the liver. 


\section{PLA'TE III.}

Figs. 1-6. The Development of the Distoma tarda.

N.B. All the figures are from original drawings, and under the same magnifying power, except figs. $1 \mathrm{~g}, 4 a$, and $6 b$, which are but little magnified.

Fig. 1. The development of a series of sacciform creatures which occur on the viscera of the snail, and appear to be the "nurses" of young, which afterwards assume the Distoma-form : Distoma-"NuRses." From extremely minute, oval or pyriform bodies, $1 a$, and $1 b$, they are formed into longer or shorter, more or less regular bodies possessing a vermicular motion, $1 c, 1 d, 1 d^{\prime}$, and inclosing a cavity in which a multitude of germs are placed which are commencing their development. $1 e$, an individual possessing rather more powerful vermicular motion, and presenting half-developed embryos ; the resemblance which these embryos bear to the Distomalarve is already apparent. $1 f$, an individual which has lost all its power of motion, and whose skin has become distended almost into a delicate membrane by the vast crowd of embryos (viz. developed Cercaria). $1 \mathrm{~g}$, an assemblage of these Distoma nurses as they usually appear when covering the internal organs of the snail. 
Figs. 2-6. The last (third?) generation of the Distoma. Embryos, Larve, Pupe, Distomata.

FIG. 2. The successive forms of the development of the germs into embryos; the Distoma-larve correspond wholly with the forms given in Plate II, figs. 5 . The spiculum on the anterior part of the head is at last distinguishable.

Fig. 3. Distoma-larve or Cercaria. (Cercaria armata, Siebold,) after they have quitted the "murses" and snails and are swimming about in the water; $3 b$ and $3 d$, individuals witl contracted bodies, moving on a flat surface; $3 e$, a lateral view.

Fig. 4. Distoma-pupa. 4a, a portion of the integument of the snail, closely beset with the oval Distoma larve, in the pupa state; slightly magnified. $4 b$, a Distoma larva, on the point of forming its mucoid case. $4 c$, a larva recently become a pupa, the abdomen of which is turned upwards; $\left(\frac{6}{60} r^{\prime \prime}\right.$ long, $x^{3} \sigma^{\prime \prime \prime}$ broad). $4 d$ and $4 e$, rather older pupa ; $4 f$ and $4 g$, pupee, the animals of which are ready to quit the pupa case. The organs marked $s-\ddot{o}$ are the same in all the figures as in fig. $5 ; s$, the orifice of the excretory organ; $t$, the borders of the posterior body surrounding the root of the tail, which form a horse-shoe shaped acetabulum; $u$, the abdominal sucker; $v$, a pore situated between the sucker and the posterior border of the body, which in figs. $4 f$ and $4 g$ appears to be connected with the serpentine organs $x x ; y$, the excretory organ; $a$, the oral orifice; $\ddot{o}$, the cast off frontal spiculum.

Fig. 5. The animals produced from the pupæ, true Distomata, Distoma tarda; 5 a, an individual recently escaped from the pupa; $5 b, 5 c, 5 d$, individuals extracted from the pupæ, for comparison 
with fig. $5 a$; figs. $5 e$, $5 f$, and $5 g$, are full-grown individuals, found in the liver of the fresh-water snail.

Fig. 6. Large "nursing" individuals, in which the Distoma-larve are already become pupæ, and have attained their full development. Fig $6 a$, a "nurse" in which a fully developed Distoma tarda may be seen among a crowd of fully and half developed larvee. Fig. 6 b, a similar " nurse" with four such Distomata, which are placed alternately on the opposite sides.

Figs. $A, B, C$, The Echinorhynchus of the sole, in a young state.

Fig. $A$. An echinorhynchus, inclosed in a thick, membranous cyst. Fig. $B$, the same extracted from the cyst. Fig. $C$, the same with its proboscis protruded. 


\section{N D E X.}

'Alberations of generation,' definition of term, 1; distinction between it and 'Metainorphosis,' 6

Amphistomem clavatum, 99

Aicudonta, animalculæ in, and on, 90

Ancylus lacustris, 95

Aits, feeders amoug, 109

Aphides, mode of generation of, 105

Ascidice, Nilne Edwards on, 47; description of young, 48 ; circulation of blood in, $\$ 7$

Aspidogaster conchicola, 93

Astacus fuviatilis, occurrence of Distomata in muscles of, 95

Baer on Distoma duplicatum, 92

Batiachians Trematoda enter from without, 99

Bees, "feeders" among, 109

Bojanus, yellow cylindrical worms of, 62

Bothriocephalus, nature of, 103

Botiyllus, 4S, 50, 51

Bucephalus polymorphus of Baer, probably only a nursing animal, 96

Campanularia, Lovèn on, 32

Campanularia geniculata, description and derelopment of, 32 ; "nurses" of, 36

Cercaire, description of pupa state of, 57 ; dereloped from "King's yellow worms" of Bojanns, 62; description of development, 6t; mode of exit from "nurses," 65; frequency in auricle of snail, 66; origin of unses of, 69; "Nests," 65; "Parent nurses" of, 69

Cercaila echinata, description of, 53; armata, description and development of, 74; pupa state of, 77; Distoma which originates in, 80 ; ephemera, "nurses" of, described only by Siebold, S7-SS; Mitzsch's observations on pupa state of, 88 ; Distomata developed from, ib.
Cestoid entozoa, Miescher's memoir on, 102

Cestoid worms, resemblance to vegetables, 104

Chamisso, 1819, on the alternate generation of Salpe, 40

"Chaotic swarm" of Baer, 90

Claviform Polypes, 26

Colpodium, 90

Coralline Polypes, 37

Corymorpha mutans, 27, 30

Coryne, 26; Ehrenberg on, 27; fritillaria, description and development of, 27; aculeata, 30 ; vulgaris, 31

Cyancea capillata, 25

Cystic entozoa, a nursing generation, 100

Diplostomum clavatum, 95; volvens, ib.

\section{Distoma, 59}

Distoma hepaticum, 52 ; duplicutum, 87; larva of Aspidoguster conchicola, certainly a larval form, 93; "Parent nurse" of, ib.; "Nurses" of, ib.; cirrigerum, 95 ; annuligerum, 99

Distomata developed from $\mathrm{Cer}$. ephem., 88

Echinorynchi, "loose ovaries" of, their probable nature, 101; mode in which they penctrate into the animals infested by them, ib.

Ehrenberg on Coryne, 27

Ephyra, 19-20

Eschricht, examination of his theory of the development of Salpe, 40,42; Observations on the Echinorynchi of Haddock, 101 ; on Bothriocephalus, 103; anatomical researches on the Salpœ, 112

Germ-sacs of Siebold, the "nurses" of, Cer. ephem., 89.

Holostomum cuticola, 9S; brevicaudatum, ib.

Hydatid cysts, containing Distonata, 98 . 
King's yellow worms, the nurses of Cercarice, 62.

Leucochloridium paradoxum, 95.

Limnceus stagnalis, 53-59, 60 .

Lovèn on Syncoryne ramosa, 30; on Campanularice, 32.

Lucernarice, Ehrenberg on the, 19.

Medusce, general description of, 11; propagation of, 12; "nurses" of, 24-26;M. aurita, development of, 13 ; description of young of, 14; Strobila developed into, 19 ; history of researches on, ib. ; relation of periods of development to season, $25 ; M$. papillata, Abilgaard on, 31 .

Meyen on Salpe, 40.

Miescher, memoir on cestoid entozoa, 102.

Milne Edwards on Ascidice, 47.

Monostomum, 61 ; M. mutabile, description of young of, 71 .

Mï̈ller, C.F., on Coryne, 30.

Nematoidea, 100.

Nitzch on the pupa state of Cercaria, 57.

Nordman on Trematoda in the eyes of animals, 96.

"Nurses" of Medusa, 24-26; of Salpa" 46; of Campanularia, 36 ; of Cercarice, 88 .

"Nurses" and "feeders" of insects, distinction between, 111; both always fcmales, ib.

Opalina ranam of Ehrenberg, 96 .

Paludina vivipara, 62 ; occurrence of pupæ in auricle of, 88 .

Parancecium, 90.

"Parent-nurses" of Cercarice, 69; of Distoma duplicatum, 93.

Planorbis cornea, 53.
Plumularix, 37.

Polypes, claviform, 26 ; coralline, 37.

Pupa state of Cercar. ephemera, 88; of Cercar. armata, 77.

Psorospermata of Müller, 97.

Pyrosoma, 47.

Sacculi in which Cercaria occur, 81; are in fact the "nurses," 84 .

Salpa, alternate generation of, 38-39; description of, 38 ; associated and solitary, 39; Meyen on, 40; Chamisso on the alternate generation of, 40 ; examination of Eschricht's theory of the development of, 40-42; Eschricht's anatomical researches on, $112 ; S$. zonaria, $39-40$; S. pinnuta, Chamisso on, 41 ; $S$. cordiformis, 40-41.

Sars, M., on Corymorpha nutans, 30; on Scyphistoma-strobila, 21 ; description of the young of Ascidia, 48; on the development of Salpœ, 46 .

Scyphistoma-strobila, description of, 19 , $20,21$.

Siebold on pupa state of Cercar. 58; period of year at which the animals quit the pupæ, 59; on development of Distomata within saccular "nurses," 85.

Spharularia, probably a "nurse," 100.

Succinea amphibia, occurrence of, Leuco: parado $x$ in tactile, horns of, 95 .

Syncoryne Sarsii, 27, 31; S. ramosa, Lovèn on, 30-31.

Termites, division of labour among, 110.

Tetrarynchus, 102.

Trematoda, development of, 52 .

Trematode animals, development of, 94.

Tubularia, 37.

Wasps, feeders among, 109. 



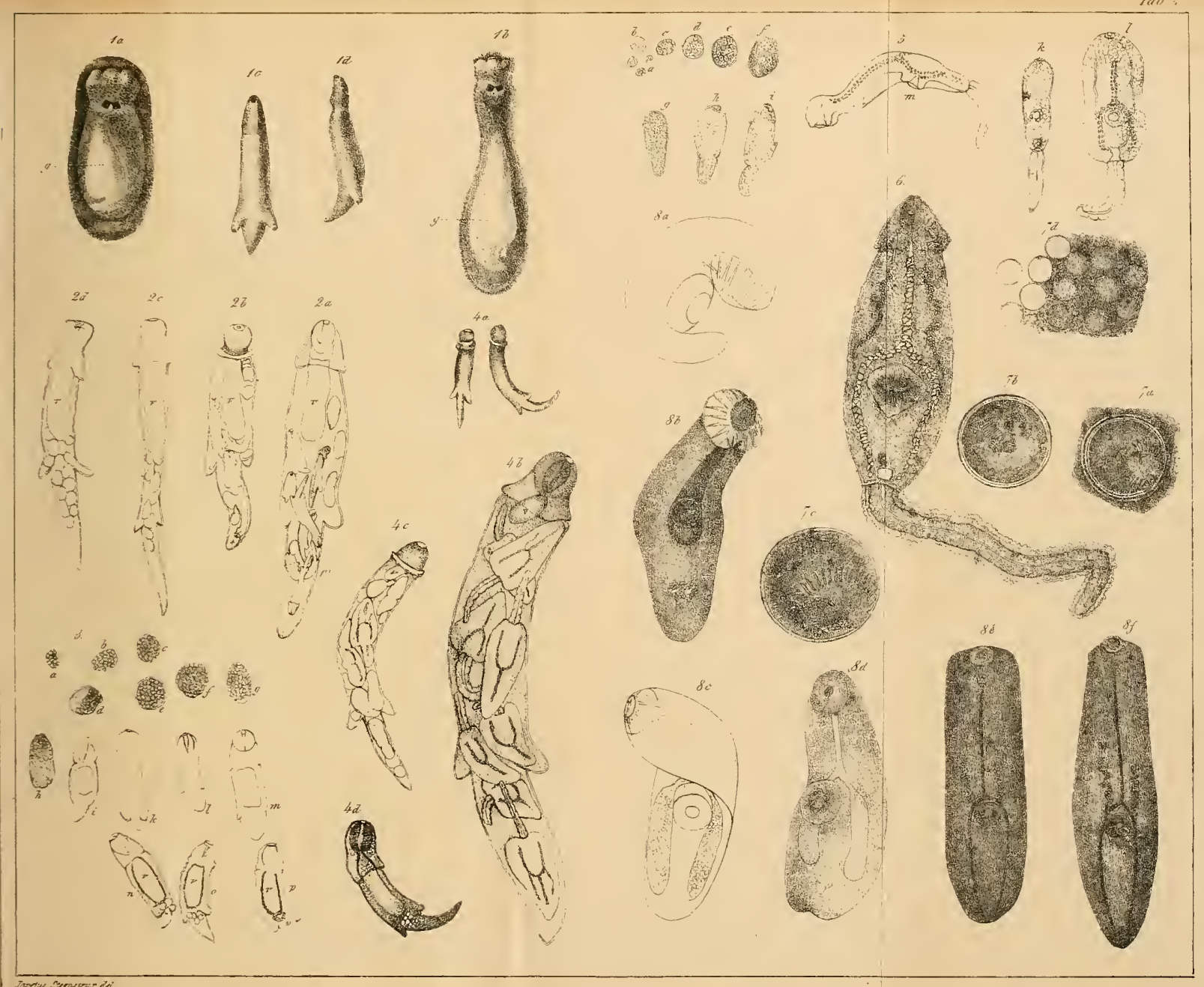

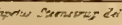






\section{REPOR'T}

OF THE

\section{SECOND ANNUAL MEETING}

\section{oF \\ THE RAY SOCIETY,}

Held at Cambridge, June 23, 1845.

PROFESSOR JOHN PHILLIPS, F.R.S.

IN THE CHAIR.

WITH

THE LAWS OF THE SOCIETY, LIST OF OFFICERS, MEMBERS, \&c. \&c.

\section{LONDON :}

C. AND J. ADLARD, BARTHOLOMEW CLOSEv 


\title{
OFFICERS OF THE RAY SOCIETY.
}

\author{
放resiturnt. \\ Professor Bell, F.R.S. \\ Councill.
}

Professor D. T. Ansted, M.A. F.R.S.

Chas. C. Babington, Esq. M.A. F.L.S.

Professor Balfour, M.D. F.L.S.

Robert Balu, Esq. M.R.I.A. Sec. R.Z.S.I.

Rev. M. J. Berk elex, M.A. F.L.S.

George Busk, Esq. F.R.C.S.

J. Dalrymple, Esq. F.R.C.S.

C. Daubeny, M.D. F.R.S.

Sir P. G. Egerton, Bart., M.P. F.R.S.

Professor Edward Forbes, F.R.S. L.S.

Robert K. Greville, LL.D. F.R.S.E. H.M.C.P.S.

Sir W. J ARDine, Bart. F.R.S.E. L.S.

Rev. Leonard Jeny ns, M.A. F.L.S.

Professor Owen, F.R.S.

Professor John Phillips, F.R.S.

Professor F. Royle, M.D. F.R.S. L.S.

Prideaux J. Selby, Esq.

Hugh E. Strickland, Esq. M.A. F.g.S.

Wr. Thompson, Esq., Pres. Nat. Hist. Soc. Belfast.

N. B. WARD, Esq. F.L.S.

\section{Treasurer.}

J. S. Bowerbank, Esq. F.R.S. F.L.S., 45, Park Street, Islington, London.

\section{Eecretaries.}

G. Johnston, M.D., Berwick upon Tweed.

E. Lankester, M.D. F.R.S. F.L.S., 22, Old Burlington Street, London. 


\section{REPORT OF THE RAY SOCIETY.}

IN presenting a Report for the present year, your Council feel it incumbent on them to explain the cause of the delay which has taken place in the publication of the volumes due for the first year's subscription. When they presented their Report last year there was every prospect of a speedy issue of the first volume, but on account of the increase of members rendering it necessary to reprint a large portion of the work after it had gone to press, and the nature of the Reports on various branches of Natural History requiring that the proof sleets should pass through many hands for correction, the issue has been unavoidably delayed, and they feel that, but for the exertions of many members of the Society, to whom the sheets were sent for correction, it would have been impossible to have presented that volume at the present time.

The Council feel great pleasure in accompanying the presentation of the volume above alluded to with the first part of the great work on the British Nudibranchiate Mollusca. The very great value and importance of this work, recognized as they have been by all British Zoologists since its announcement, have justified the Council in sparing neither paius nor expense in producing it in a form not unworthy of its intrinsic merits. They feel assured that the new process of lithotinting which has been employed on this occasion, and which affords almost facsimile imitations of the original drawings, will satisfactorily show to what extent that process may be employed in the illustration of subjects in Natural History. The superintendence of the publication of this work has been committed to a subcommittee, consisting of Dr. Jonnston, Professor Edwand Fonbes, and Mr. WM. Thomison.

It was fully expected that a volume, consisting of ' Memorials of Ray,' would have been ready for distribution, with the works now before the Society; and notwithstanding some unexpected delay, the Council have to announce that this work, edited by Dr. Lankester, will be presented very shortly to the Members as part of the first year's publications.

The Council have the satisfaction of stating that the following works are either completed or in a forward state for publication, viz.: 
1. Burmeister, On the Organization of Trilobites; edited by Professors BeLl and E. Forbes.

2. Zuccarini, On the Morphology of the Coniferæ.

3. GAND, On the Geographical Distribution of the same.

4. Grisebach's Report on Botanical Geography.

5. Steenstrup, On the Alternations of Generation, translated by George Busk, Esq.

6. Part II, of the British Nudibranchiate Mollusca of ALder and Hancock.

The Council have also to announce that arrangements are now pending with Professor Agassiz, of Neufchatel, for the publication of his great work of a complete Bibliograply of Zoology and Palæontology.

The following works are either preparing for publication or under consideration:

1. Iconographia Linnæana, to consist of illustrations of the specimens in the Linnæan collection, at present existing in the Museum of the Linnæan Society ; to be edited by Professors BeLL and E. Forbes.

2. Continuation of Reports on the Progress of Zoology and Botany.

3. Translation of Azara's Natural History of Paraguay.

It is satisfactory to the Council to be able to state that the list of Members is at present nearly 700 , and that daily accessions are being marle to the number.

The Council cannot conclude this Report without recording their great obligations to the Council of the Geological Society of London, for granting them the use of their room for the purpose of conducting their business.

Dr. Abstract of Treasurer's Account, $1845 . \quad C r$.

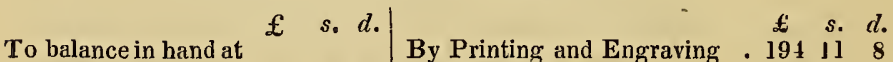

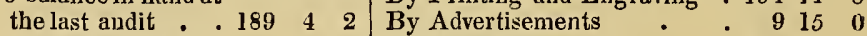

To Subscriptions re- $\quad$ By Translations • . . 2276

ceived to June 8 th,

1845..$\quad 314 \quad 18 \quad 9$

By Salary to Clerk, 1 qr. $\quad \begin{array}{rrr}6 & 5 & 0\end{array}$

$\begin{array}{llll}314 & 18 & 9 & \text { By petty expenses, books, sta- }\end{array}$

tionery, \&c. $\quad . \quad \cdot \quad \cdot 17 \quad 3 \quad 11$

To Balance in Treasurer's

$\lcm{£ 250331}$

bands

$\frac{2531910}{£ 504 \quad 211}$

The above accounts, extending from Sept. 28th, 1844, to June 15th, 1845, bave been examined by us, and compared with the vonchers, and found to be correct.

Signed, W. SPENCE.

Fred. S. Farre. 
Moved by W. Spence, Esq. ; seconded by W. Yarrell, Esq.

That the Report now read be adopted and printed for circulation among the Members.

Moved by Professor Clarke ; seconded by Horton Lloy , Esq.

That the thanks of this Meeting be given to the Members of the Council for the past year, and that the following gentlemen be requested to act as Council for the ensuing year.

D. T. ANSTED, ESQ.

CHARLES C. BABINGTON, ESQ.

J. H. BALFOUR, MI.D.

ROBERT BALL, ESQ.

THONAS BELL, ESQ.

REV. M. J. BERKELEY.

GEORGE BUSK, ESQ.

J. DALRYMPLE, ESQ.

C. DAUBENY, M.D.

SIR P. G. EGERTON, BART.

EDWARD FORBES, ESQ.
R. K. GREVILLE, ESQ.

SIR W. JARDINE, BART.

REV. L. JENYNS.

RICHARD OWEN, ESQ.

JOHN PHILLIPS, ESQ

F. ROYLE, II D.

PRIDEAUX J. SELBY, ESQ.

HUGH E. STRICKLAND, ESQ.

W. THOMPSON, ESQ.

N. B. WARD, ESQ.

Moved by Sir Henry De la Beche; seconded by Dr. Falconer,

That the thanks of this Meeting be given to Professor BELL, President, to Mr. Bowerbank, Treasurer, and to Dr. Johnston and Dr. Lankester, Secretaries, and to the Local Secretaries, for their services.

Moved by ['rofessor Allman; seconded by S. Hailstone, Esq.

That the thanks of this Meeting be given to H. E. STRickLAND, Esq. to W. Macdonald, Esq., and to Dr. Lankester, for their assistance in translating the volume of Reports on the Progress of Zoology and Botany, and to Dr Johnston, Professor E. Forbes, and W. Thompson, Esq. for their aid in bringing out the work of Messrs. AldEr and HANcock, on the Nudibranchiate Mollusca. 
HONORARY LOCAL SECRETARIES.

\begin{tabular}{|c|c|c|c|c|}
\hline Aberdeen & & & & Dr. Dickie. \\
\hline Bath & $\because$ & $\cdots$ & $\cdots$ & R. F. George, Esq. \\
\hline Beccles & . & $\cdots$ & $\cdots$ & H. Davey, Esq. \\
\hline Beverley & .. & . & . & Dr. Beverley Morris. \\
\hline Birmingham & . & . & . & Dr. Percy. \\
\hline Bristol & & . & . & Dr. W. Budd. \\
\hline Bury St. Edm & nds & . & . & Dr. Ranking. \\
\hline Chelmsford & $\cdots$ & . & . & G. Meggy, Esq. \\
\hline Cheltenham & $\cdots$ & . & $\cdots$ & W. Cary, Esq. \\
\hline Cork & $\cdots$ & $\cdots$ & . & Dr. Harvey. \\
\hline Derby $\quad$. & $\cdots$ & $\cdots$ & . & R. J. Bell, Esq. \\
\hline Edinburgh & . & $\cdots$ & . & Dr. Douglas Maclaga \\
\hline ester & $\cdots$ & . & - & J. M. Hiteh, Esq. \\
\hline $\begin{array}{l}\text { Godalıning } \\
\text { Halifax }\end{array}$ & $\because$ & $\cdots$ & & J. D. Salmon, Esq. \\
\hline ld $\cdots$ & $\begin{array}{l}\cdots \\
\cdots\end{array}$ & $\because$ & $\because$ & $\begin{array}{l}\text { Dr. Inglis. } \\
\text { Llovd Thomas, Es }\end{array}$ \\
\hline $\begin{array}{l}\text { Hatfield } \\
\text { Hereford }\end{array}$ & $\begin{array}{l}\cdots \\
\cdots\end{array}$ & $\ddot{m}$ & $\ddot{\cdots}$ & $\begin{array}{l}\text { Lloyd Thomas, Esq. } \\
\text { T.Tucker Price, Esq. }\end{array}$ \\
\hline Hertford & $\cdots$ & $\cdots$ & . & Dr. Reed. \\
\hline Hull & . & . & .. & G. Norman, Esq. \\
\hline Lancaster & - & . & . & S. Simpson, Esq. \\
\hline Leeds & . & . & . & T. P. Teale, Esq. \\
\hline Leicester & . & . & . & J. Harley, Esq. \\
\hline Liverpool & & $\cdots$ & . & Dr. Dickenson. \\
\hline Lydd, Romney & Marsh & $\cdots$ & $\cdots$ & Dr. Plomley, \\
\hline Lynn . . & $\cdots$ & $\cdots$ & $\cdots$ & Geo. Sayle, Esq. \\
\hline Manchester & $\ddot{x}$ & $\cdots$ & $\cdots$ & Peter Barrow, Esq. \\
\hline $\begin{array}{l}\text { New } \\
\text { Nors }\end{array}$ & yne & $\cdots$ & $\cdots$ & J. Thornhill, Esq. \\
\hline $\begin{array}{l}\text { Nor } \\
\text { Not }\end{array}$ & • & $\cdots$ & $\cdot$ & 1. Blightwell, Esq. \\
\hline $\begin{array}{l}\text { Nott } \\
\text { Plym }\end{array}$ & $\begin{array}{l}\cdots \\
\cdots\end{array}$ & $\cdots$ & . & $\begin{array}{l}\text { Booth Eadison, Esq. } \\
\text { Rev. J. Hore. }\end{array}$ \\
\hline ngth & $\cdots$ & $\because$ & & S. Lovejoy, Esq. \\
\hline $\begin{array}{l}\text { Reading .. } \\
\text { Reigate .. }\end{array}$ & .. & • & . & W. Hansom, Esq. \\
\hline Ryde, Isle of I & ight & .. & . & Dr. Bell Salter. \\
\hline Scarborough & . & . & $\cdots$ & Dr. Murray. \\
\hline Shrewsbury & $\cdots$ & . & . & Rev. W. A. Leighton. \\
\hline Sidn & & . & . & Dr. Cullen. \\
\hline Stowmarket & & . & . & R. C. Bree, Esq. \\
\hline Tenby, South & Vales & . & . & Dr. Falconer. \\
\hline Torquay & 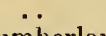 & $\ddot{q}$ & $\cdots$ & Dr. Battersbey. \\
\hline $\begin{array}{l}\text { Whitehaven, } \\
\text { Winchester }\end{array}$ & umber & & $\cdots$ & Wm, Dickinson, Esq. \\
\hline $\begin{array}{l}\text { Winchester } \\
\text { Witham }\end{array}$ & • & $\cdot$ & - & Dr. A. D. White. \\
\hline Worcester & . & • & . & Dr. Streeten. \\
\hline York & $\cdots$ & . & . & W. H. Tuke, Esq \\
\hline
\end{tabular}

THE FOLLOWING MEMBERS OF THE COUNCIL.

\begin{tabular}{|c|c|c|c|c|}
\hline Belfast & & & . & W. Thompson, Esq. \\
\hline Cambridge & $\cdots$ & . & $\cdots$ & Charles C. Babington, Esi. \\
\hline Dublin & . & .. & $\ldots$ & Robert Ball, Esq. \\
\hline Glasgow & .. & .. & .. & Dr. J. H. Balfour. \\
\hline Greenwich & .. & .. & & George Busk, Esq. \\
\hline King's Cliffe & .. & . & & Rev. M. J. Berkeley. \\
\hline ()x ford & . & .. & . & Dr. Daubeny. \\
\hline
\end{tabular}




\section{THE LAWS OF THE RAY SOCIETY.}

1. That this Society shall be called The RAY Societr; and that its object shall be the promotion of Natural History, by the printing, of original works in Zoology and Botany; of new editions of works of established merit ; of rare Tracts and MSS.; and of translations and reprints of Foreign works which are generally inaccessible from the language in whicb they are written, or from the manuer in which they have heen published.

N.B.-It will be a direction to the Council that they sball not print anything that appears to them suitable to the Transactions of established Societies; nor any work which a respectable publisher shall undertake to publish without charge to the author.

II. Every subscriber of One Guinea annually to be considered a Member of the Society, and to be entitled to one copy of every book published by the Society during the year to which his subscription relates; and no Member shall incur any liability beyond the annual subscription.

III. That the annual subscriptions shall be paid in advance, and considered to be due on the $2 d$ day of February in each year; and that such Members as do not signify their intention to withdraw from the Society before the $2 \mathrm{~d}$ day of June, shall be considered to continue Members, and be liable for the year's subscription.

IV. The management of the Society shall be vested in a Council of Twenty-one Members, of whom one third shall have their stated residences in London, and all of whom shall be eligible for re-election at the annual meeting.

V. That the Council bereafter shall be elected by the Members, at a meeting to be held at the time and place of the meeting of the British Association for the Advancement of Science, and that no Member whose subscription is in arrear be allowed to vote at any meetings.

VI. That the Council shall elect two Secretaries (one of whom shall be resident in London) and a Treasurer, who shall ex officio be Members of the Council.

VIl. The annual subscription shall be deposited in a chartered bank, in the name of the Treasurer and two Members of the Council.

VIII. The accounts of the receipt and expenditure of the Society shall be examined annually by two Auditors appointed by the Council; the Auditors to be Members of the Society, who are not Members of Council, and their statement circulated among the Subscribers.

IX. That the number of copies of the Society's publications shall, unless otherwise directed by the Council, be limited to the number of actual Subscribers who shall have been enrolled, and paid their subscriptions, on or before the $2 \mathrm{~d}$ day of June.

$\mathrm{X}$. That the Editors of Works published by the Society be entitled to a number of copies, not exceeding 20 , as may be decided by the Council. 


\section{REGULATIONS FOR THE DELIVERY OF BOOKS.}

They are delivered, free of expense, within three miles of the General Post Office, London.

They are sent to any place in England, beyond the distance of three miles from the General Post Office, by any conveyance a Member may point out. In this case the parcels are booked at the expense of the Society, but the carriage must be paid by the Member to whom they are sent.

They are delivered, free of expense, at any place in London which a Member, resident in the country, may name.

They are sent to any of the Hon. Local Secretaries of the Society, each Member being expected to pay the Local Secretary a due share of the carriage of the parcel in which the books are sent.

Any number of country members may unite, to have their books sent in one parcel, to any address they may name. In this case they are requested to depute one of their number to transmit to the Secretary for London a list of the names of those whose books are to be included in the same parcel.

Those Members who wish their books to be included in any of the parcels to Local Secretaries, are requested to send in their names (with their Christian name in full) and particular address to the various Local Secretaries, who are respectfully requested to forward to the Secretary for London an accurate list of all such names with as little delay as possible.

Unless intimation to the contrary be given to the Secretary for London, the future deliveries will be made in accordance with the delivery of the first volume. 


\section{LIST OF SUBSCRIBERS.}

Academy, Royal Irish

Adam, Thomas, esq. Saville green, Halifax

Adlard, C. and J. Bartholomew close

Ainslie, W. esq. Woodhill, by Ripley, Surrey

Alder, Joshua, esq. Newcastle-on-Tyue

Aldridge, James, m.D. Cheltenham

Alford, $\mathbf{H}$. esq. Taunton

Alison, W.P. Professor, M.D. Edinburgh

Allanson, J. esq. Infirmary, Leeds

Allardyce, Dr. Cheltenham

Alleard, John, esq. F.L.s. \&c. Stratford green, Essex

Allchin, W. H., esq. м.в. University College

Allis, Thomas H., esq. York

Allman, Professor, Dublin

Amicable Book Society, Lancaster

Ansted, D. T. esq. M.A. F.r.s. Professor of Geology, King's College

Anthony, John, esq. Caius College, Cambridge

Archer, F. esq. Liverpool

Ashmolean Museum, Oxford

Atkinson, Rev. J. C. B.A. 7, Victoria place, Scarborough

Austin, R. A. C. esq. sec. G.s. \&c. Merrow, Guildford, Surrey

Babington, C. C. esq. M.A. F.L.s G.S. \&c. St. John's College, Cam.

Babington, C. esq. B.A. St. John's College, Cambridge

Backhouse, W. J. esq. Darlington

Backhouse, T. J. esq. Sunderland

Bailey, - esq. Museum of Economic Geology

Baird, Rev. John, Yetholm, Roxburgshire

Baird, W. M.D. British Museum

Baker, Rohert, esq. Writtle, Essex

Balfour, Professor, M.D.F.L s. Edinburgh

Ball, John, esq. B.A. M.r.I.A. \&c. 85 , Stephen's green, Dublin

Ball, Robert, esq. M.R.I.A. 3, Granby row, Dublin

Balloch, Robert, esq. 177, West Regent street, Glasgow

Banks, Dr. Dublin

Barf, A. esq. 7, Paradise place, Hackney

Barnes, Rev. H. F. Ryde, Isle of Wight

Barker, T. esq. Surgeon, York

Barrow, Peter, esq. 7, C'lifford street, Manchester

Bartlett, J. P. esy. Kingston Rectory, near Canterbury 
Bates, H. Walter, esq. Leicester

Battersby, Dr. Torquay

Baxter, W. esq. Botanic garden, Oxford

Bayton, Rev. W. S. Chichester, Sussex

Beadon, W. jun. esq. Taunton

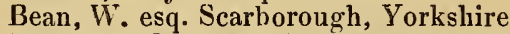

Bearpark, G. E. esq. 74, East street, Leeds

Beatty, Professor, T, E. M.D. M.R.I.A. Merrion square, Dublin

Belfast Library, Natural History Society

Bell, J. T. esq. 10, Northwick terrace

Bell, Matthew, esq. M.P. F.H.S. \&c. Grosvenor crescent, Belgrave sq.

Bell, Professor, F.r.s. L.s. G.s. \&c. New Broad street, City

Bell, Robert, J. esq. Mickleover House, near Derby

Bell, Miss, East Sliafto, by Morpeth, Northumberland

Bennett, James Risdon, M.D. 24, Finsluury place

Bennett, J. I. esq. F.R.s. F.z.s. SEc. L.s. \&c. British Museum

Benson, John, esq.

Bentley, S. esq. Birmingham

Bergin, T. esq. M.R.I.A.President of the Microscopical Society, Dublin

Berkeley, Rev. M. J. M.A. F.L.s. \&c. King's Cliffe, Wansford

Bidwell, H. esq. Wellington, Salop

Bird, George, esq. Tollerton, near Alne Station, Yorkshire

Birkbeck, H. esq. Keswick, near Norwich

Birkbeck, Morris, esq. Bradford, Yorkshire

Birmingham Library

Blackie, W. G. esq. Villa-field Printing Office, Glasgow

Blackwall, John, esq. Oakland, near Llanrwst, Denbiglıshire

Bladon, James, esq. Pontypool

Blood, J. Howell, esq. White Hall, Witham, Essex

Blount, J. H. esq. Birmingham Dispensary

Boase, -, esq. Truro, Cornwall

Bodenham, F. S. esq. Hereford

Bodley, T. esq. F.G.s. Pittville, Cheltenham

Bompas, Charles S. esq. Bristol

Bold, T. J. esq. 24, Cloth Market, Newcastle-on-Tyne

Bonar, Miss, Kimmerghame, or 11, Chester place, Regent's park

Boniville, A. C. de, esq. Corpus Christi College, Cambridge

Borrer, W. esq. F.r.s. u s. \&c. Henfield, Sussex

Botfield, J. B. esq. M.P. F.R.s. L.s. \&c. 9, Stratton street

Bowerbank, E. S. esq. Sun street, Bishopsgate

Bowerbank, J. S. esq. F.R.s. G.s. \&c. 45, Park street, Islington

Bowman, William, esq. Golden square

Bowman, James, esq. Halifax

Boyd, J. C. esq. Liseard, Cheshire

Brackenridge, G. W. esq. F.s.A. G.s. \&c. Bromwell House, Brislington, Bristol

Bramley, L. esq. Halifax, Yorkshire

Bransby, Rev. John, M.A. F.L.s. C.P.s. \&c. Lynn, Norfolk

Branton, John, esq. Bush Hall, near Hatfield

Bree, Robert Charles, esq. Stowmarket, Suffolk

Brightwell, T. esq. F.L.s. Norwich

Brishanc, sir T. M. Bart. K.c.B. K.C.H. D.c.L. P.R.S.E. \&c. Macker'stown, near Kelso 
Bristol Microscopical Society

Broderick, W. esq. Belford

Brodhurst, B. esq. London Hospital

Bromfield, W. A. M.D. Ryde, Isle of Wight

Broome, C. E. esq. l, Cliesterfield place, Clifton, Bristol

Broughton, Rev. D. The Cliff, Nantwich

Brown, C. F. esq. Harrowgate

Brown, Edwin, esq. Burton-on-Trent

Brown, Robert, D.c.L. F.R.s. v.P.L.S, \&c. British Museum

Brown, R. esq. M.R.c.s. Preston, Lancashice

Brown, Isaac, esq. Hitchin, Herts

Browne, W. M. esq. Westminster Fire Office, King st. Covent garden

Brydges, J. H. esq. F.L.s. \&c. Boultibrooke, Presteigu, Raduorshire

Buchanan, Walter, esq. Suffolk place, Hyde park gardens

Buckley, Nathaniel, m.D. Rochdale

Buckman, J. esq. Medical Hall, Cheltenham

Buckton, G. B. esq. Oakfield Lodge, Hornsey, Middlesex

Budd, Geo. Dr. Dover street, Piccadilly

Budd, William, M.D. Bristol

Budd, - M.D. Plymouth

Bull, J. esq. Godalming

Burlington, Lord, 10, Belgrave square

Burton, John, esq. Croom's hill, Greenwich

Busk, George, esq. Dreadnought Hospital, Greenwich

Butler, William, esq. Witham, Essex

Byerley, J. esq. Upper Woodside, Cheshire

Callwell, Robert, esq.M.R.I.A. Herbert place, Dublin

Canino, The Prince of

Carr, William, esq, Hurst cottage, Blackheath park, Kent

Carr, W. esq. M.R.c.s. Lee

Carpenter, W.B. M.D. F.R.s. Fullerian Prof. Royal Inst.

Cary, Walter, esq. Chelt hilI, Cheltenham

Carter, J. esq. Petty Cury, Cambridge

Catlett, - M.D. Taunton

Chadivick, C. M.D. Leeds

Chambers, R. esq. Edinburgh

Chandler, A. T. esq. Godalming:

Chandler, Mrs. Bramley, near Guildford

Children, J. G. esq. F.R.s s.A. L.S. \&c. Torrington square

Christie, Dr. John, Keith, Banffshire

Church, John, esq Woodside place, near Hatfield, Herts

Clapp, William, esq. Dreadnought Hospital, Greenwich

Clark, Rev. J. D. the Hall, Belford

Clark, H. esq. Corpus Christi College, Cambridge

Clark, Rev. Professor, M.D. Professor of A natomy, Cambridge

Clarke, Rev. Benjamin, J. Tuam, Ireland

Clarke, W. B. M.D. 26, Dockwray square, North Shields

Clarke, H. G. M.D. Berwick-upon-Tweed

Clay, Mrs. P. Newwater Haugh, Berwick-upon-Tweed

Clear, William, esq. Cork

Cleaver, Mrs. H. Sissinghurst

Clifford, Rev. F. C. Elden Rectory, near Thetford, Suffolk 
Clifton, A. C. esq. Welwyn, Herts

Clifton, James, esq. Stoneport, Worcestershire

Coates, John, esq. surgeon, Rochdale

Collingwood, F. J. W. esq. Glanton Pyke, Whittingham, Northumb.

Colquhoun, Dr. Glasgow

Conyngham, Lord Albert, к.C.H.F.S A. \&c. Bourne place, Canterbury

Conway, P. L. esq. Burton-under-Needwood, Litchfield

Cooper, W. W. esq. St. John's College, Cambridge

Cooke, James, esq. Lanesend Cottage, Melksham, Wiltshire

Cooke, W. R. esq. Burford, Oxon.

Copeman, G. esq. Coltishall, near Norwich

Cornwall Library, Truro

Corsellis, C. C. M D. Asylum, Wakefield

Cottingham, E. esq. surgeon, Bexley, Kent

Cotton, John, esq. Doogulloch Station, River Goulbourn, Port Phillip, Australia

Crampton, Sir Philip, Dublin

Cresswell, Rev. R. Salcombe Vicarage, Sidmouth

Croker, Dr. C. P. M.n.I.A. Merrion square, Dublin

Crosse, J. G. esq. Norwich

Crotch, Rev. - , Taunton

Cruickshank, Alexander, esq. 12, Rose street, Aberdeen.

Cullen, W. H. r..D. Sidmouth

Cumming, H. esq. 80, Gower street

Cuthbertson, Donald, esq. L.L.B. 10, Fife place, Glasgow

Currer, Miss, Eshton Hall, Yorkshire

Currie, Robert, esq. Newcastle-on-Tyne

Curtis, - esq. Harrow

Cutler, Miss, Budleigh Salterton, Devonshire

Dale, J. C. esq. M.A. F.I.s. c.P.s. \&c. Glanville's Wooton, Sherborne

Dalyell, Sir J. Graham, bart. Hanover street, Edinburgli

Dalrymple, John, esq. 56, Grosvenor street, Bond street

Dalrymple, D. esq. Norwich

Dallachay, Mr. John, Haddow-house, Aberdeen

Darwin, C. esq. Down, Kent

Daubeny, Professor, M.D. F.R.s. a. s. \&c. Oxford

Davies, Mrs. St. Leonard's place, York

Davies, W. M. esq. Liverpool

Davey, H. esq. Beccles, Suffolk

Davis, Robert, esq. York

Dawes, J. S. esq. F.G.S. West Bromwich, Staffordshire

Day, Dr. 3, Southwick street

Deane, Henry, esq. Clapham common

De la Beche, Sir H. F.n.s. G.s. \&c. Craig's court

Dennes, G. E. esq. F.L.s. \&c. Vine street, Golden square

Denny, H. esq. Leeds

Devon and Cornwall Natural History Society

Dickinson, Joseph, M.D. 24, Great George square, Liverpool

Dickenson, William, esq. North Mosses, Whitehaven, Cumberland.

Dickie, George, M.D. Lecturer on Botany, Aberdeen

Dickson, Dr. Curzon street, May Fair

Dillwyn, L. L. esq. Parkwern, Swansea 
Dilke, C. Wentworth, esq. 76, Sloane street

Doubleday, Edward, esq. F.L.s. \&c. British Museum

Douglas, F. M.D. Kelso

Douglas, R. C. esq. Corpus Christi College, Cambridge

Dover Proprietary Library

Dowell, E. W. esq. Swaffham, Norfolk

Dublin, Royal Society

Duncan, P. esq. M.A. F.G.s. \&c. Museum, Oxford

Dundas, Mrs. Beechwood, Murrayfield, Edinburgh

Dunnett, James, esq. Bury St. Edmunds

Ducane, Captain n.N. Branted park, near Witham

Dyce, Dr. 198, Union street, Aberdeen

Eddison, Booth, esq. 14, High pavement, Nottingham

Edgeworth, - M. P. esq 1, North Audley street

Edlin, Dr. Ed. Umbala, India

Edwards, F. C. esq.2, John street, Downshire Hill, Hampstead

Edwards, Thomas, esq.

Egerton, Sir P. G. Bart m P. F.R.s. G.s. \&c. Oulton park, Cheshire

Elliott, John, esq. Kingsbridge

Ellison, K. esq. surgeon, Liverpool

Elsey, J. R. esq. Bank of England

Elwes, John, esq. Bossington house, Stockbridge, Hants

Embleton, Robert, esq. Embleton, near Alnwick

Einbleton, Dr. Newcastle

Enniskillen, The Earl of, D.c.L. F.R.s. G.s. \&c. Florence court, Enniskillen

Evans, Mrs. Shenley hill, Herts, \& 72, Oxford terrace, Edgeware rd.

Ewing, Rev. Thomas

Eyton, 'T. C. esq. F.g.s. z.s. \&c. Eyton Hall, Shrewsbury

Falconer, Dr. W. Tenby, South Wales

Falconer, Dr. H. F.G.s. '23, Norfolk street, Strand

Farre, Dr, Frederic, Bridge street, Blackfriars

Farren, Charles, m.D. Dublin

Fellows, Sir C. 30, Russell square

Fennell, James $H$. esq. 15, Paris street, New road, Lambeth

Ferguson, Wm. esq. 18, Wharton street, Lloyd square

Fielding, Geo M.D. F.R.s. \&c.

Fielding, G. H. esq. Lenham lodge, Kent

Finsbury Medical Book Society, 2, St. Mary Axe

Fitton, E. B. esq. 53, Upper Harley street

Fitton, William H. M.D. F.R.s. \&c. 53, Upper Harley street

Fitton, W. J. esq. B A. Trinity College, Cambridge

Fitzivilliam, Earl

Fleming, Dr. Manchester

Eletcher, Rev. C. Southwell, Nottingham

Fletcher, Bell, M.D. Birmingham

Flower, J. W. esq. 6I, Bread street, City

Forbes, Professor Edward, F.R.s. \&c. King's College, Loudon

Forlbes, J. M.n. F.R.S. F.L.S. \&c. Old Burlington street

Forster, Edward, Esq. F.R.s. v. P.L.S. \&c. Mansion House street

Fox, Rev, Dartin, Delamerc Rectory, Chester 
Fox, George T. esq. F.r.s. G.s. \&c. Durham

Frampton, Dr. A. New Broad street, City

Freeborn, J. J. S. esq. 38, Broad street, Oxford

Frere, H. T. esq. Corpus Christi College, Cambridge

Fry, J. S. esq. 2, Charlotte street, Park street, Bristol

Fryer, J. H. esq. Whitley House, Northumberland

Fuge, J. H. esq. F.R.c.s.E. Plymouth

Fyfe, W. W. esq. Berwick-on-Tweed

Fysh, Rev. Frederick, Marina house, Torquay

Gall, A. C. esq. Ripley, Surrey

Gandy, J. H. esq. Trinity College, Cambridge

Gardner, Samuel J. esq. Sheffield

Garnons, Rev. L. P. B.D Sidney College, Cambridge

George, Richard F. esq. Gay street, Bath

Giles, James, esq. The Elms, Lancaster

Gilsson, G.S. esq. Saffron Walden, Essex

Gillett, W. E, esq. Freshwater House, near Taunton

Glasgow Philosophical Society

Goadsley, Edward, esq. Albert place, Manchester

Goutley, Thomas, esq, Chipping Norton, Oxon

Goldsworthy, J. H. esq. High street, Stepney

Goodsir, Harry D. S. esq. R.N.

Goodsir, John, esq. College Museum, Edinbirgh

Gordon, Rev. George, Manse of Birnie, by Elgin, N.B.

Gordon, P. L. esq. Craig Myle, Aberdeen

Gott, William, esq. Leeds

Gott, John, esq. Wither, near Leeds

Gough,G S. esq. M.R.I.A.Gren. Gds 45, Park st. Gros. sq. or A thenæuin

Gould, John, esq. F.R.s. L.s. z.s. \&c 21, Broad st. Golden sq.

Gourlie, William, J. esq. 8, South Frederick st. Glasgow

Grainger, R D. esq. F.R.s. \&c. \&c. Anerley, Norwood

Gratton, James, esq. Shoreditch

Gray, John, esq. Greenock

Gray, William, jun. esq. York

Gray, T. esq. 20, Monteith row, Glasgow

Greenhill, Dr. Oxford

Greening, Williain, esq. Marlborough place, Kent road

Greenwood, Alfred, esq. Chelmsford, Essex

Gretton, Rev. H. Nantwich Rectory, Cheshire

Greville, R. K. LL.D. F.R.s.e. \&c. George's square, Edinburgh

Griffith, William, esq. Calcutta

Griffith, Mrs. Torquay

Griffitlis, - $\rightarrow$, esq. Ireland

Gruggen, J. B. esq. surgeon, Chichester

Grut, N. esq. F.r.s.e. \&c. 5, Inverleith row, Edinburgh

Gurney, J. H. esq. Earlham, near Norwich

Gull, Dr. Guy's Hospital

Hailstone, S. esq. F.L.s. Horton Hall, near Bradford, York

Haines, Dr. 26, Warren's place, Cork

Hall, John, esq. West road, Congleton

Hall, C. R. m D. Holmes Chapel, Cheshire 
Hall, N. esq. IVortley, near Leeds

IIamilton Rev. James, 7, Lansdown place, Brunswick square

Hancock, John, esq. Newcastle-on-Tyne

Handforo, George C. esq. Cheyne walk, Chelsea

Hands, Benjamin, esq. Hornsey, Middlesex

Hanley, Sylvanus, esq. Nervington green

Hanson, Samuel, esq. 15, Trinity square, Tower hill

Hanson, William, esq. Reigute

Hardwicke, William, esq. Calthorpe street, Gray's inn lane

Hardy, James, esq. 7, Mulgrave terrace, Gateshead

Harley, James, esq. Leicester

Harley, F. esq. Cortling stock, Nottinghamslire

Harrinson, J.esq. Reading

Harrison, Rev. J. B. Barham, near Canterbury

Harrison, Dr. Cork, Ireland

Hartshorne, Rev. C., Rectory, Northampton

Harvey, J. R. M.D. 18, St. Patrick's place, Cork

Harvey, W. H. esq. Trinity College, Dublin

Hastings Literary and Scientific Society

Haywood, J. W. esq.

Head, Edward, esq. Mr. Crossing's, 15, Morrice square, Devonport

Henderson, W. T. esq. London and Westminster Bank, Lothbury

Henderson, Thomas, esq. South Dispensary, Liverpool

Henfrey, Arthur, Esq. F.L.s. \&c. Museum of Economic Geology

Henslow, Professor, Cambridge

Hepburn, Sir T. B. M.P. Smeaton, Preston Kirk, N.B.

Hepburn, Thomas B. esq. Shabden park, Chipstead, Reigate

Hepburn, A. esq. Whittingham, near Preston Kirk, Mid Lothian

Heppenstall, Jolin, esq. Upper Thorpe, near Sheffield

Herbert (see Manchester, Dean of)

Heslop, R. C. M.D. Preston, Lancashire

Hetling, E. esq. Bristol

Hewetson, J. esq. Corpus Christi College, Cambridge

Hewlet, George, esq. Harrow

Hey, Samuel, esq. Leeds

Heysham T. C. esq. Carlisle

Higginbotham, J. esq. F.R.c.s. Nottingham

Higgins, C. H. esq. Taunton

Hill, IV. T. esq. Portivood hall, near Stockport

Hinckes, Rev. William, Hampstead

Hindle, James, esq. Norton, near'Doncaster

Hitch, J. W. M.D. Gloucester

Hodgson, H.B. esq. Acomb House, York

Hodson, Joseph, esq. surgeon, Birmingham

Hodgkin, Dr. Lower Brook street

Hogg, J. esq. 12, King's Bench walk

Holland, William, esq. Light Cliff, near Halifax, Yorkshire

Holt, George, esq. Liverpool

Hore, Rev. W. S. M.A. F.L.s. \&c. 30, Trafalgar pl. Stoke, Devonport

Horne, C. esq. Claphan common

Horner, Lennard, esq. 2, Bedford row

Horrocks, Miss E. M. Antermony house, Lennox town, Glasgow

Horsfield, Dr. F.r.s. L.S. G.s. \&c. India house, London 
Howell, $\rightarrow$, M.D. F.R.s.E. Deputy Inspector of Hospitals, Bristol Howells, J. esq.

Howitt, Thomas, esq. Lancaster

Hoyer, J. esq. Crown court, Threadneedle street

Hudson, Anthony, esq. Norwich

Hudson, E. D. esq. Little Thorpe, near Leicester

Hudson, R. esq. F.R.s. F.s. \&c. Clapham common

Holme, Dr. Edward, Manchester

Humphries, Edward, esq. surgeon, Kingsland

Hunter, M. esq. 22, Artillery place, Finsbury

Huntingdon, Frederick, esq. Hull

Husband, W. D. esq. surgeon, York

Hutton, Thomas, esq. F.G.S. M.R.I.A. \&c. Dublin

Huxley, James Edward, M.D. Gloucester

Hyndman, George C. esq. Belfast

Ibbotson, S. L. B. esq. 22, Upper Phillimore place, Kensington

Image, Rev. Thos. A.M. F.G.s. \&c. Whepsted, near Bury St. Edmunds

Ingham, Robert, esq. M.A. F.G.S. \&c, Westoe

Inglis, James, M.D. Halifax, Yorkshire

Inman, Dr. Thomas, Liverpool

Ipswich Philosophical Society

Irvine, Hans, esq. m.B. Dublin

Isaacson, W. esq. Huntingdon

Jackson, Dr. Oxford

Jackson, H. esq. James's row, Sheffield

James, Captain R. E. Dublin

Janson, Joseph, esq. F.L.s. 32, Abchurch lane

Jardine, SirW.Bart.F.n.s.E. L.S. \&c. Jardine hall, Lockerby, Dumfries

Jefferson, J. esq. St. John's College, Cambridge

Jeffreys, J. G. esq. F.R.s. L.s. \&c. Swansea

Jenyns, Rev. L. M.A. F.L s. c.p.s. \&c. Swaffam Bulbeck

Jepson, W. M.D. 80, Chapel street, Salford

Jerdon, Archibald, esq. Lintalee by Jedburgh

Johnston, George, m.D. LL.D. F.R.c.s.e. Berwick-upon-Tiveed

Jones, Capt. M.P. F.G.s. \&c. 30, Charles street, St. James's

Jones, - esq. 23, Solıo square

Johnson, J. W. esq. Ipswich

Joy, Thomas, esq. 10, St. Giles's street, Oxford

Jubb, Abrām, esq. surgeon, Halifax

Juman, Dr. Liverpool

Kane, W.esq. B.A. T.c.D. Exmouth

Kay, David, M.D. Bradford, Yorkshire

Keenlyside, R. H. M.D. Stockton-on-Tees

Kelaart, Dr. 40, Bryanstone Street, Portman Square

Keman, J. esq.

Kennedy, J. M.D. Woodhouse, near Loughlorough

Kenrick, Miss, Stonelıouse, near Canterbury

Kernon, Thomas, esq. Avcbury house, Marlborough, IVilts

King, R. L. esq. Rev. Dr. Tancock's, Truro, Cornwall

King, John, esq. Ipswich 
King, Richard, M.D. Sackville street

King, Henrr. Castle gate, York

Kirby, T. B. esq. Leicester

Kirkman, Dr. Walton, near Woodbridge, Suffolk

Kitching, Alfred, esq. 57, Myton gate, Hull

Kitching, John, esq. Darnell hall, near Sheffield

Kitching, W. V. esq. St. John's College, Cambridge

Knapp, Dr. 9, Duncan street, Edinburgh

Knapp, A. C. esq. 10, Paragon, Clifton

Knowles, Professor C. B. Birmingham

Köninck, L. de, esq. Liége

Lacy, E. esq. M.R.c.s. \&c. Poole, Dorset

Landsborough, Rev. D. Park-end, Saltcoats, Ayrshire

Lane, E. esq. Plymouth

Langmore, Dr. 40, Finsbury square

Langmore, W. B. esq. 4, Christopher street, Finsbury square

Langstaff, J. esq. 9, Cambridge square, Hyde park

Lankester, E. m D. F.R.S. L.s. \&c. 22, Old Burlington street

Laycock, Dr. C. R. 5, Adelaide road, Haverstock hill

Leckenby, John, esq. Scarborough, Yorkshire

Lee, Dr. F.r.s. F.R.A.s. \&c. Hartwell, near Aylcsbury, Bucks

Lee, Rev. James P. King Edward's s'chool, Birmingham

Lee, W. S. esq. Morningside, near Aberdeen

Leeson, Dr. Green wich

Leighton, Rev. W. A. B.A. F.R.s.e. \&c. Luciefield, Shrewsbury

Leslie, James, esq. Chanonry, Old Aberdeen

Leyland, E. esq. Corn market, Halifax

Lindley, Professor, D. PH. F.R.s. \&c. 21, Regent street

Lingin, Charles, M.D. Hereford

Lingwood, R. M. esq. M.A. F.L.s. \&c. Lyston house, Ross, Hereford

Lister, J. J. esq. F.R.s. Upton, near Stratford, Essex

Little, Rev. William, Manse, Kirkpatrick, Moffat

Litton, Professor, M.D. R.D.s. \&c. Dublin

Liverpool Library, Lyceum

Liverpooi Medical Institution

Liverpool Royal Institution

Lizars, W. H. esq. St. James's square, Edinburgh

Lizars, Professor A. J. M.D. 17, King street, Aberdeen

Llewcllyn, - esq. Swansea

Lloyd, Williain Horton, esq. F.L.s. z.s.\&c. Park square, Regent's park

Loftus, W. K. esq. C'aius College, Cambridge

London Institution, Finsbury circus

Longchamps, M. de Selys, Liege

Lovejoy, S. esq. Reading

Loughton, W. Gore, esq. Hatch court, near Taunton

Lowe, James, esq. Liseard Vale, Cheshire

Luard, William W. esq. Witham lodge, Witham, Essex

Ludlow Natural History Society

Lye, James Black, M.D. Hereford

Lyell, Charles, M. F.r.s. L.s. G.s. \&c. 16, Ilart street, Bloomslury

Lyle, Mrs. Achcson, Dublin 
Macdonald, Alexander, esq. 5, Regent terrace, Edinburgh

Macdonald, W. B. esq Rammerscales, Lochmaben

Mackay, Dr. G. 26, East Emma place, Stonehouse

Mackey, G. Y. esq. Curator of the Coll. Botanical Gardens, Dublin

Mackintosh, George, esq. Campsie, near Glasgow

Mackintyre, Dr. F L.s. Hackney

Mackenzie, Skelton, esq. LL.D. Dublin

Maclagan, Douglas, M.D. F.R.s.e. 129, George street, Edinburgh

Maclagan, P. W. M.D. Assistant Surgeon in the Army, Canada

Maclagan, Lieutenant Robert, Royal Engineers

Macmeikan, John, esq. London Hospital

Mac Taggart, D esq. Halifax

Manchester Natural History Society

Manchester, The Hon and Rev. Dean of, Spofforth, Yorkshire

Marshall, Matthew, esq. Bank of England

Martin, Dr. Glendale, Isle of Skye

Martin, Dr. Adam, Rochester, Kent

Matteson, William, jun. esq. surgeon, York

Maund, Benjamin, esq. Broomsgrove, Worcestershire

Maxwell, Wellwood, esq. Munshes Castle, Douglass

Me Andrew, $R$ esq. Liverpool

Meggy, George, esq Chronicle Office, Chelmsford

Melrose, Jonathan, esq. Writer, Coldstream, Berwickshire

Mercer, James, M.D. F.R.c.s.E. 50, Northumberland st, Edinburgh

Melville, Alex. esq. Assist. Demonst. of Anatomy, Univ. Edinburgh

Mereditl, W. L. M.D. Cork

Meynell, Thomas, esq. York

Miller, O. T. esq. Royal Marine Infirmary, Plymouth

Miller, George, esq M.R.c.s.e. Emsworth, Hants

Mitchell, Alexander, esq. 20, Upper Kirk gate, Aberdeen

Mitchell, E. W. Esq. 28, Great Russell Street, Bloomsbury

Mitchell, D. W. esq. 5, Mortimer street, Cavendish square

Mitchell, Dr. Mauchline, Argyleshire, N.B.

Mitford, Captain, Hunmanby, Yorkshire

Moggridge, Matthew, esq. Swansea

Moon, William, esq. surgeon, Tottenham, Middlesex

Moore, J. C. esq. 37, Hertford street, May Fair

Moore, John, esq. Leicester

Mordaunt, John, esq. Ashton Water, near Bristol

Morley, George, esq. Leeds

Morris, Beverley, R. A.B. M.D. Beverley

Mullinix, - esq. 7, Adelphi terrace

Munford, Rev.George, East Wiich Vicarage, Lynn

Munn, W. A. esq. Throwley house, Faversham, Kent

Munro, Miss, Fritham, Stoney cross, Hants

Murchison, R.I. esq. F.R.s. \&c. Belgrave square

Murdoch, W. M.D 320, Rotherhithe street

Murray, Patrick, M.D. Scarborough, Yorkshire

Nasmyth, Alex. esq. F L.s. G.s. \&c. 13, George st. Hanover square

Naylor, G. F. esq. Asylum, Wakefield

Needham, J. esq. F.L.S. Leicester

Neill, Patrick, LL.D. F.R.S.e. L.S. \&c. Cannon Mills, Edinburgh 
Nelson, Jno. G. esq. Colchester, Essex

Neville, Henry, esq. Hervey hill, co. Londonderry, Ireland

Newbold, W. W. esq. B.A. Sharrow Bank, Sheffield

Newcastle Literary and Scientific Society

Newman, Edward, esq. F.L.s. 9, Devonshire street, Bishopsgate

Newnham, W. O. esq. St. John's College, Cambridge

Newnham, William, esq. Farnham, Surrey

Newport, George, esq. F.R.s. Southwick st. Cambridge ter.

Norfolk and Norwich Literary Institution

Norman, George, esq. F.G s. \& C. Beverley road, Hull

Norris, Henry, esq. South Petherton

Northamptou, the Marquess of, P.R.s. \&c. 145, Piccadilly

Norwich, the Lord Bishop of

Nunneley, Thos. esq. Surgeon, Leeds.

Nutford, Capt. Hunmanby, Yorkshire

Ogilby, W. esq. Upper Gower street

Ogilvie, J. F. esq. Morningside Lunatic Asylum

Oldham, Professor, Dublin

Ollivant, Dr. Trinity College, Cambridge

Otter, Captain, Hydrographic Survey

Owen, Professor, F.R.s. L.s. \&c. Royal College of Surgeons

Palıner, Dr. S. Birmingham

Parker, C. L. esq. Oxford

Parkinson, esq. F.L.s. Cambridge terrace, Hyde park

Parnell, R. M.D. F.R.s.c. \&c. 50, Rankeilor street, Edinburgh

Partridge, Richard, esq. F.R s. King's College, London

Pattisson, Jacob H. esq. LL.B. Witham House, Witham

Pattisson, W. H. esq.

Patterson, Robert, esq. Belfast

Paxton, Jas. M.D. Rugby

Peachey, W. jun. esq Ebernoc, near Petworth, Sussex

Pearce, J. C. esq. Bradford, Wilts, near Bath

Pease, Mrs. Feetham, near Darlington

Percival, W. esq. Ist Life Guards, Hyde Park Barracks

Pereira, J M.D. F.R.s. \&c. Finsbury square

Percy, Edmund, esq. Nottingham

Percy, J. M.D. Birmingham

Phelps, Rev. H. D. Snodland rectory, West Malling, Kent

Phillips, Professor John F.R s. York

Pigg, Thomas, jun. esq. 7, Ridley place, Newcastle-on-Tyue

Pinder, Rev. George, Sedburgh, Yorkshire

Plant, John, esq Leicester

Player, Mrs. Tenby, South Wales

Playfair, Lyon, Dr. Museum Economic Geology

Plomley, James F. esq. Rye, Sussex

Plomley, Francis, M.D. Ph. D. F.s.A. \&c. Lydd, Romney Marsh, Ken

Pollexfen, Rev. J. H. Bradford, Yorkshire

Popham, John, M.D. Cork

Potts, W. J. esq.

Powell, Hugh, esq. Clarendon street, Somers Town

Power, Rev.Josh. M.A. Librarian of the University, Cambridge 
Power, Thomas, M.D. St. Patrick's hill, Cork

Pratt, S. P. esq. 53, Lincoln's inn fields

Preston Literary and Philosophical Society

Prestwich, Joseph, jun. esq. Mark lane

Price, William, esq. Leeds

Price, Thomas T. esy Surgeon, Hereford

Pritchard, A. esq. 3, Canonbury lane, Islington

Prower, Rev. J. M. Purton, near Swindon, Wilts

Quain, Richard, M.D. University College Hospital

Quekett, E.J. esq. F.L.S. 50, Wellclose square

Ralıan, R.B. Captain, R.N. Hatch Beauchamp, near T'auntun

Radcliffe Library, Oxford

Rankin, Robert, esq. Hastings, Sussex

Ranking, W. H. M.D. Bury St. Edmunds

Ransome, Robert, esq. Ipswich

Raper, W. A. M.D. Parade, Portsmouth

Rattray, W. esq. St. Nicholas street, Aberdeen

Rawson, T. W. esq. Halifax, Yorkshire

Ray, George, esq. Milton, near Sittingbourne, Kent

Ray, John, esq. Heanor Hall, Derbyshire

Reade, Rev. J. B. Stone Vicarage, near Aylesbury, Bucks

Reid, F. G. M.D. Hertford

Reid, John, M.D. St. Andrews

Reeve, Lovell, esq. A.L.s. \&c. King William street, Strand

Reckitt, William, esq. M.A. \&c. High street, Boston, Lincolnsliu'e

Reigate Institution, Reigate, Surrey

Reynolds, Henry, esq. 42, Moorgate street

Richardson, John, M.D. F.R.s. L.s. \&c. Haslar Hospital, Gosport

Ringrove, John esq. Potters Barr

Robb, James, M.D. Prof. Nat. Hist. King's College, Frederickton, New Brunswick

Robertson, W. esq. F.z.s. Neweastle-on-Tyne

Robertson, W. H. M.D. Buxton, Derbyshire

Robertson, John, esq. Duffield Bank house, Derby

Robinson, Rev. George, Armagh

Rohloff, - esq. Plymouth

Rolfe, Rev. S. C. E. N. Heacham Hall, Lynn, Norfolk

Ross, Andrew, esq. 21, Featherstone buildings, Holborn

Rothery, H. C. esq. B.A. 10, Stratford place

Rowntree, J. esq. Scarborough

Royle, Prof. J. F. M.D. F.R.s. L.s. G.s. Stc. 4, Bulstrode street, St. Marylebone

Rudd, E. J. esq. Halifax, Yorkshire

Russell, F. esq. Brislington, Bristol

Russell, James, M.D. Plilosophical Institution, Birmingham

Russell Medical Book Society

Rutherford, W. esq.

Ryder, Charles, esq. Stamp and Taxes Office, Somerset House

Sabine, W. esq. B.A. Jesus College, Cambridge

Sabine, Colonel 
Salmon, John D. esq. Godalming:

Salmon, R. esq. Downham, Norfolk

Salter, T. Bell, m.D. F.L.s. Ryde, Isle of Wight

Salter, H. H. esq. King's College

Sandivith, Humplrey, м.D. 1, Albion street, Hull

Satterfield, Joshua, esq. Manchester

Saull, W. D. esq. F.G.s. A.s. \&c. 15, Aldersgate street

Say, Rev. F. H. S. Braughing Vicarage, Ware, Herts

Sayle, George, esq. King's Lynn

Seager, J. L. esq. Millbank, Westminster

Searle, George, esq. Cumming street, Pentonville

Sedgwick, Rev. Professor, F.R.s. \&c. Cambridge

Selby, Prideaux J. esq. F.L.s. G.s. \&c. Twizel, Northumberland

Sellers, William, M.D. Royal College Physicians, Edinburgh

Semple, Robert H. esq. 3, Hans buildings, Islington

Shaw, Dr. Hophouse, near Boston, Lincolnshire

Shapter, Thomas, M.D. Exeter

Sharp, Henry, esq. Bolton le-Moor, Lancashire

Sheppard, James, M.D. Stonehouse, Devonport

Shuttleworth, Robert James, esq. Berne

Shuttleworth, John, esq. Manchester

Sidney, M. J, F. esq. Cowper, near Morpeth

Simpson, J. Y. M.D. Prof. Midwifery University Edinhurgh

Simpson, Samuel, esq. The Greaves, Lancaster

Sion College Library, London Wall

Slaney, W. H. esq. care of T. C. Eyton, esq. Eyton Hall, Shrewshury

Smith, Alfred, esq. M.r.c.s. St. Paul street, Portland square, Bristol

Smith, Rev. J. J. M.A. Caius College, Cambridge

Smith, Dr. Pye, Homerton

Smith, Charles, esq. M.R.c.s. Bury St. Edmunds

Smyth, W. H. esq. Caius College, Cambridge

Solly, R. H. esq. P.R.s. L.s. \&c. Great Ormond street, Queen square

Solly, E. esq. F.R s. Bedford row

Sowerby, James de C. esq. F.L.s. z.s. \&c. Royal Botanic Garden, Regent's park

Spence, W. esq. F.R.s. L.s. \&c. 18, Lower Seymour st. Portman sq.

Spence, Rev. John, East Keal, Spilsby, Lincolnshire

Spicer, J. W. G. esq. Esher place, Esher, Surrey

Spragge, W. K. esq. South Down buildings, Tor, Devonshire

Spragge, F. esq. South Down buildings, Tor, Devonshire

Squire, Lovell, esq. Falmouth

Stallard, J. P. esq. Leicester

Stanger, W. M.D. Cape of Good Hope

Stark, Robert, M. esq. Annandale street, Edinburgl

Statham, Rev. S. F.

Statter, William, esq. Wakefield

Staunton, F. B. esq. 20, Waltham terrace, Merrion avenue, Dublin

Stcel, C. W. esq. Lewisham

Steuart, Sir James, Bart.

Sterens, W. V. esq. Horton, near Slough

Stewart Allan, M.D. 50, High street, Paisley

Stewart, J. Vandeleur, esq. Rockhill, Letterkenny, Ireland

Stock, Daniel, esq. Bungay 
Stocks, J. C. esq. Bombay Residency, India

Stokes, W. R. esq. Shrewsbury

Stokes, Charles, esq. F.R.s. G.s. \&c. 4, Verulam buildings, Gray's Inn

Strickland, Hugh E. esq. M.A. F.G.S. \&c. 39, Holywell, Oxford

Strickland, Arthur, esq. Bridlington Quay, Yorkshire

Strickland, J. H. esq. 22, North Audley street

Streeten, R. J. N. M.D. Worcester

Sweetlove, J. esq. Liverpool, Nat. Hist. Soc.

Swineard, Frederick, esq. Precentor's court, York

Subscription Library, Bromley house, Nottinghaın

Sutherland, Captain G. M. Shilden hall, Halifax

Tancred, Sir Thomas, Bart. Shotley hill

Tate, George, esq. F.G.s. Alnwick, Northumberland

Tatham, John, esq. jun. Settle, Yorkshire

Taylor, Richard, esq. F.L.s. s.A. \&c. Red Lion court, Fleet street

Taylor, Henry, M.D. Nottingham Dispensary

Taylor, Dr. Robert, Edinburgh

Teale, Joseph, esq. Leeds

Teale, T. P. esq. Leeds

Tennant, James, esq. F.G.s. \&c. 149, Strand

Theakstone, J. W. esq. Scarborough, Yorkshire

Thomas, W. L. esq. Hatfield

Thomas, Henry, esq. Sheffield

Thompson, Thomas, esq. M.A. F.R.s. \&c. Solicitor, Hull

Thompson, W. esq. Pres. Nat. Hist. Soc. Belfast

Thompson, Theoplilus, M.D. Bedford square, London

Thompson, George, esq. Liverpool

Thomsun, R. D. M.D. Glasgow

Thomson, Professor Allen, 26, India street, Edinburgh

Thornhill, J. esq. Lit. and Phil. Soc. Newcastle-on-Tyne

Thornwell, R. esq. Burton-on-Trent

Thorpe, Rev. W. Wormersley, near Pontefract, Yorkshire

'Tomkins, C. M.D. Abingdon

Torquay Natural History Society

Torrie, T. J. esq. F.G.s. \&c. 21, Royal Circus, Edinburgh

Toswell, C. S. esq. 8, Torrington place

Travis, J. H. esq. York

Trinity College, Dublin

Tripe, Dr. Plymouth

Troughton, Nathaniel, esq. Coventry

Tudor, Richard, esq. Bootle, Liverpool

Tuke, W. M. Esq. York

Tuke, James, H. esq. York

Turner Dawson, esq. F.R.s. s.A. L.s. \&c. Yarmouth

Tweedy, M. esq. Alverton, Truro

Twining, Willian, M.D. 13, Bedford place, Russell square

Twiss, Travers, Dr. Prof. Political Economy Univ. Coll. Oxford.

Varenne, E. G. esq. Kelvedon, Essex

Verneuil, M. Edward de, Paris

Walker, D. esq. M.A. Colchcster, Essex 
Walker, J. jun. esq. Axbridge, near Wells, Somerset

IValker, John, esq Chesterfield

Waller, Edward, esq. Finnow House, Burrisokane, Ireland

Walmsley, V. O. esq. Westwood House, near Wigan, Lancaster

Walton, John, esq. F.L.s. \&c. 9, Barnsbury square, Islington

Walton, Richard. esq. Cambridge

Warburton, H. esq. M.P. F.R.S. PRES. G.s. \&c. 45, Cadogan pl. Chelsea

Ward, N. B. esq. F.L.s. z.s \&c. Wellclose square

Ward, N. esq. London Hospital

Warington, Robert, esq. Apothecaries' Hall

Warren, T. W. esq. 40, Blessington street, Dublin

Warwickshire Natural History Society

Waterhouse, G. esq. British Museun

Waterhouse, J. esq. Halifax

Watson, James, M.D. St. Vincent street, Glasgow

Webb, J. F. esq. Bungay

Webster, William, jun. esq Upton, Cheshire

Weddell, Robert, esq. Berwick-on-Tweed

Weeks, Richard, esq. Hampton Lodge, Hurst Pierpoint, Brighton

Welch, R. esq. Huddersfield

Wellbeloved, Rev. C. York

Wells, Robert, esq. 2, Archibald place, Edinburgh

Wells, William, esq. Primrose house, Liverpool

Wharton, Rev. Thomas, Bath, Jamaica

Wheatstone, Professor, King's College

Wheeler, Mrs. 2, Sussex place, Southampton

Whish, H. esq. Corpus Christi College, Cambridge

White, Adam, esq. British Museum

White, A. D. M D. Winchester

White, C. G. esq. Poplar

White, Alfred, esq. F.L.s. \&c. Cloudesley square, Islington

White, H. H. esq. 13, Old square, Lincoln's Inn

Whitehaven Library

Whiting, Josh. B. esq. King's Lynn, Norfolk

Whitla, F. esq. Belfast

Wickenden, Joseph, esq. Surgeon, Birmingham

Wickham, W. J. esq. Winchester

Wilkinson, M. A. E. M.D. Manchester.

Williams, Rev. J. Euston Glebe, Chorley, Lancashire

Wilson, Charles, M.D. Kelso

Wilson, T. J. esq. Surgeon, Lockerby

Wilson, Fdward, esq. Lydstep house, Tenby

Wilson, Dr. 3, Devonport street, Sussex square

Wilton, J. W. esq. Gloucester

Winchester, The very Rev. the Dean of

Windsor, John, esq. F.L.S. F.R.c.s.E. \&c. Manchester

Winn, Charles, esq. Nostell, near Wakefield

Winter, T. B. esq. Cannon place, Brighton

Winterbottom, P. M. M.D. Westoe, S. Shields

Winterbottom, James Edward, esq. F.L.s. \&c. Newbury, Berks

Wintle, G. S. esq. Eastgate street, Gloucester

Witham Literary Institution

Wix, Rev. S. F.R.s. A.s. St. Bartholomew's Hospital 
Wollaston, T, V. esq. Jesus College, Cambridge

Wollaston, Miss, Clapham common

Wood, S. V. esq. F.g s. \&c. 14, Bernard street, Russell square

Wood, Neville, M.D. Lower Belgrave street, Belgrave square

Wood, Samuel, A.M. M.D. Avenue House, Bandon, co. Cork

Wood, Mrs. E. Stout hall, Swansea

Woodd, Basil, T. esq. F.L.s. \&c. 14, Great Cumberland street

Woodford, Dr. Taunton

Wooley, J. esq. Trinity College, Cambridge

Wright, G. P. esq. Auburn Cottage, Hawley road, Kentish town

Wright, Thomas, esq. V.P. Philosophical Institution, Cheltenham

Yarrell, William, esq. F.L.s. z.s. \&c. Ryder street, St. James's street

York Philosophical Society

Young, James, esq. Hull

Young, Dr. J. F. F.z s. \&c. Upper Kennington lane 




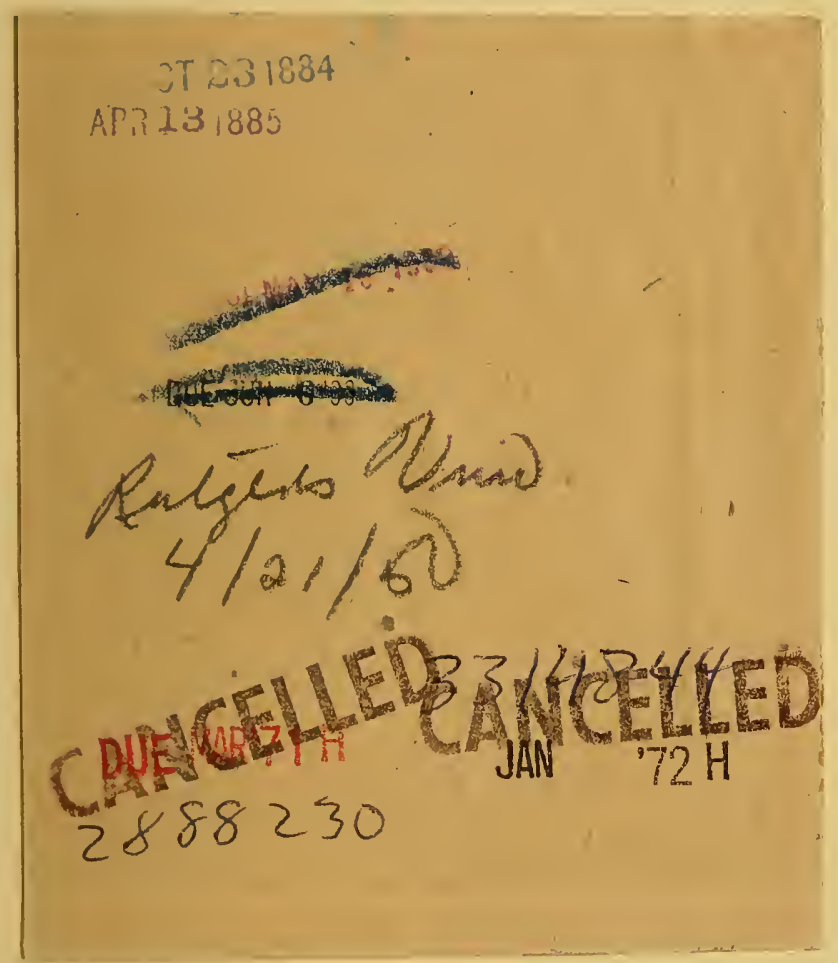


5 .

$6 x$

(5) $\frac{3}{3} \times 3$

Hits

3.

8 